Columbia Law School

Scholarship Archive

Faculty Scholarship

Faculty Publications

2020

\title{
Stakeholder Preferences and Priorities for the Next WTO Director General
}

\author{
Matteo Fiorini \\ European University Institute Robert Schuman Centre for Advanced Studies, matteo.fiorini@eui.eu \\ Bernard Hoekman \\ European University Institute, Robert Schuman Centre for Advanced Studies (RSCAS), \\ bernard.hoekman@eui.eu
}

Petros C. Mavroidis

Columbia Law School, petros.mavroidis@unine.ch

Douglas Nelson

Tulane University, dnelson@tulane.edu

Robert Wolfe

Queen's University School of Public Studies, Robert.Wolfe@queensu.ca

Follow this and additional works at: https://scholarship.law.columbia.edu/faculty_scholarship

Part of the Dispute Resolution and Arbitration Commons, International Law Commons, International Trade Law Commons, Securities Law Commons, and the Transnational Law Commons

\section{Recommended Citation}

Matteo Fiorini, Bernard Hoekman, Petros C. Mavroidis, Douglas Nelson \& Robert Wolfe, Stakeholder Preferences and Priorities for the Next WTO Director General, EUROPEAN UNIVERSITY INSTITUTE, ROBERT Schuman Centre for Advanced Studies, Global Governance Programme Working Paper No. RSCAS 2020/ 43 (2020).

Available at: https://scholarship.law.columbia.edu/faculty_scholarship/2691

This Working Paper is brought to you for free and open access by the Faculty Publications at Scholarship Archive. It has been accepted for inclusion in Faculty Scholarship by an authorized administrator of Scholarship Archive. For more information, please contact scholarshiparchive@law.columbia.edu. 

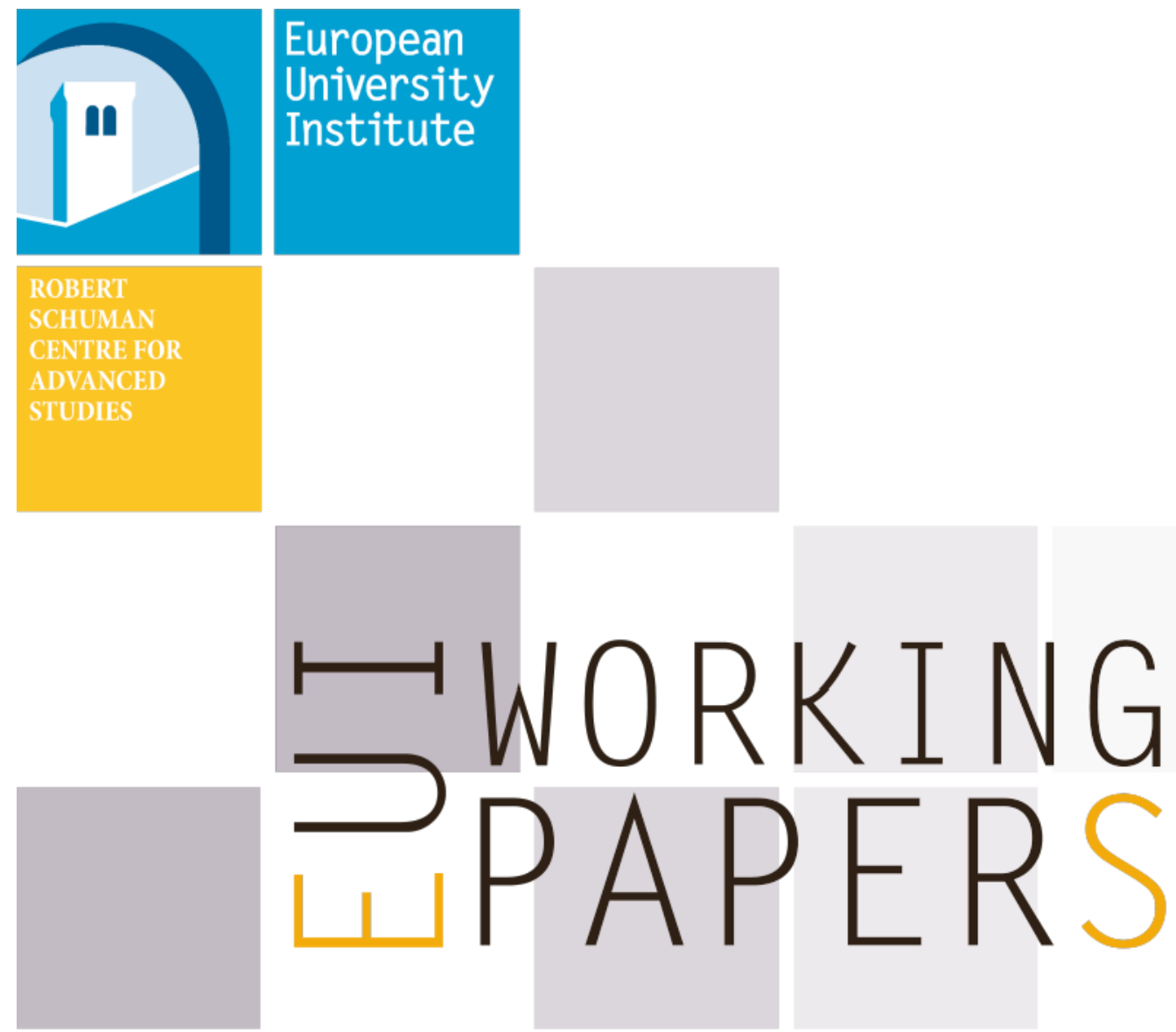

RSCAS 2020/43

Robert Schuman Centre for Advanced Studies Global Governance Programme-404

Stakeholder Preferences and Priorities for the Next WTO Director General

Matteo Fiorini, Bernard Hoekman, Petros C. Mavroidis, Douglas Nelson and Robert Wolfe 
European University Institute

Robert Schuman Centre for Advanced Studies

Global Governance Programme

Stakeholder Preferences and Priorities for the Next WTO Director General

Matteo Fiorini, Bernard Hoekman, Petros C. Mavroidis, Douglas Nelson and Robert Wolfe

EUI Working Paper RSCAS 2020/43 
Terms of access and reuse for this work are governed by the Creative Commons Attribution 4.0 (CCBY 4.0) International license. If cited or quoted, reference should be made to the full name of the author(s), editor(s), the title, the working paper series and number, the year and the publisher.

ISSN 1028-3625

(C) Matteo Fiorini, Bernard Hoekman, Petros C. Mavroidis, Douglas Nelson and Robert Wolfe, 2020

This work is licensed under a Creative Commons Attribution 4.0 (CC-BY 4.0) International license. https://creativecommons.org/licenses/by/4.0/

Published in April 2020 by the European University Institute.

Badia Fiesolana, via dei Roccettini 9

I - 50014 San Domenico di Fiesole (FI)

Italy

Views expressed in this publication reflect the opinion of individual author(s) and not those of the European University Institute.

This publication is available in Open Access in Cadmus, the EUI Research Repository:

https://cadmus.eui.eu 


\section{Robert Schuman Centre for Advanced Studies}

The Robert Schuman Centre for Advanced Studies, created in 1992 and currently directed by Professor Brigid Laffan, aims to develop inter-disciplinary and comparative research on the major issues facing the process of European integration, European societies and Europe's place in $21^{\text {st }}$ century global politics.

The Centre is home to a large post-doctoral programme and hosts major research programmes, projects and data sets, in addition to a range of working groups and ad hoc initiatives. The research agenda is organised around a set of core themes and is continuously evolving, reflecting the changing agenda of European integration, the expanding membership of the European Union, developments in Europe's neighbourhood and the wider world.

For more information: http://eui.eu/rscas

The EUI and the RSCAS are not responsible for the opinion expressed by the author(s).

\section{The Global Governance Programme}

The Global Governance Programme is one of the flagship programmes of the Robert Schuman Centre. It is a community of outstanding professors and scholars that produces high quality research and engages with the world of practice through policy dialogue. Established and early-career scholars work on issues of global governance within and beyond academia, focusing on four broad and interdisciplinary areas: Global Economics, Europe in the World, Cultural Pluralism and Global Citizenship.

The Programme also aims to contribute to the fostering of present and future generations of policy and decision makers through its executive training programme: the Academy of Global Governance, where theory and 'real world' experience meet and where leading academics, top-level officials, heads of international organisations and senior executives discuss on topical issues relating to global governance.

For more information: http://globalgovernanceprogramme.eui.eu

The European University Institute and the Robert Schuman Centre are not responsible for the opinions expressed by the author(s). 


\begin{abstract}
The WTO is looking for a new Director-General (DG). What does the trade community think is needed? This paper reports on the results of an expert survey undertaken as part of a research project on global trade governance at the European University Institute to solicit views on what WTO members and the international trade community consider the most important attributes of candidates for the position, as well as views on the substantive policy and institutional reform priorities confronting the WTO - and thus the new DG. The results suggest strong support for someone with managerial and political experience, and a professional network that spans international organizations, major capitals, and international business. African respondents assign the highest priority to regional diversity. Resolving the dispute settlement crisis is the highest priority for most respondents; launching discussions on new issues obtains the least support. There is broad agreement on the importance of addressing a range of negotiating topics and institutional reforms, but substantial variation in the rankings assigned by different groups of respondents to specific issues.
\end{abstract}

\title{
Keywords
}

WTO; governance; international organizations; leadership attributes; stakeholder preferences. 


\section{Introduction*}

In June 2020, the WTO began the process of looking for a new Director-General (DG) after the unexpected decision by the incumbent, Roberto Azevedo, to step down before the expiry of his term. The next DG will be selected through a process of consultations aimed at forming a consensus around one of the candidates put forward by WTO members that decide to do so. The selection process is in the hands of the WTO Membership - i.e., governments - who may or may not have well-defined views on what makes for a good candidate and may or may not perceive the appointment to matter enough to engage in the process and invest resources to push for or against candidates.

Abstracting from the political process through which the next DG eventually will be appointed, in this paper we explore what the trade community think is needed. We are interested in determining the extent to which there is agreement across governments, the business community, NGOs, and other stakeholder groups on the desirable characteristics of the DG. To do so we implemented an expert survey to solicit views on what WTO members and the international trade community consider to be important attributes of candidates for the position. The survey also was used to collect information from respondents on substantive policy and institutional reform issues to explore whether there is a commonality of views regarding the 'work program' priorities confronting the next DG.

\section{The survey: design, sampling frame and participation}

The survey ran between June 5-21, 2020 using an online survey platform. Data were collected through June 24. The questionnaire was sent by email to all WTO delegations and distributed through e-mail and social media channels to trade practitioners using a contact list developed by the Global Economics program of the EUI Robert Schuman Centre for Advanced Studies. Recipients were requested to forward the survey to others in their networks working on trade and WTO matters. The sampling frame is not designed to ensure respondents will be perfectly representative of the WTO stakeholder community and no claim to this effect is made.

Responses to all questions used a 5-point scale: very low (strongly disagree), low (disagree), neutral, high (agree) and very high (strongly agree). Respondents were asked to indicate their professional affiliation (more than one allowed), whether they are based in Geneva, their gender and the nationality of their company/organization/institution, where relevant (no nationality information was requested from staff of the EU and international organizations). ${ }^{1}$ Any question could be left unanswered. Annex 1 presents the survey instrument.

A total of 1,092 people opened the survey; $75 \%$ (819) responded to at least one question. Around 800 responses were received for most of the questions (the lowest number of respondents for a question is 733; the highest 807). Government officials (including the EU) represent the second largest category of respondents $(24.6 \%)$ after academia $(25.1 \%)$; followed by the private sector (companies and business associations) (19\%); staff of international organizations (18\%) and NGOs, labor unions, think tanks ( $11 \%$ of the sample). There was at least one government respondent for 76 of the 164 WTO members (46\% of the membership). Of the government and EU respondents, $31 \%$ (66) are based in Geneva. ${ }^{2}$

\footnotetext{
The authors are very grateful to everyone who took the time to fill out the survey.

1 Survey responses are anonymous. The software used makes it impossible for the researchers to identify respondents.

2 Respondents in retirement were asked to indicate their professional affiliation during their last working position. When they did so, only the latter category was applied to characterize the profession of the respondents. Excluding the cases of retirees, 36 respondents specified 2 professional affiliations and 4 respondents specified 3 professional affiliations. Whenever data are presented or analyzed across different categories of professional affiliation, respondents declaring multiple professional affiliations are counted in all relevant categories.
} 
The geographic distribution of respondents is as follows: of the 616 respondents that specified the nationality of their company/organization/institution, 37\% are in Europe, 20\% in North America, 18\% in Asia, $12 \%$ in Africa, and $11 \%$ in Latin America and the Caribbean. Less than $1 \%$ of the respondents report they are based in the Middle East (6 respondents) or in countries belonging to the Commonwealth of Independent States (5 respondents). This should be considered when comparing responses by geographic region.

In what follows we focus on the reported ranking of the issues by groups deemed to be of greatest salience for the selection process: Geneva delegations; government officials not based in Geneva; the private sector and NGOs. In addition, we report results for respondents aggregated by geographic region. One reason for doing so is to be able to engage on questions concerning the desirable origin of the DG and whether DG appointments should consider regional diversity over time. The survey responses, question-by-question, are summarized in Annex 2 for the sample as a whole and for different groups of respondents, including many that are not discussed in this summary. Annex 2 also reports the total number of respondents for each question.

\section{Preferred characteristics of the next DG}

The responses ranking desirable professional characteristics of the next DG reveal three clear messages.

\subsection{Message \#1: Strong agreement on desirable professional attributes}

Respondents gave the greatest weight to the following four attributes (ranked in order of the share of 'high' and 'very high' responses): (1) management experience; (2) political experience; (3) economics training; and (4) experience as a WTO negotiator. All four attracted more than $75 \%$ high/very high scores (Figure 1, panel a).

Much less priority was given to the nationality of the DG, the notion that a DG should come from a region that has not yet provided one, and gender. Less than $40 \%$ of all respondents gave the latter two attributes a high or very high score, and more than $20 \%$ scored them as low or very low. The lowest ranked attribute across the sample is whether the DG should be from a developed country: $90 \%$ of respondents rate this as very low, low or neutral. This is of interest given that some WTO members have argued that there is an informal understanding that the DG should rotate between a national from a developed country following one from a developing country, etc.

Only $25 \%$ of the sample accord gender a rating of high or very high. Female respondents give this attribute a higher weighting than men, but do not differ in their overall ranking of the various characteristics. 
Figure 1: Strong agreement on preferred Attributes

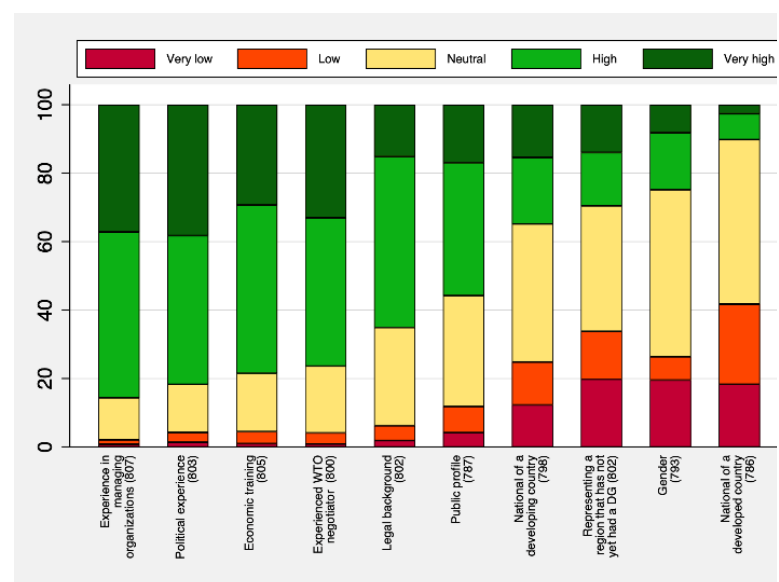

(a): Attributes sorted by sum of high \& very high shares

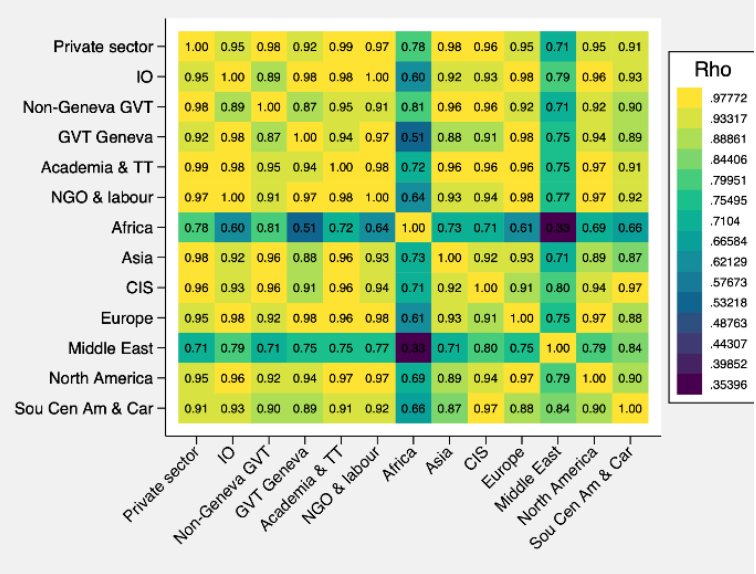

(b): Spearman rho correlation between group rankings

Note: The survey question underlying the correlations in panel (b) is: What priority do you assign to the following characteristics for the WTO DG? See Annex 1 for survey questions.

A 'heatmap' of group-specific Spearman rho correlations (Figure 1, panel b) reveals there is substantial overlap across groups of respondents regarding the ranking of the 10 characteristics. $^{3}$ Only two respondent groups differ significantly in their ranking of attributes: Africa and the Middle East. ${ }^{4}$ African respondents accord the greatest priority (highest ranking) for the DG being a national of developing country, as well as prioritizing the notion that the Director-General should represent a region that has not yet contributed a DG. Almost $80 \%$ of African respondents rank order these two elements as either high or very high priority.

\subsection{Message \#2: Competence and regional diversity over time}

Overall, $70 \%$ of all respondents either agree (30\%) or strongly agree (40\%) that the selection of the next DG should be solely based on expertise and competence (Figure 2, panel a). At the same time, slightly more than $60 \%$ agree $(43 \%)$ or strongly agree $(20 \%)$ that the selection should ensure regional variation over time. Less priority is given to alternating (rotating) between a developed and a developing country national. Respondents also accord less support to the notion that the DG should not be from one of the three largest trading powers (China, the EU or the US). This last question generated a high share of very low or low responses (40\%), indicating that while there is little support for the DG having to come from a developed country, there is relatively strong opposition to the notion that a DG should not come from one of the large trade powers. ${ }^{5}$ In conjunction with those discussed above, these results suggest a substantial preference for regional diversity but less support for prejudging or restricting the origin of the DG.

3 Spearman's rho is a nonparametric method for measuring the correlation between two variables using rank order information for each variable. It ranges between -1 and 1 . The higher the number the more similar is the rank ordering.

4 Respondents were mapped into country groupings using the WTO definition of geographic regions. One consequence is that North African countries are part of Africa, not the Middle East. In what follows we will accord less discussion to the Middle East and CIS groups given the low number of respondents (6 and 5, respectively).

5 More detailed analysis indicates that respondents from North America and Europe are the most opposed. In both cases some $50 \%$ rank this very low or low. 
Figure 2: The selection of the DG should:

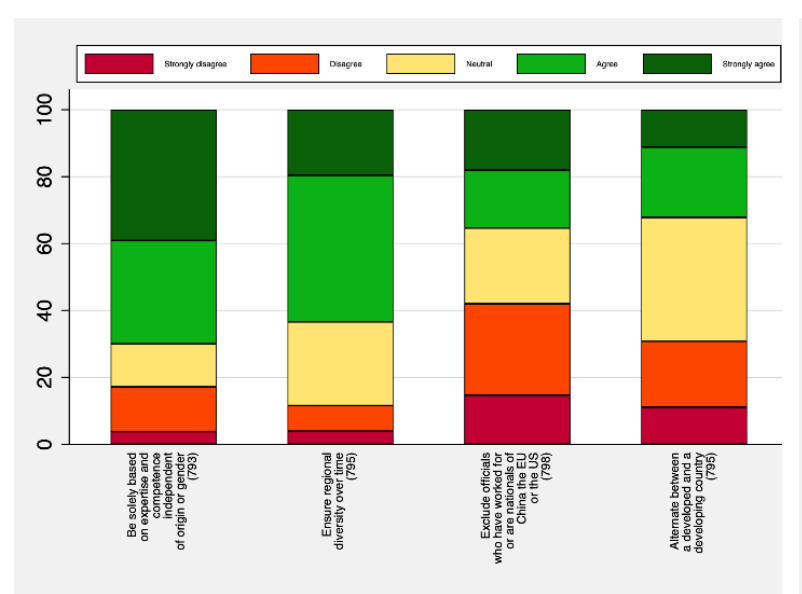

(a): whole sample

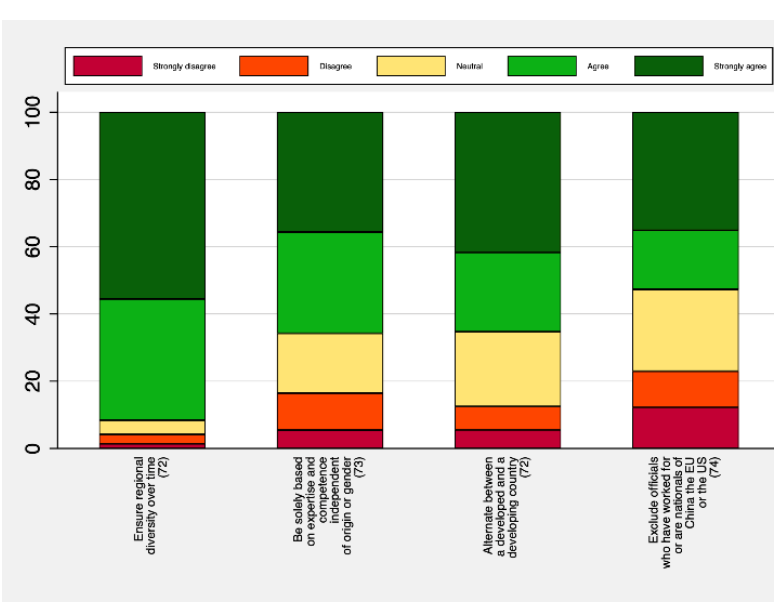

(b): respondents from Africa

Notes: Bars sorted by the joint share of agree and strongly agree responses.

Although there is broad agreement that competence is a high priority, there are also clear differences in rankings across some respondent groups. Geneva delegations place the greatest priority on competence as the dominant selection criterion, with more than $80 \%$ ranking this as high or very high. Conversely, African respondents accord the highest priority to regional diversity (more than $95 \%$ ranking this as high or very high) (Figure 2, panel b). ${ }^{6}$ Other groups of respondents that favor regional variation over time more strongly than the sample as a whole include respondents from CIS countries, government officials outside Geneva and respondents from NGOs and labor organizations. The latter are outliers in also putting a lower weight on competence as the sole criterion: $40 \%$ of NGO/labor-affiliated respondents rank this as low or very low. This increases to $80 \%$ for African NGOs.

\subsection{Message \#3: Connections to large capitals, business and international organizations matters most}

Overall there is strong agreement on assigning the highest priority to the new DG having personal connections and recent professional experience with three types of players: (i) international organizations; (ii) the capitals of the largest trade powers (Beijing; Berlin, Brussels (EU); Tokyo; and Washington DC); and (iii) international business. The share of high and very high priority responses for these three categories is above $60 \%$ for the total sample (Figure 3$)^{7}$

Correlation analysis reveals that respondents from Africa and NGOs and labor organizations tend to assign high and very high priorities in a different order with respect to the rest of the sample (Figure 3, panel b). For these categories of respondents, the highest (or second highest) priority goes to the new DG having connections and experience with regional organizations. Moreover, respondents from these two categories assign statistically lower priority to connections and experience with the capitals of the largest trade powers relatively to the rest of the sample. For both categories this is the lowest ranked option in terms of joint share of high and very high priority responses (less than 40\%).

6 This preference is less strong for African WTO delegates in Geneva who completed the survey, where 65\% ranked regional diversity as high or very high, and $25 \%$ ranked this as very low.

7 The high ranking accorded to links with international organizations is not influenced by a large share of respondents being affiliated with such organizations. Both government officials and Geneva delegations rank links to IOs as the top priority, while business respondents rank this as the third priority. 


\section{Figure 3: How Important Are Personal Connections \& Recent Professional Experience}

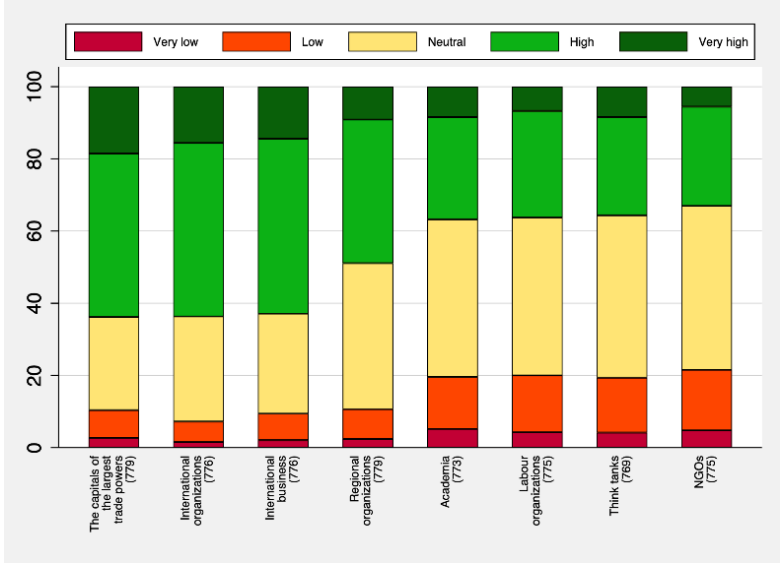

With:

(a): Attributes sorted by sum of high \& very high shares

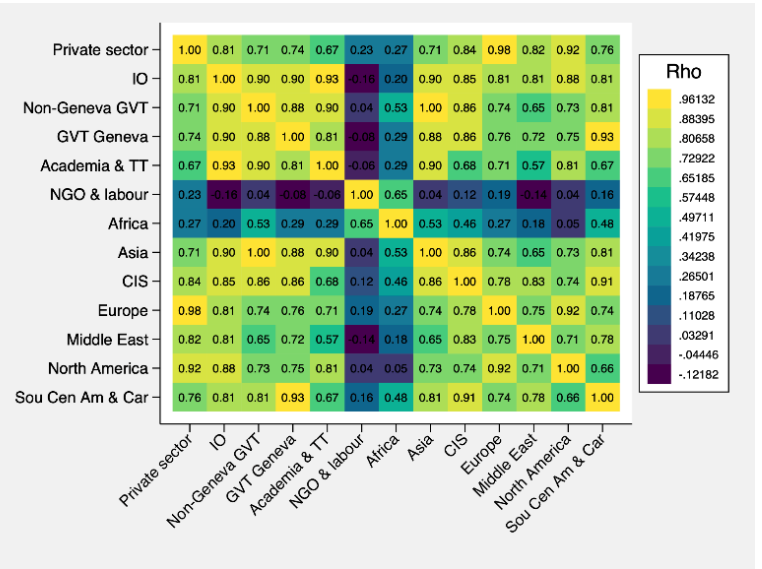

(b): Spearman rho correlation between groups

Officials in Geneva differ from government officials in capitals in assigning a lower ranking to the DG having connections to academia, think tanks, and NGOs. This pattern is also reflected in responses to questions about the need for greater engagement with trade stakeholders discussed in Section 3 below.

\subsection{Digging deeper on desirable attributes: divergent rankings across groups}

Estimation of ordered probit models reveals some statistically significant divergences in rankings across groups. Results of these estimations are reported in Annex $2 .{ }^{8}$ Space constraints preclude a detailed description of the findings - in what follows we briefly highlight a selection of statistically significant differences of group rankings relative those of the total sample (i.e., all respondents).

\section{Geographic groups}

African respondents place a statistically significant higher priority on the DG coming from a developing country and representing a region that has not yet supplied a DG. They also and rank political experience less highly than the total sample. Respondents from African countries also differ from the total sample in assigning a lower ranking to the DG having strong connections in the capitals of the major trading powers, and giving a higher priority to connections to international organizations, academia and think tanks and NGOs.

Respondents from other geographic regions also display statistically significant differences in rank orderings on some questions but tend to have priorities more similar to the total sample. An exception are respondents from the CIS and Middle Eastern countries. The number of respondents from both regions is very small, however, and may therefore not be very representative. Interested readers are referred to Annex 2.

8 To assess whether a group's ranking of the priority accorded to an option or issue differs in a statistically significant manner from that of the sample as a whole, we estimate ordered probit models where the dependent variable is given by the answers to a specific question, with values ranging from 1 (very low/strongly disagree) to 5 (very high/strongly agree). The regressor of interest is a dummy variable taking value 1 if the respondent belongs to the group of interest. The results are reported in graphs that plot both point estimates and the respective $95 \%$ confidence interval. If a confidence interval is wholly to the right or wholly to the left of 0.0 on the horizontal axis, the ranking accorded by a group to an issue is statistically significantly different from that of all respondents taken together. 


\section{Capital-based government officials}

Officials in capitals (i.e., not based in Geneva) rate political experience and gender less highly than the sample as a whole, while according a higher priority to WTO experience and selecting a DG from a developing country, ensuring regional diversity over time and choosing a DG from a region that has not yet supplied a DG. This group of respondents also ranks links with international business, labor organizations, academia and think tanks more highly than the total sample.

\section{Geneva-based officials}

Statistically significant differences in the (priorities) rankings of Geneva delegations are observed for the following attributes. Relative to the whole sample, Geneva delegation place higher priority on political experience, public profile, connections in major capitals, WTO experience, and gender. Conversely, they rank developing country nationality, coming from a region that has not yet supplied a DG, and having strong connections with labor organizations, academia, think tanks, and NGOs less highly than other respondents.

\section{Private sector}

Both Spearman rho correlation and ordered probit analyses reveal that business is closely aligned with the total sample. Business respondents reveal a statistically significant higher ranking for a DG with management experience and, not surprisingly, do the same for the DG having connections to international business. Links with international organizations, academia, and think tanks are ranked less highly than the overall sample.

\section{NGOs}

Relative the overall sample, NGOs put greater priority on political experience, a national of a developing country, connections with academia, labor organizations, think tanks, regional organizations, and gender. As do business respondents, NGOs also rank the DG having connections with themselves more highly than the totality of respondents.

\section{Substantive challenges facing the WTO (and thus the DG)}

In addition to questions concerning the desirable attributes and background of the DG, the survey collects information on the priorities accorded to different substantive matters that confront the WTO membership. Here also the responses suggest three broad messages.

\section{Everything is a priority - except launching discussions on new issues}

A first question concerned the relative importance of addressing a set of issues that most observers would regard as 'immediate' challenges confronting the WTO that should figure on the agenda of the $12^{\text {th }}$ WTO Ministerial meeting in 2021. These span monitoring COVID-19 pandemic trade-related measures; concluding ongoing negotiations on different subjects, both multilateral and plurilateral; launching discussions on new issues; clarifying the role of the trade policy in tackling climate change; negotiating stronger rules on the use of subsidies and industrial policies; and the WTO's role in realizing the UN sustainable development goals (SDGs).

Respondents regard all these different issues as priorities for the institution and thus the DG. The exception is launching discussions on new issues, which gets fewer scores of high or very high and, as important, a greater share of low or very low scores (Figure 4, panel a). Although there is a commonality of views in that most of the identified issues are priorities, there are also differences across groups on 
the ranking of specific issues. The heatmap of Spearman rho correlations (Figure 4, panel b) indicates that Geneva delegations and NGOs differ from other respondent groups. Geneva officials rank concluding the long-running multilateral negotiations on fishing subsidies and agricultural support as the most important priority, with some $90 \%$ of respondents giving this a high or very high score. In contrast, officials in capitals accord a higher rank to concluding ongoing plurilateral talks on ecommerce, domestic regulation of services, investment facilitation and MSMEs, which is seen as less important by Geneva-based officials. Both groups of officials place great weight on monitoring of COVID-19-related policy measures.

NGOs are an outlier in their ranking of priorities. Clarifying the role of the WTO in attaining the SDGs and the role of trade policy in combatting climate change are regarded to be the first and second priority, respectively, with $90 \%$ of respondents giving the WTO-SDG issue a score of high or very high. This group is also more opposed to concluding plurilateral talks, with $25 \%$ giving this a low or very low score (compared to less than $10 \%$ for the total sample).

Figure 4: Heading towards MC12, what priority do you assign to the following issues?

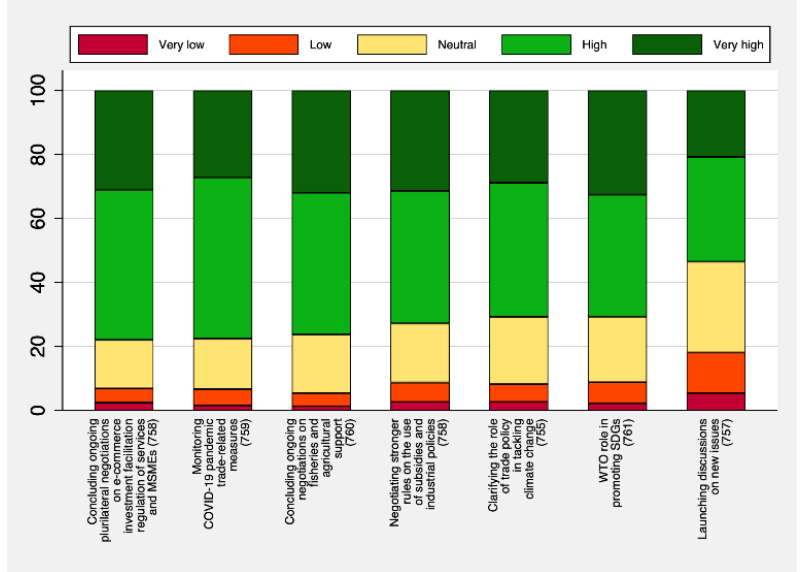

(a): Attributes sorted by sum of high \& very high shares

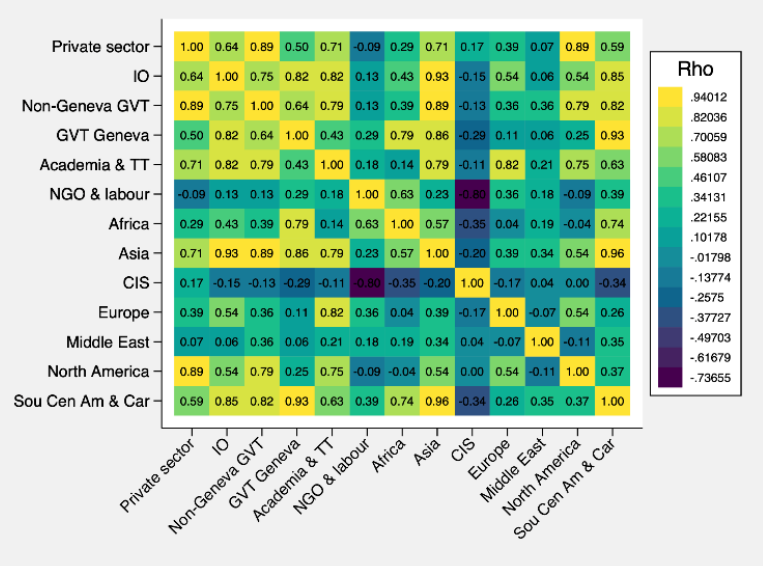

(b): Spearman rho correlation between groups

Ordered probit analysis reveals additional differences in rankings of issues across groups (see Annex 2). The private sector (business) and government officials in capitals are aligned on the relative importance accorded to concluding plurilateral talks, revealed in a statistically significant higher ranking for this issue. Capital-based officials also rank negotiating stronger rules on subsidies more highly than the sample. This is also the case for engaging on the SDGs, an issue that African respondents and NGOs also rank higher than the total sample. Business is an outlier in according a higher ranking to launching of discussion on new issues. Finally, Geneva delegations accord a statistically significant lower ranking to clarifying the role of trade policy in addressing climate change.

\subsection{Institutional reform priorities: dispute settlement first... and second}

In addition to substantive policy matters, many WTO members have also engaged in a process to identify measures that could be taken to improve the functioning of the organization. The survey included questions relating to institutional reform, asking respondents to rank the priority accorded to resolving specific problems affecting the operation of the WTO and specific suggestions that have been made to address them. The survey asked respondents their views on the priority accorded to the following issues/options:

a) Make the Appellate Body (AB) operational again

b) Reform dispute settlement and revisit the role of appellate review

c) Improve compliance with notification obligations 
d) Resolve differences on special and differential treatment for developing countries

e) Strengthening the trade policy monitoring process

f) Use WTO bodies to defusing potential disputes (e.g., through "specific trade concern" processes)

g) Deepening engagement with stakeholders (e.g. through thematic sessions)

h) Analyze the distributional effects across countries of national trade policies

i) Provide support for plurilateral agreements

The results reveal that addressing the dispute settlement crisis is considered to be the highest priority issue confronting the next DG, with over $80 \%$ of respondents giving the options of making the $\mathrm{AB}$ operational again and reforming dispute settlement and revisiting the role of appellate review a score of high or very high. Moreover, these options attracted virtually no scores of low or very low. Other issues attracting scores of high or very high include improving compliance with notification obligations; resolve differences on special and differential treatment for developing countries; and strengthening the trade policy monitoring process (Figure 5, panel a).

The two options ranked lowest are deepening engagement with stakeholders and analyzing the crosscountry distributional effects of national trade policies. This is interesting insofar as it suggests the trade practitioners that responded to the survey do not see a strong need to consider/elicit input from the broader community affected by trade policy and WTO agreements or to consider the impact of trade policies. Given rising contestation of trade agreements and the emergence of populist political opposition to the WTO, one might have expected these options to have been given more importance.

\section{Figure 5: Institutional reform priorities}

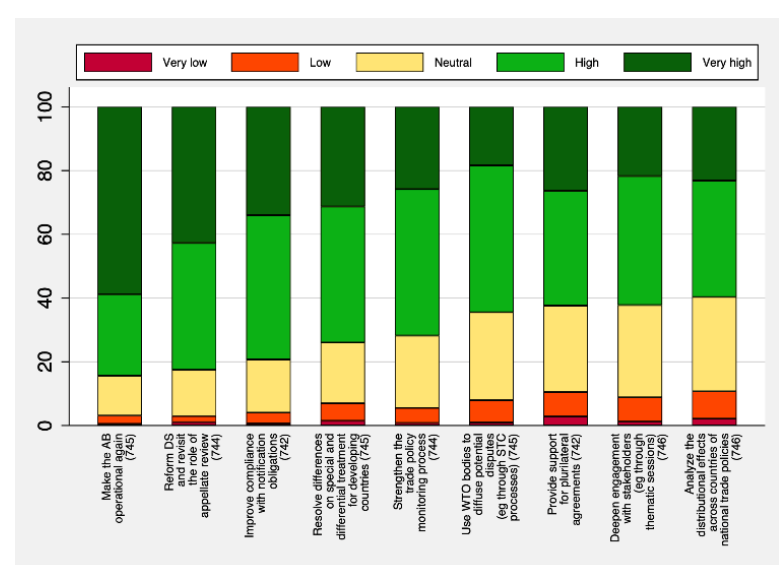

(a): whole sample

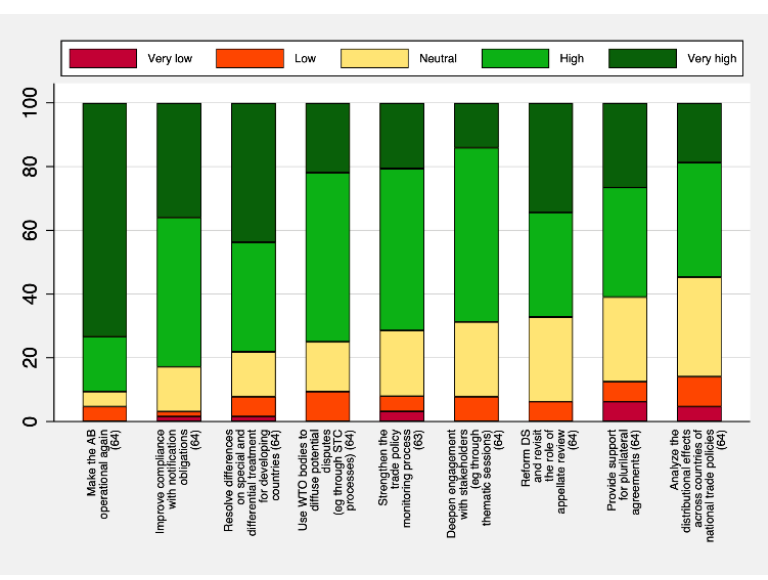

(b): respondents from Geneva delegations Notes: Bars sorted by the combined share of high and very high responses.

There are several noteworthy differences in rankings across groups. Geneva delegations, NGOs and African respondents tend to place different weights on some of the issues and options raised. African respondents place a higher priority on all these issues compared to the whole sample. They also accord a higher ranking to trade policy monitoring and to resolving differences on special and differential treatment for developing countries (Annex 2).

One difference that emerges concerns dispute settlement. Non-Geneva-based government officials are similar to the sample as a whole in ranking reform of dispute settlement highest, followed by making the $\mathrm{AB}$ operational again, suggesting that what is being picked up here is simply that resolving the conflict on dispute settlement is what matters most to governments. Noteworthy in this regard is that Geneva-based officials rank reinstating the $\mathrm{AB}$ as most important, with $95 \%$ of this group giving this a score of high or very high, but rank reform of the dispute settlement system much lower $\left(7^{\text {th }}\right.$ out of the 9 issues/options raised in the relevant question) (Figure 5, panel b). This suggests that as far as Geneva 
is concerned the first order of business is to bring the $\mathrm{AB}$ back. Whether and what to consider in terms of improving dispute settlement is seen as less of a priority by Geneva delegations. 'Geneva' ranks action to diffuse potential disputes though deliberations in WTO committees through mechanisms such as tabling 'specific trade concerns' more highly than engaging in dispute settlement reform discussion.

Turning to the options ranked last in the total sample (more engagement with stakeholders and analysis of the distributional effects of trade policies), business and government officials - both in Geneva and in capitals - are on the same page in ranking analysis of the distributional effects of trade policies last. NGOs in contrast are a clear outlier in ranking more distributional analysis highest. Geneva delegations rank greater engagement with stakeholders more highly than the total sample. Thus, the results suggest a common view regarding the priority to be accorded to distributional analysis but some divergence in views between Geneva and capitals on engaging more with stakeholders.

Ordered probit analysis reveals that government officials, whether in or outside Geneva attach a statistically greater priority (ranking) to making the $\mathrm{AB}$ operational again than do respondents overall. The probit regressions confirm that Geneva, as do NGOs and European respondents, assign a lower ranking to dispute settlement reform, whereas Latin American and African respondents rank this higher. For other differences in relative rankings on specific issues see Annex 2.

\subsection{Use video conferencing more in day-to-day operations}

A final set of questions concerned daily operations of the organizations, with a focus on two issues: the use of video-conferencing technologies and the use of voting on matters that do not imply a change in rights and obligations of WTO members. While COVID-19 has made video conferencing much more a new normal, this is something that has long been the subject of debate in the WTO. Greater use of such technologies has been advocated by some observers to enhance participation in meetings by capitalbased officials and reduce travel time/costs and the WTO's carbon footprint.

The results suggest agreement on greater use of video-conferencing, including for the delivery of training and technical assistance; making decisions through meetings that involve participation of officials via video conferencing facilities; and making use of such technology a standard option for WTO meetings. Geneva officials are less supportive of decision-making when videoconferencing is used, while business respondents are significantly more favorable to use of video conferencing than the total sample (Annex 2).

There is much more limited support for voting on operational matters, with less than $50 \%$ of respondents giving this a score of high or very high, and $20 \%$ of respondents scoring this as low or very low. Looking across groups, Geneva delegations - and respondents from North America - are least favorable to voting (see Annex 2).

\section{Concluding remarks}

It is not possible to make inferences regarding what underlies differences in rankings across groups and across issues. The survey can only reveal where there are commonalities in priorities (rankings) and where there are differences. The ordered probit models are useful in identifying when differences across groups in how they rank order issues and assign priorities but tell us nothing about what drives (explains) such differences. In this concluding section we revisit some of the main messages/findings that emerge from the survey and suggest some hypotheses suggested by the results that can be the basis for deeper analysis using other social science methods - such as structured interviews and case studies with representatives of specific groups of interest.

The bottom line that emerges from the responses to the survey regarding priorities when it comes to the professional and personal attributes of the next DG is relatively clear. Competence, political experience, a network that spans major capitals, international business and international organizations, 
knowledge of the WTO negotiating process and a background in economics are all characteristics that are ranked most highly. Moreover, Geneva-based officials often accord greater priority to these characteristics than the total sample.

One hypothesis this suggests is that the DG should not be a technocrat/WTO delegate. There is a recurring debate among trade officials and practitioners that has something of a cyclical dimension: should the WTO be led by an ex-Minister/senior politician or by a bureaucrat (a trade official)? The most recent DG was a bureaucrat; some of his predecessors were former Ministers or Prime-Ministers (e.g., Renato Ruggiero; Mike Moore). It appears that as far the respondents to the survey are concerned the pendulum has swung to a preference for the latter type of profile.

The converse of the high rank order given to the above-mentioned characteristics is that there is less support for the notion that the DG should come - or not come - from a developing/developed country; a region that has not yet supplied a DG; and that there should explicit rotation between DGs from the North and the South. There is however no consensus on this - African respondents rank these attributes much higher than the sample average. It is important to note that many groups - not only African respondents - assign a high priority to regional diversity over time. This suggests the hypothesis that conditional on competence and political/professional networks, there is significant support for considering regional diversity as a factor - but not as a rule.

The priority accorded to the DG having connections with international organizations is striking and is one that gives rise to a research question regarding the drivers of this view. One hypothesis is that it may reflect a recognition that the trade agenda increasingly spans subjects that other agencies have expertise on. It may also reflect the closer interaction between the WTO and the international development community as a result of the 2005 Aid for Trade initiative, the creation of the Enhanced Integrated Framework, and the cooperation with other organizations on the implementation of the Agreement on Trade Facilitation.

There is a substantial degree of commonality in rank orderings of substantive issues for negotiation, institutional reform, and daily operations of the WTO. Resolving the dispute settlement crisis is a clear priority for most respondents, especially government officials. There are differences between government respondents based in Geneva and capitals on how to go about this, with Geneva according a lower rank order to discussion on reforming the dispute settlement system and attaching a very high priority to reinstating the $\mathrm{AB}$. At the same time Geneva accords a higher rank to efforts to use dispute avoidance mechanisms such as using WTO bodies to discuss specific trade concerns and engaging more with stakeholders than do capital-based officials. This suggests one job for the next DG is to encourage members to explore how different elements of institutional reform can help address the dispute settlement conflict, and to engage with Geneva delegations to ensure the very strong preference for restoring the $\mathrm{AB}$ does not result in a long lasting deadlock. 


\section{Annex 1. Survey questions}

1. What priority do you assign to next Director-General's characteristics?

a) Political experience

b) Experienced WTO negotiator

c) Gender

d) Public profile

e) National of a developing country

f) National of a developed country

g) Representing a region that has not yet had a DG

h) Economics training

i) Legal background

j) Experience in managing organizations

\section{The selection of the DG should:}

a) Alternate between developed and a developing country

b) Ensure regional diversity over time

c) Be solely based on expertise and competence, independent of origin or gender

d) Exclude officials who have worked for one of the three major trading powers (China, EU, US)

3. What priority do you assign to the DG to have personal connections and recent experience with:

a) The capitals of the largest trade powers (Beijing, Washington DC, Brussels, Berlin, Tokyo)

b) International business

c) Labor organizations

d) Nongovernmental organizations

e) Academia

f) Think tanks

g) International organizations (e.g., UN, OECD, international financial institutions)

h) Regional organizations (e.g., APEC)

4. The new DG will have to turn first to MC12. What priority do you assign to:

a) Monitoring COVID-19 pandemic trade-related measures

b) Concluding ongoing negotiations on fisheries and agricultural support

c) Concluding ongoing plurilateral negotiations on e-commerce, investment facilitation, regulation of services and MSMEs

d) Launching discussions on new issues

e) Clarifying the role of the trade policy in tackling climate change

f) Negotiating stronger rules on the use of subsidies and industrial policies

a) WTO role in promoting the sustainable development goals

5. In terms of institutional reform, what priority do you assign to the following issues the next DG should take up:

b) Make the Appellate Body operational again

c) Reform dispute settlement and revisit the role of appellate review

d) Improve compliance with notification obligations

e) Resolve differences on special and differential treatment for developing countries

f) Use WTO bodies to defusing potential disputes (e.g., through "specific trade concern" processes)

g) Deepen engagement with stakeholders (e.g. through thematic sessions)

h) Strengthen the trade policy monitoring process

i) Analyze the distributional effects across countries of national trade policies

j) Provide support for plurilateral agreements

6. In terms of daily operations, what priority do you assign to the following issues:

a) Encourage use of voting on operational matters

b) Allow binding decisions to be made in virtual meetings

c) Make virtual meetings and video conferencing standard options

d) Deliver WTO technical assistance and training online and through video conferencing 


\section{Annex 2: Summary of survey responses}

This Annex first presents a series of bar charts with summary of responses for selected categories of professional affiliation and for WTO official geographic regions. For each panel in the following bar charts, items (bars) are ranked by the total share of very high (strongly agree) and high (agree) responses.

The Annex also reports estimations from discrete choice models. These results are summarized in figures that plot the point estimates and the respective $95 \%$ confidence intervals from ordered probit models where the dependent variable is given by the answers to a specific option given by a survey question. Each dependent variable is cded to take values from 1 (very low or strongly disagree) to 5 (very high or strongly agree). The regressor of interest is a dummy variable taking value 1 if the respondent belongs to the category indicated on the vertical axis, indicating either a category of professional affiliation or a geographic region.

The interpretation of the coefficients is in terms of an unobservable latent variable, which can be though of as the utility of the respondent from the new DG having a certain characteristic or prioritising a certain issue. A positive (negative) estimated coefficient with respective confidence interval lying strictly above (below) zero denotes that the respective respondents' category tends to get a higher (lower) utility - from the next DG having the characteristic or prioritising the issue specified in the text of the survey - than all other respondents. A confidence interval crossing the vertical zero line would suggest instead that the utility the respective category gets is not statistically different from that of all other respondents. 
What priority do you assign to the following characteristics for the WTO DG?

Figure A2.1: Responses by category of professional affiliation

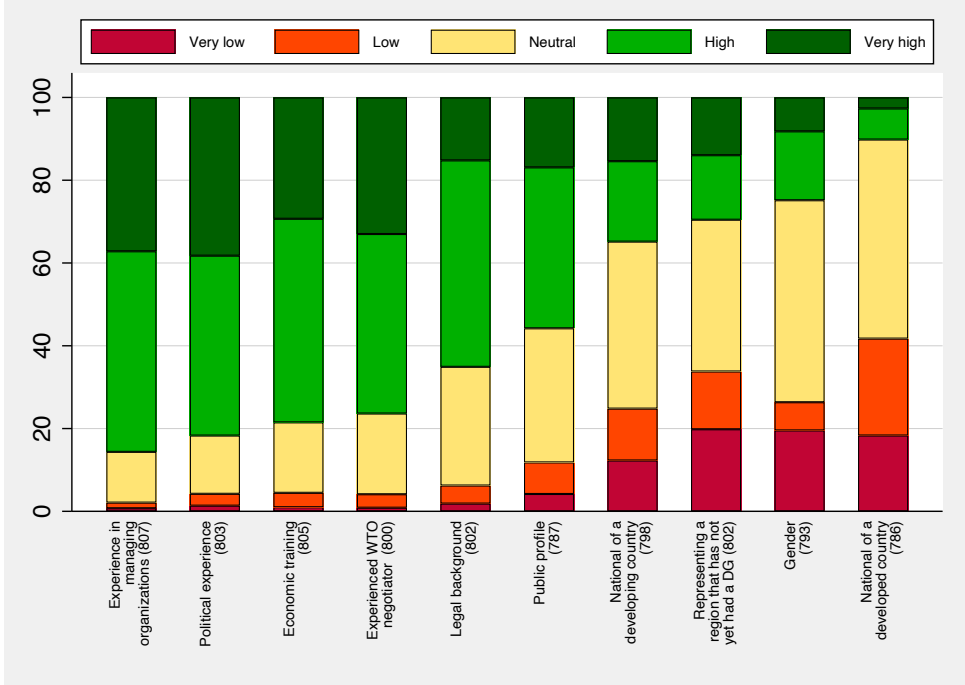

(a) Whole sample

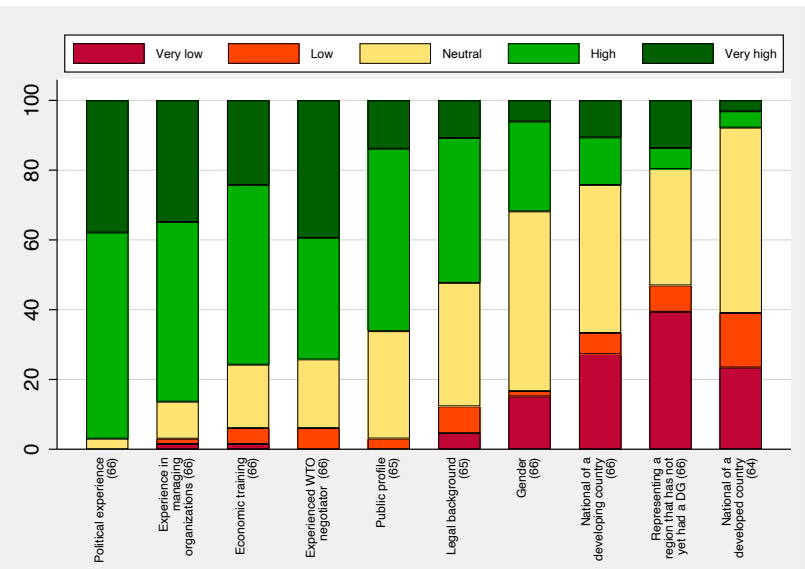

(b) Government (including EU) in Geneva

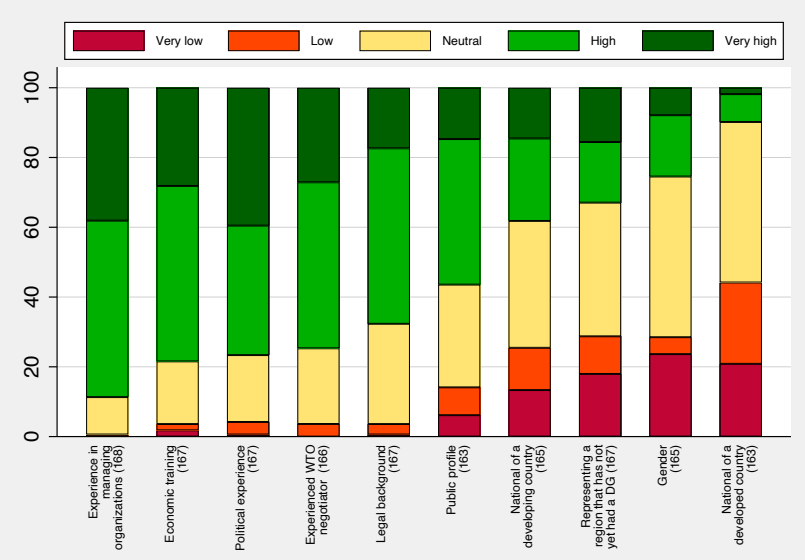

(d) Private sector

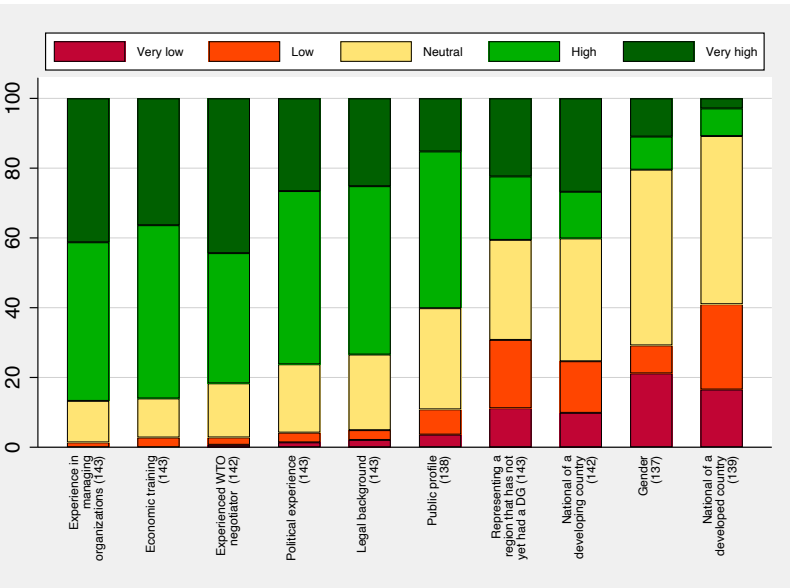

(c) Government (including EU) outside Geneva

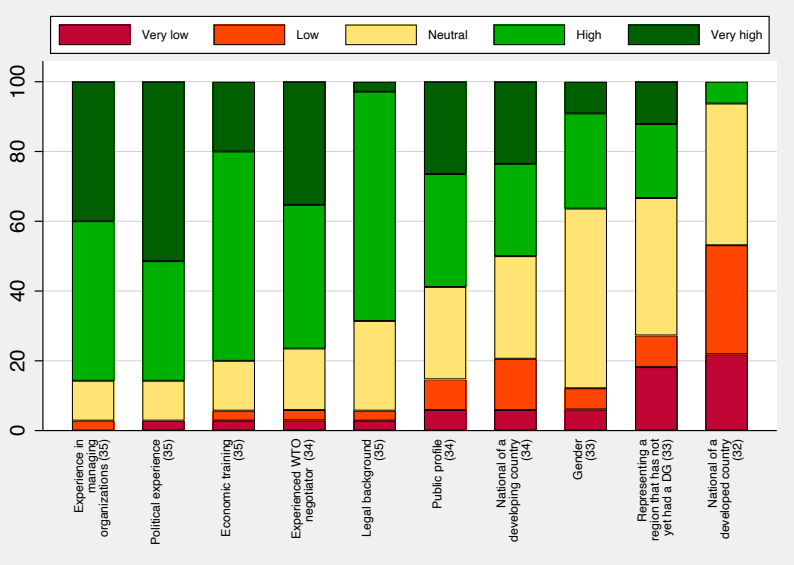

(e) NGOs and Labour organizations 
Figure A2.2: Responses by geographic region

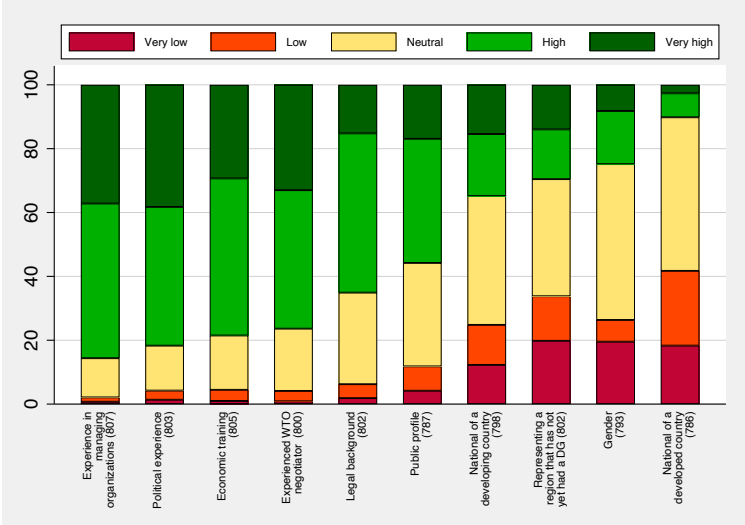

(a) Whole sample

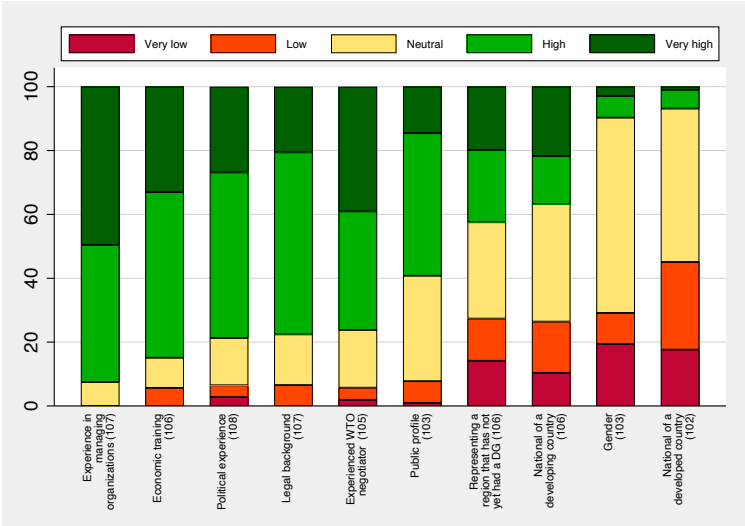

(c) Asia

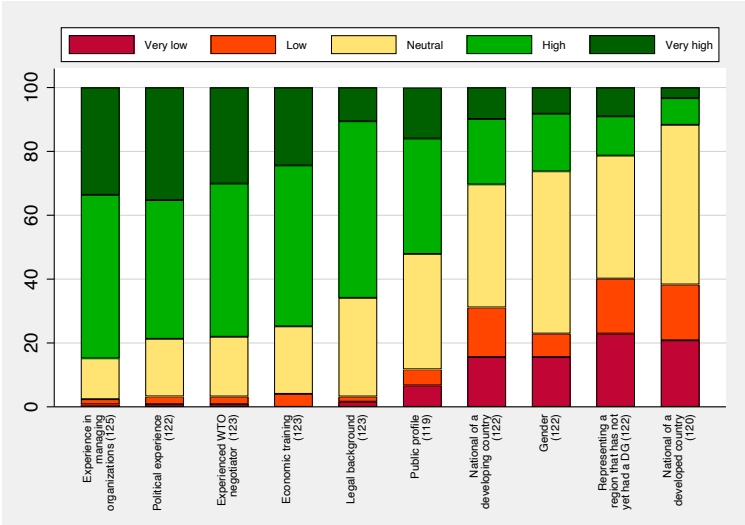

(e) North America

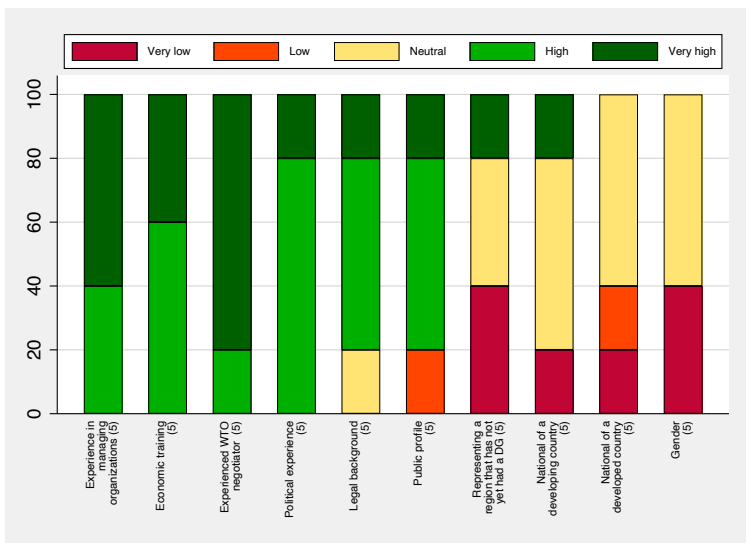

(g) CIS

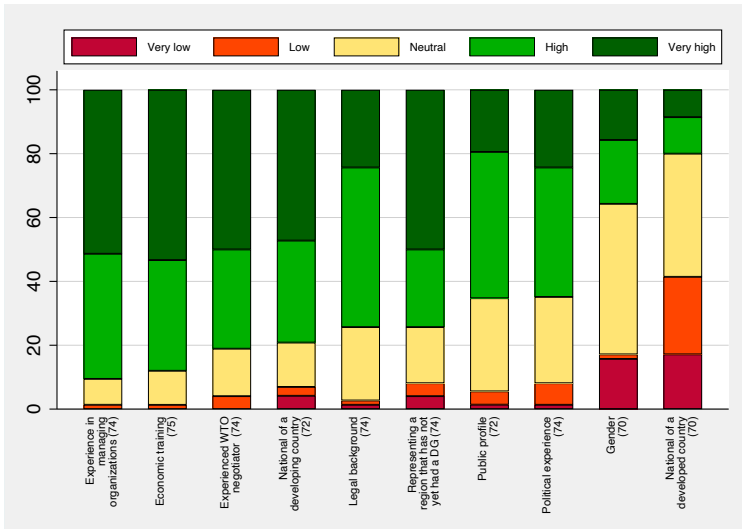

(b) Africa

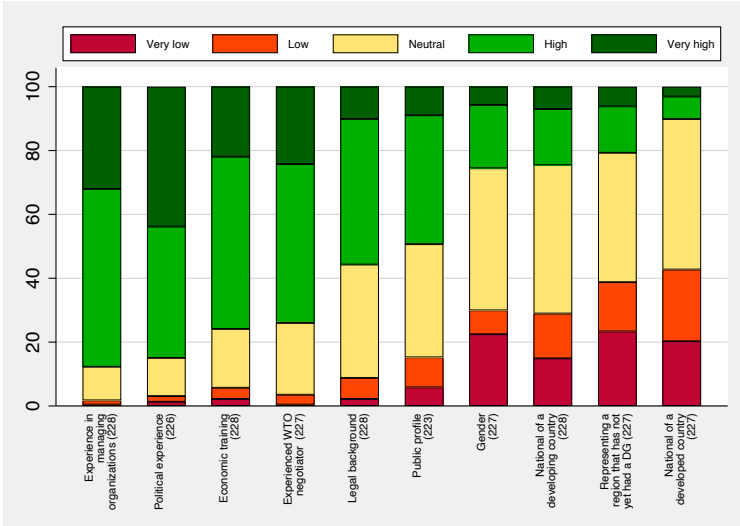

(d) Europe

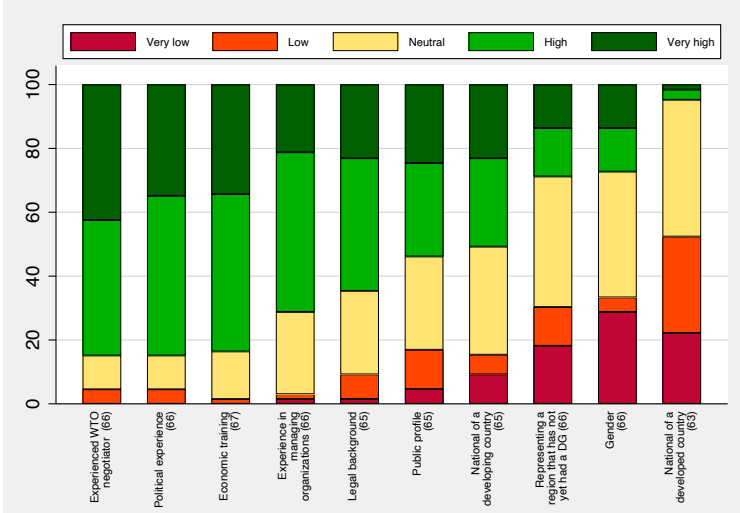

(f) South and Central America and the Caribbean

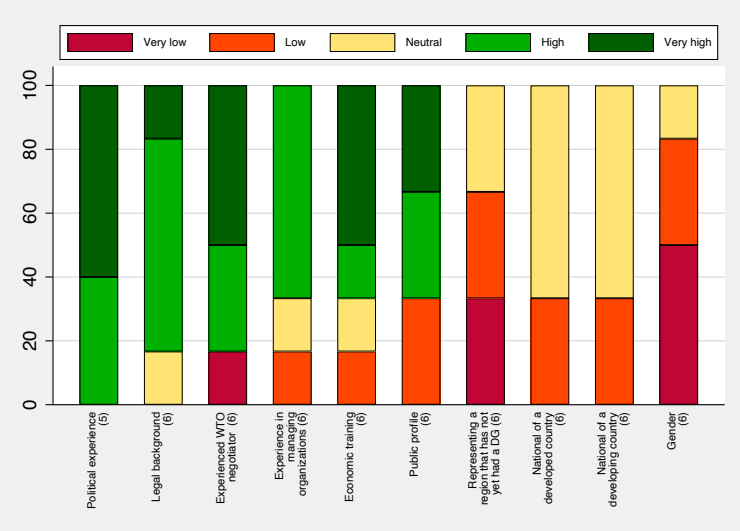

(h) Middle East 


\section{The selection of the DG should:}

Figure A2.3: Responses by category of professional affiliation

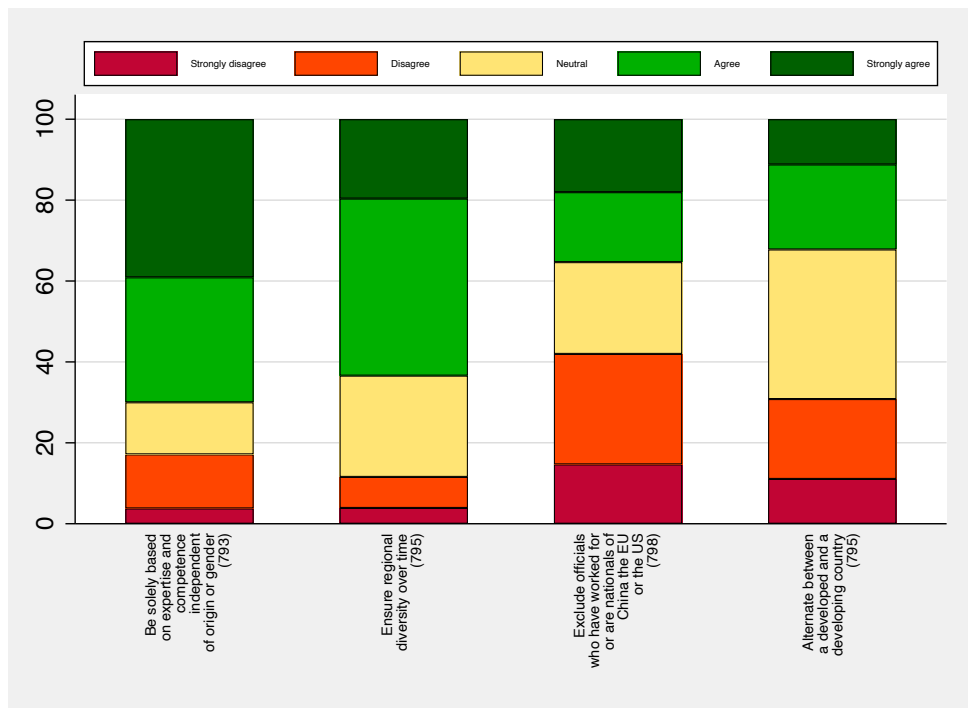

(a) Whole sample

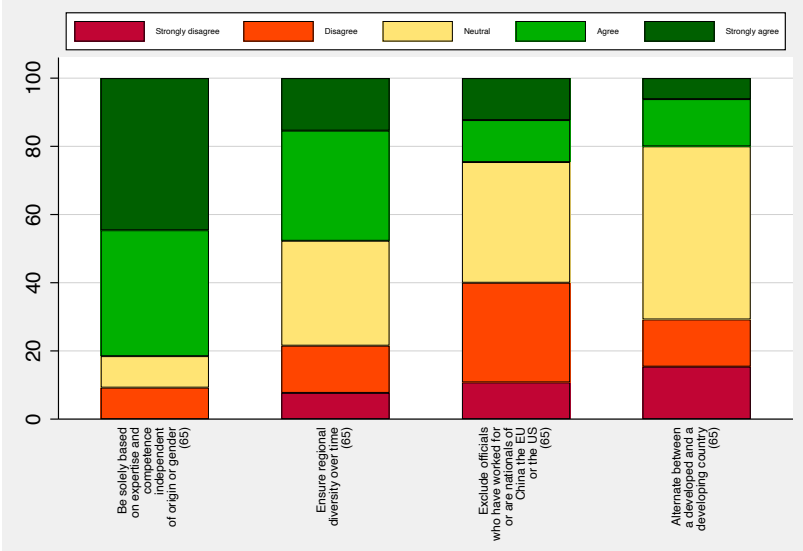

(b) Government (including EU) in Geneva

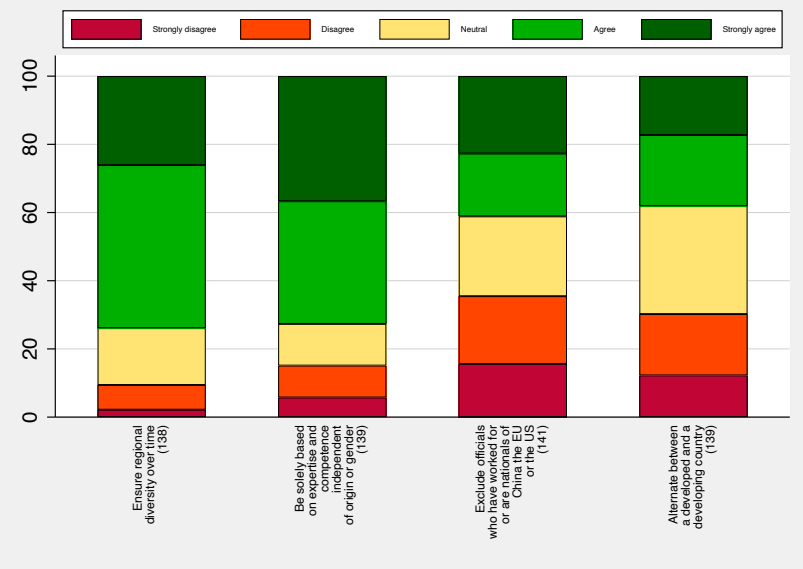

(c) Government (including EU) outside Geneva

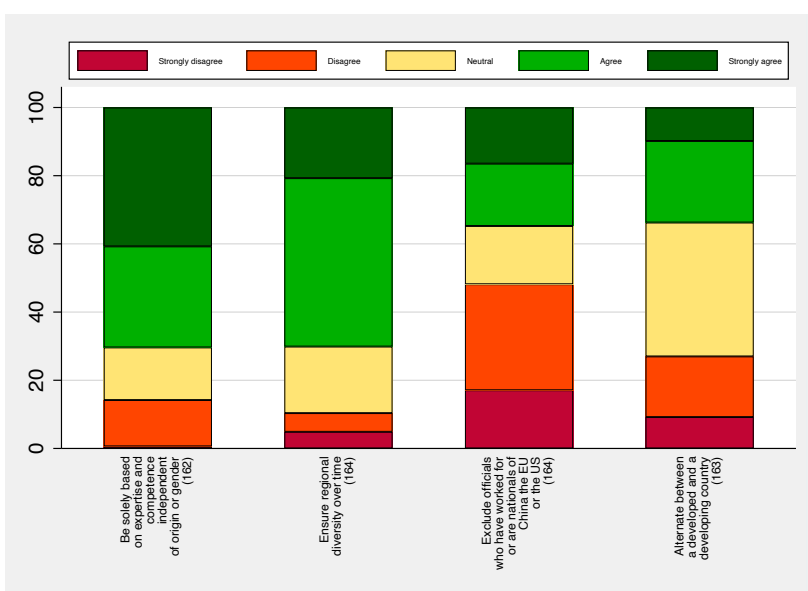

(d) Private sector

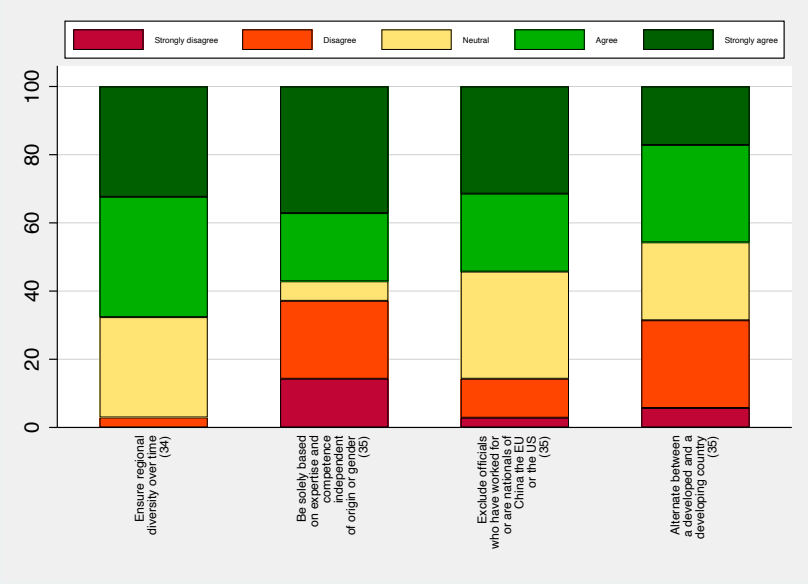

(e) NGOs and Labour organizations 
Figure A2.4: Responses by geographic region

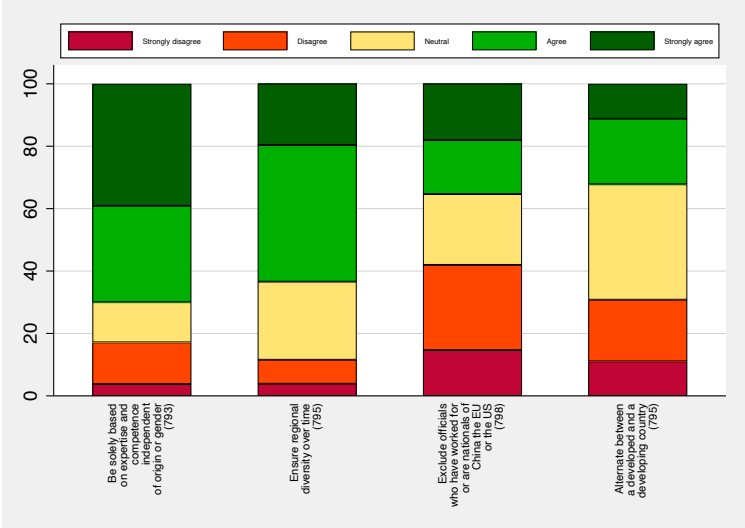

(a) Whole sample

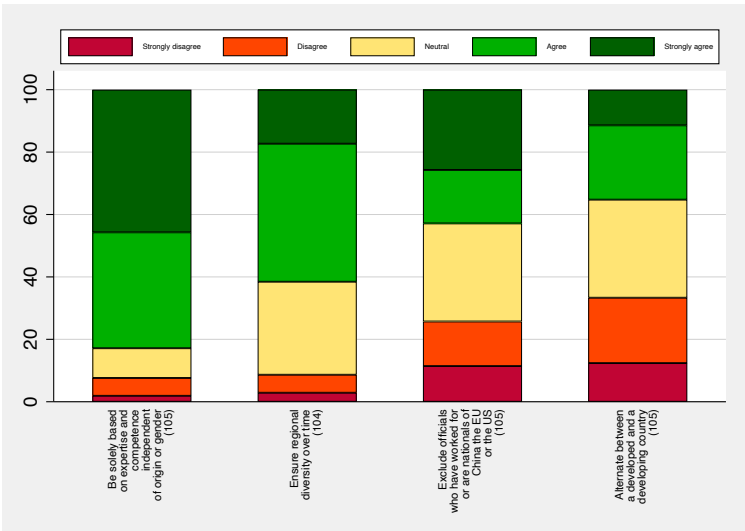

(c) Asia

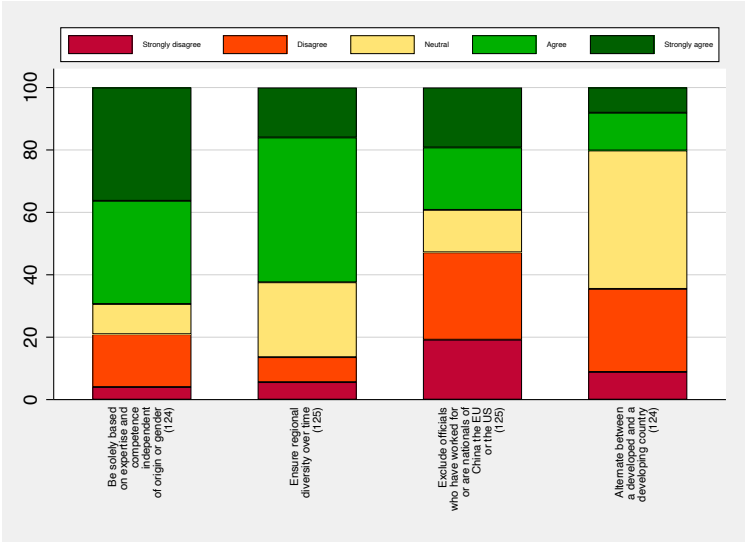

(e) North America

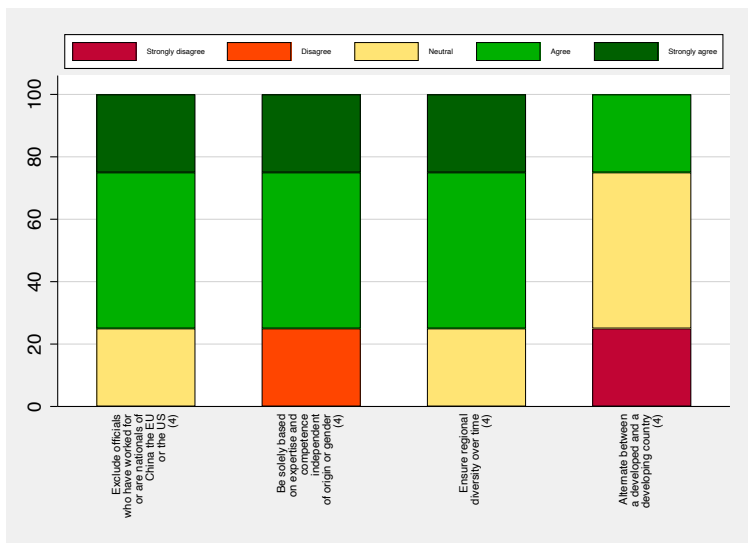

(g) CIS

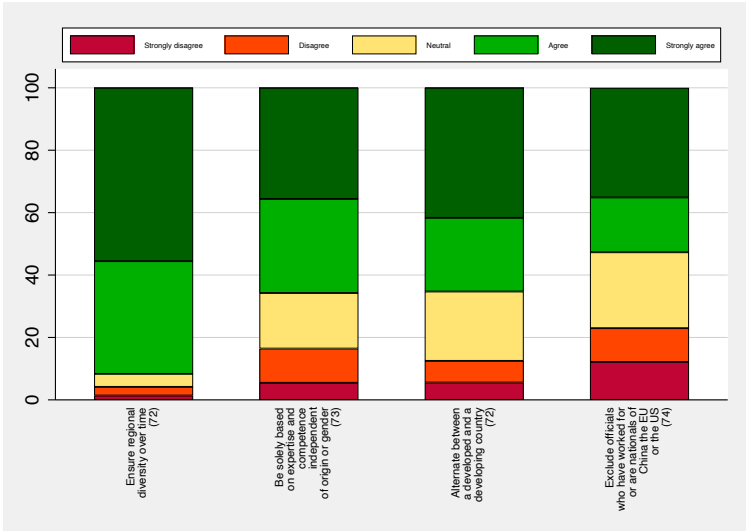

(b) Africa

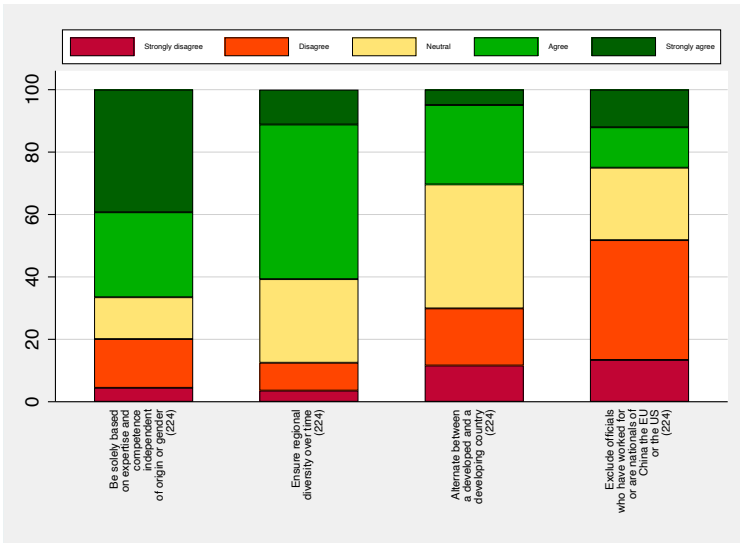

(d) Europe

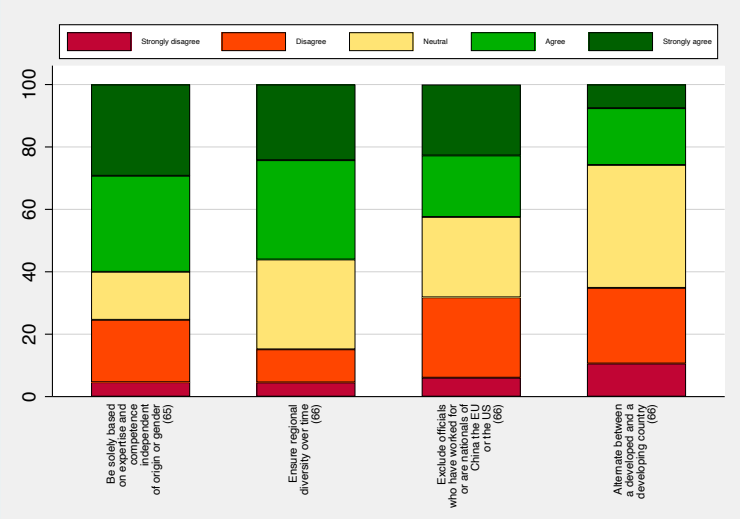

(f) South and Central America and the Caribbean

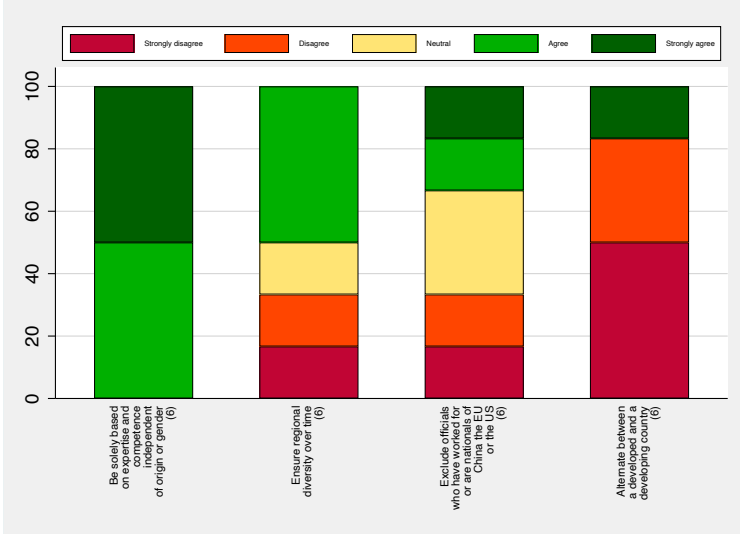

(h) Middle East 
What priority do you assign to the new DG having personal connections and recent professional experience with:

Figure A2.5: Responses by category of professional affiliation

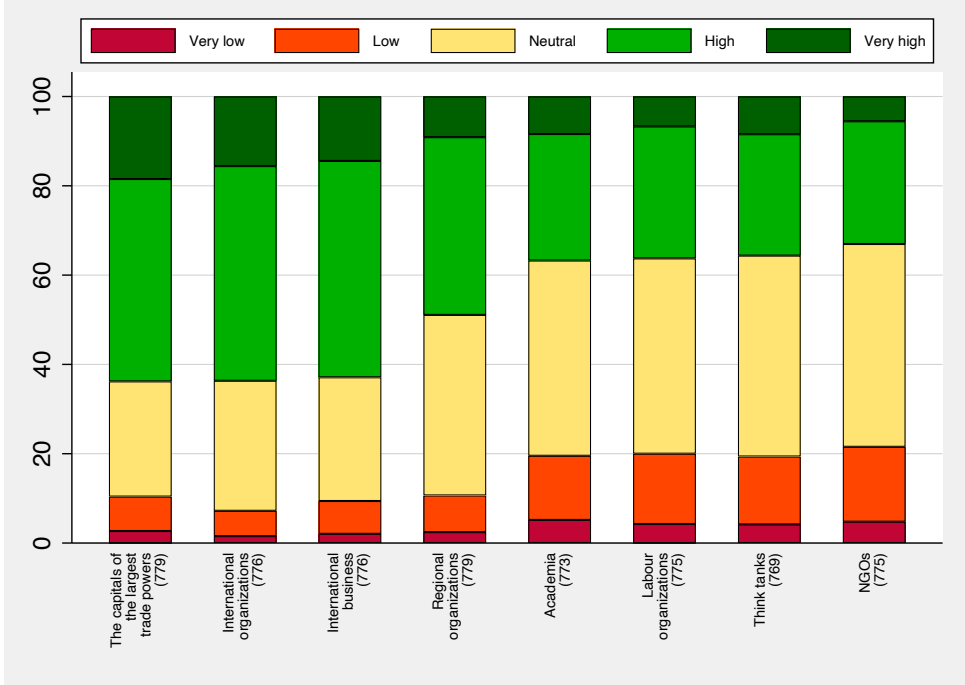

(a) Whole sample

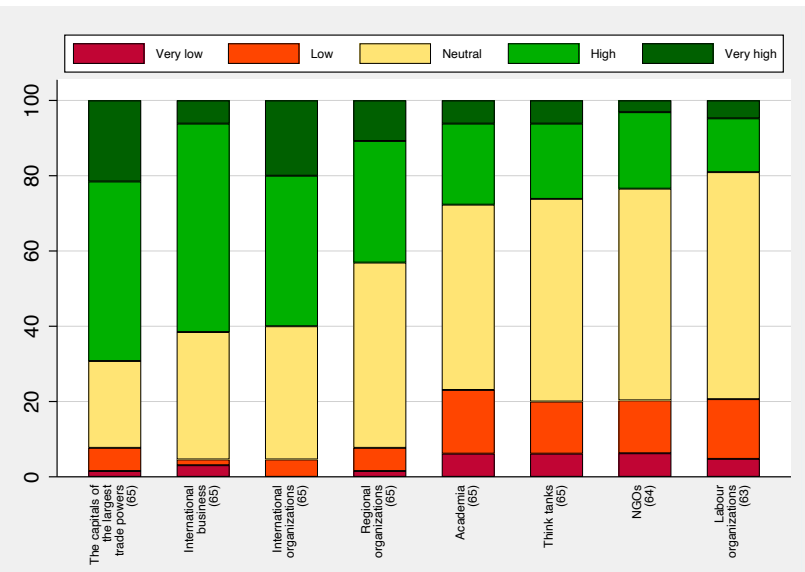

(b) Government (including EU) in Geneva

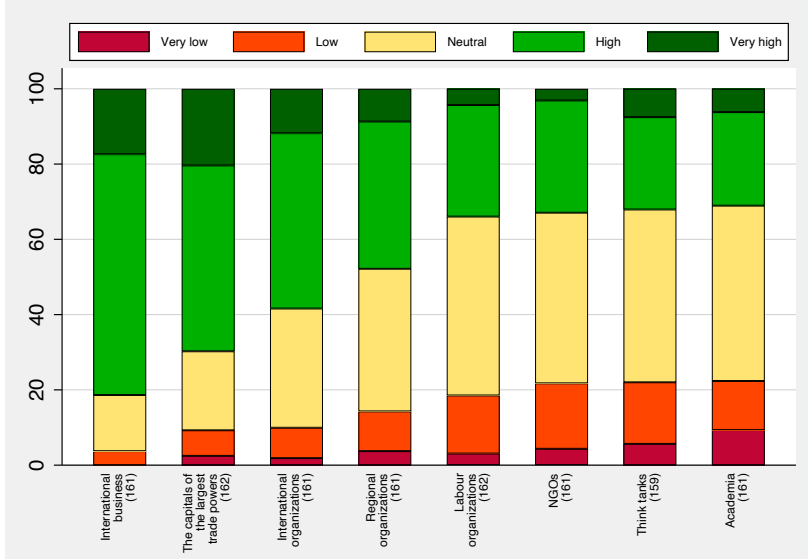

(d) Private sector

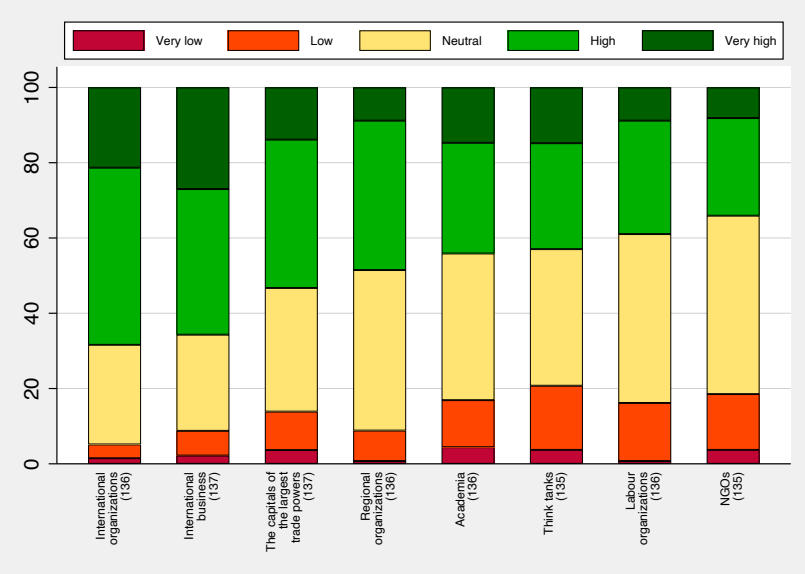

(c) Government (including EU) outside Geneva

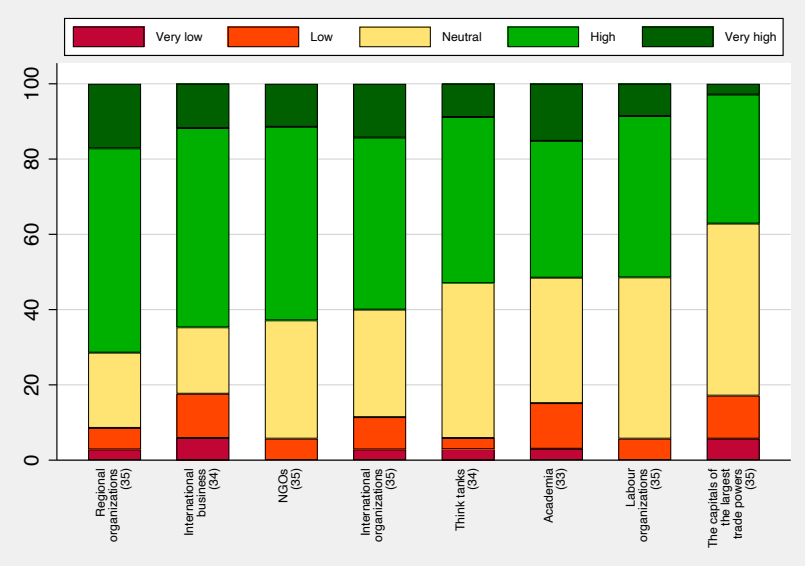

(e) NGOs and Labour organizations 
Figure A2.6: Responses by geographic region

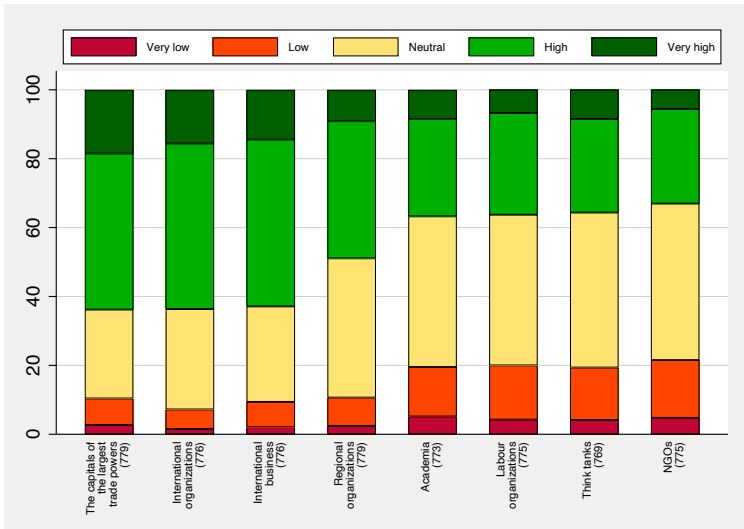

(a) Whole sample

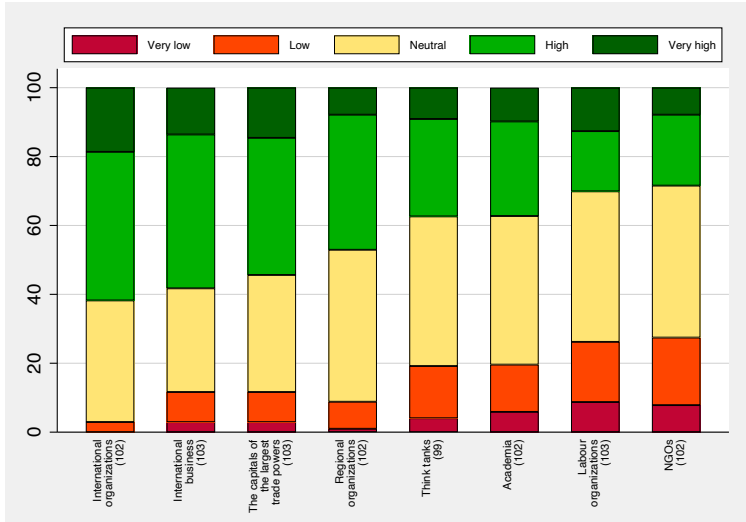

(c) Asia

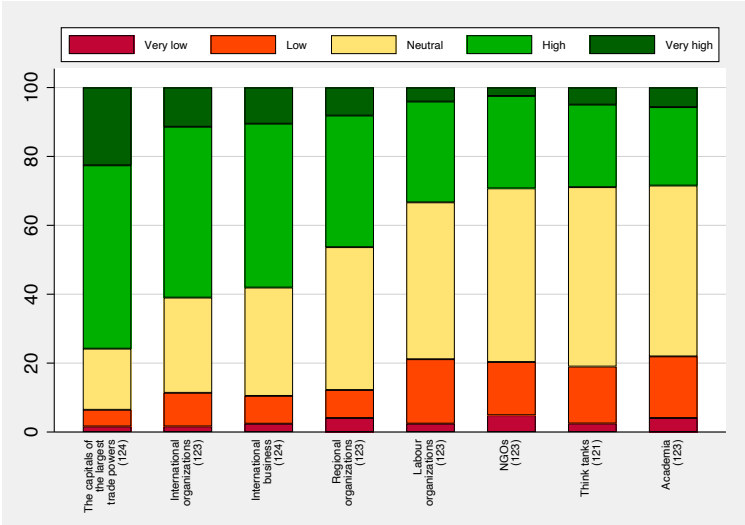

(e) North America

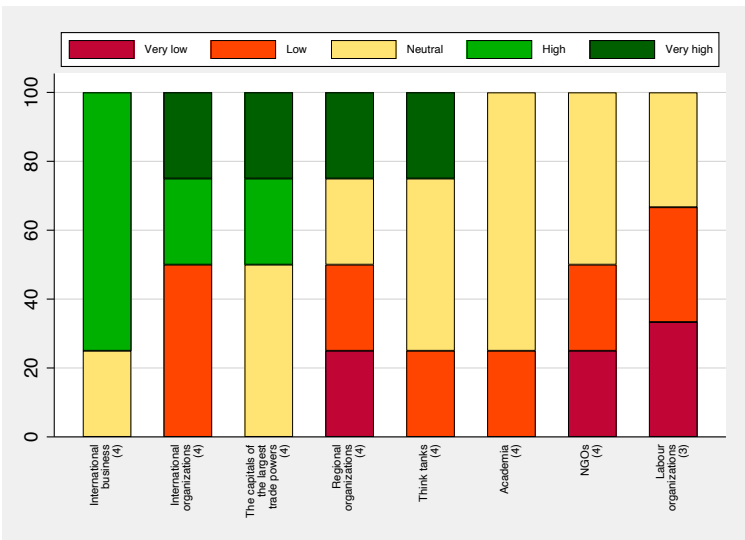

(g) CIS

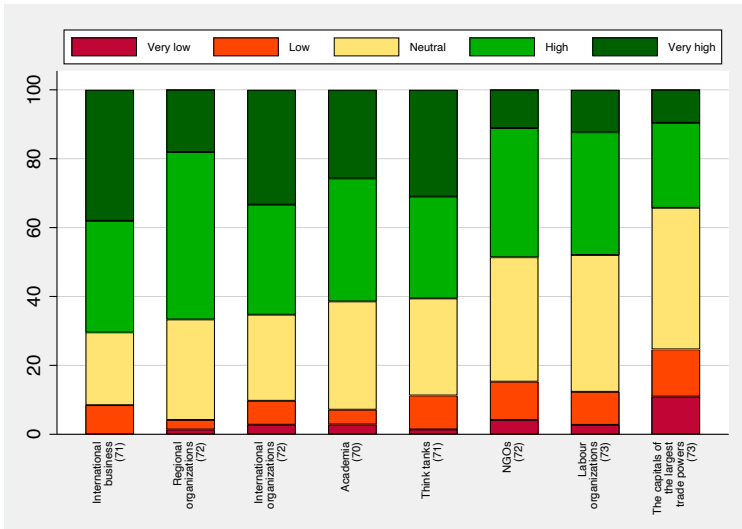

(b) Africa

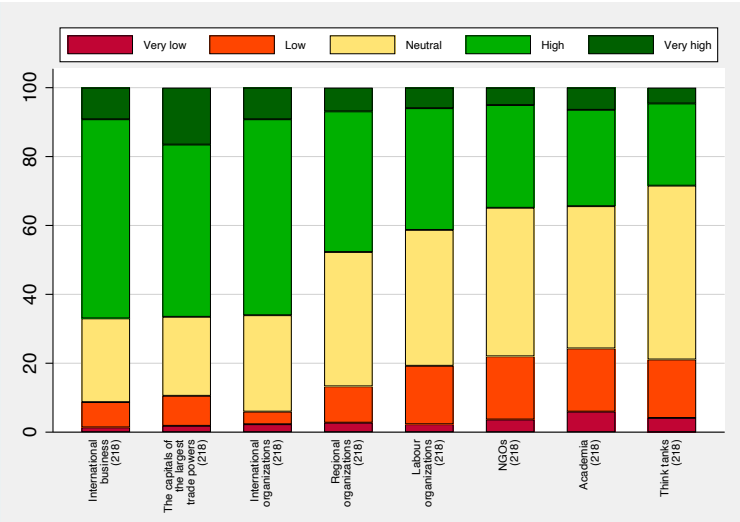

(d) Europe

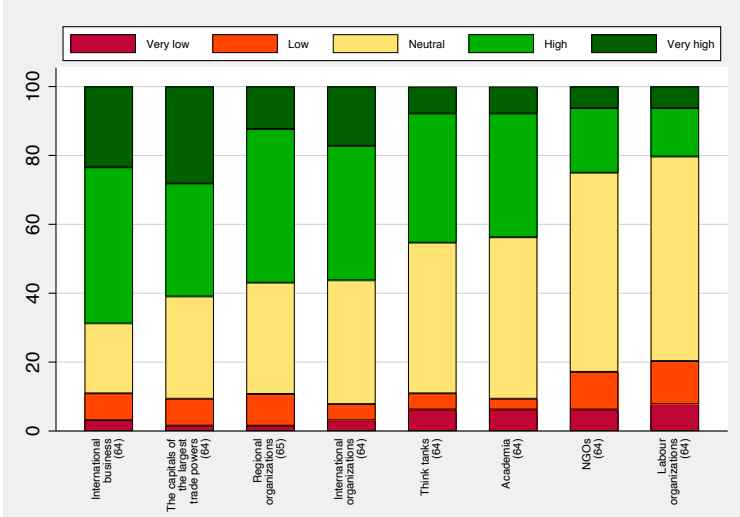

(f) South and Central America and the Caribbean

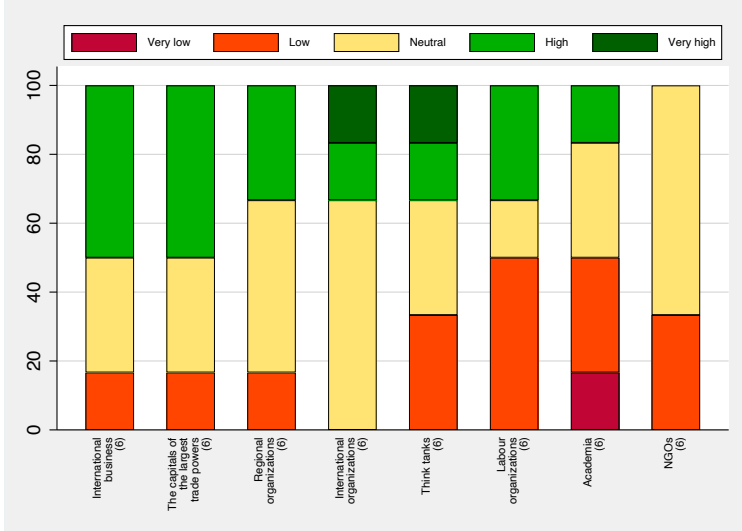

(h) Middle East 
The new DG will have to turn first to MC12. What priority do you assign to:

Figure A2.7: Responses by category of professional affiliation

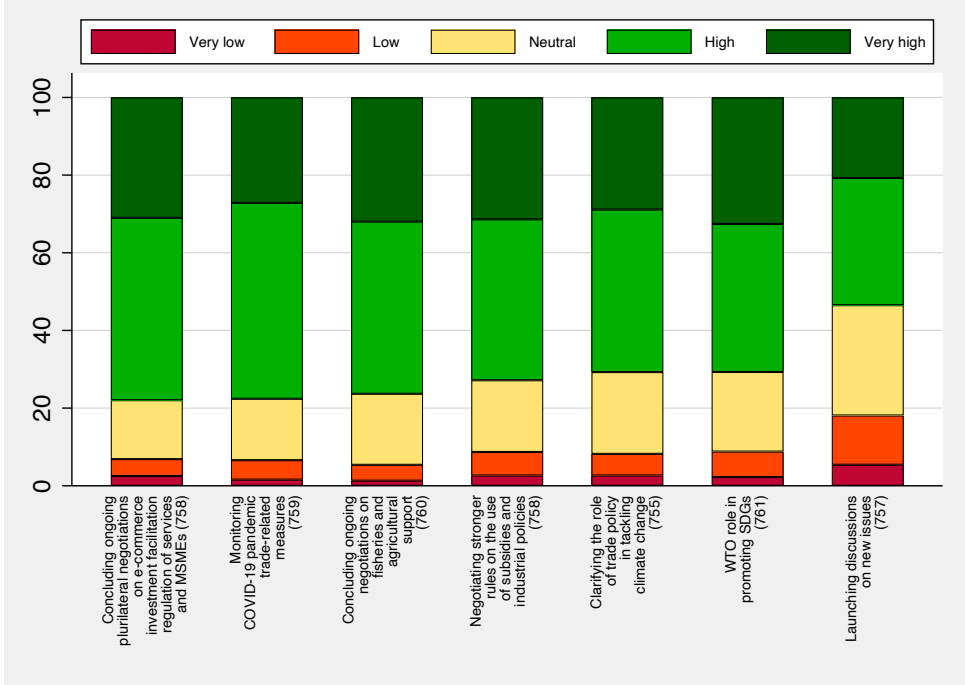

(a) Whole sample

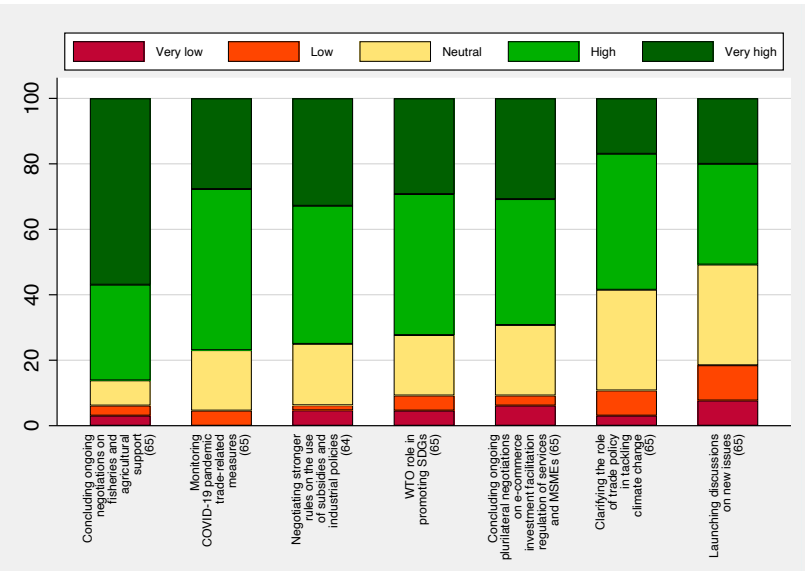

(b) Government (including EU) in Geneva

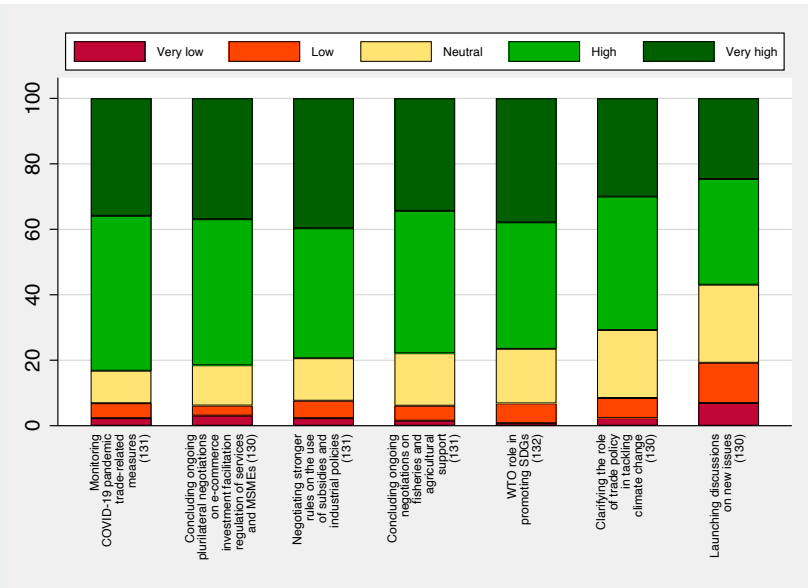

(c) Government (including EU) outside Geneva

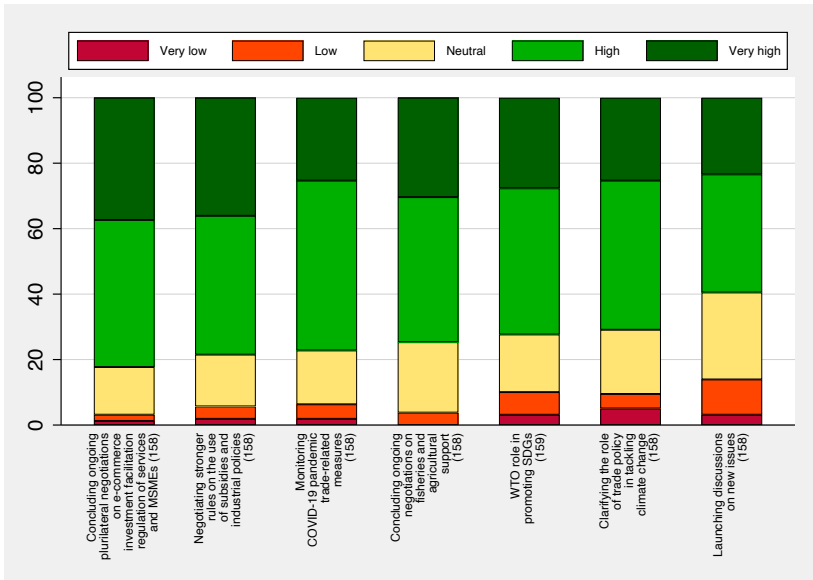

(d) Private sector

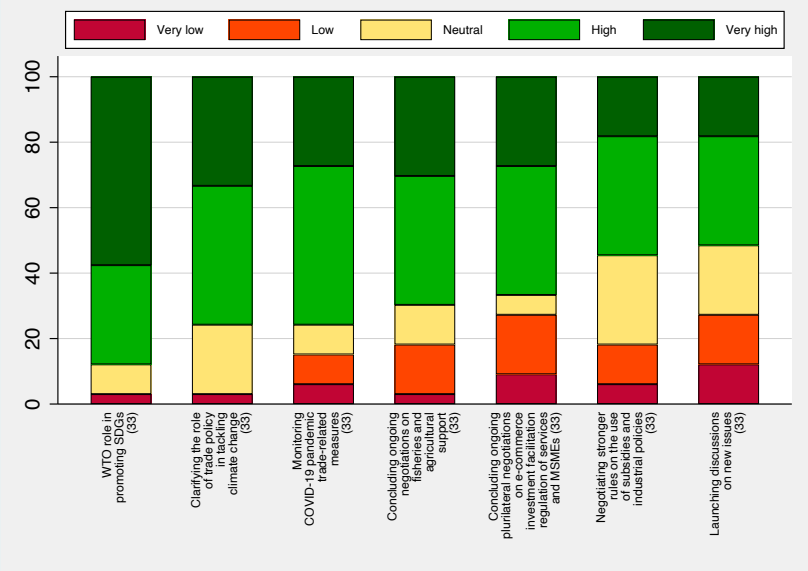

(e) NGOs and Labour organizations 
Figure A2.8: Responses by geographic region

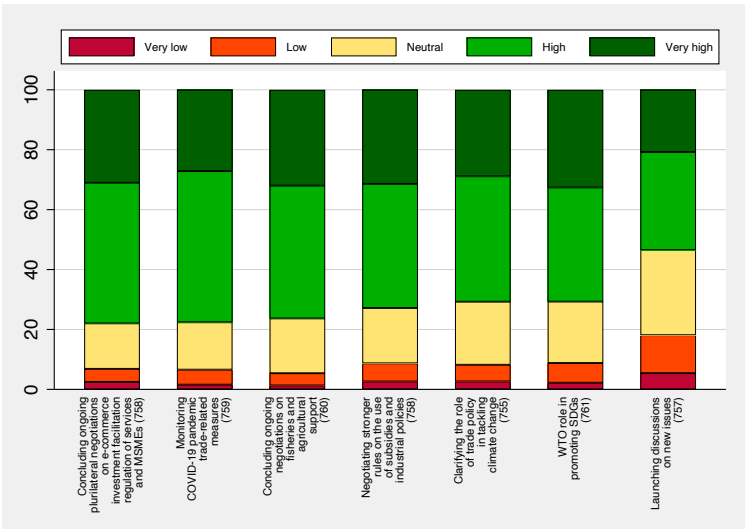

(a) Whole sample

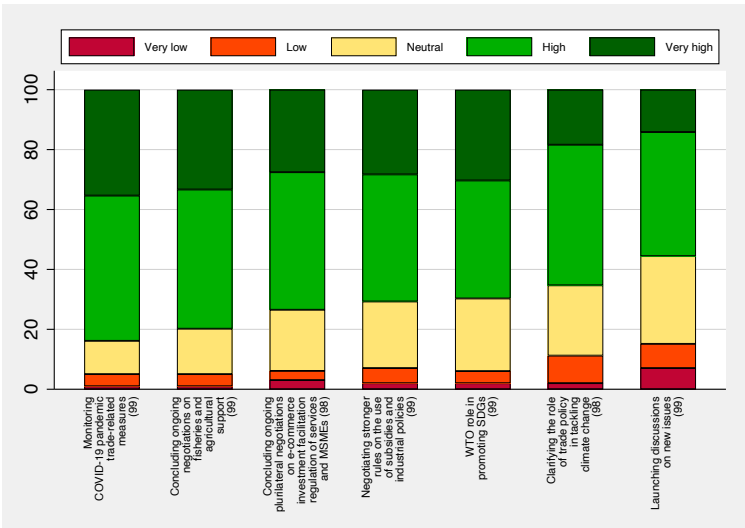

(c) Asia

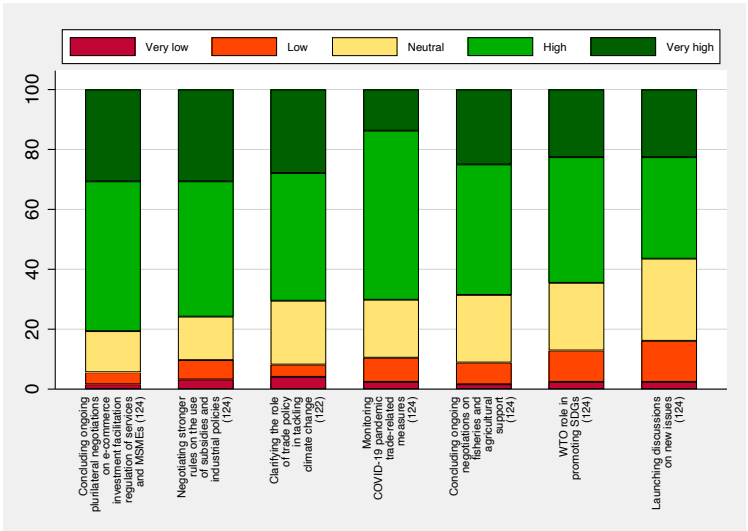

(e) North America

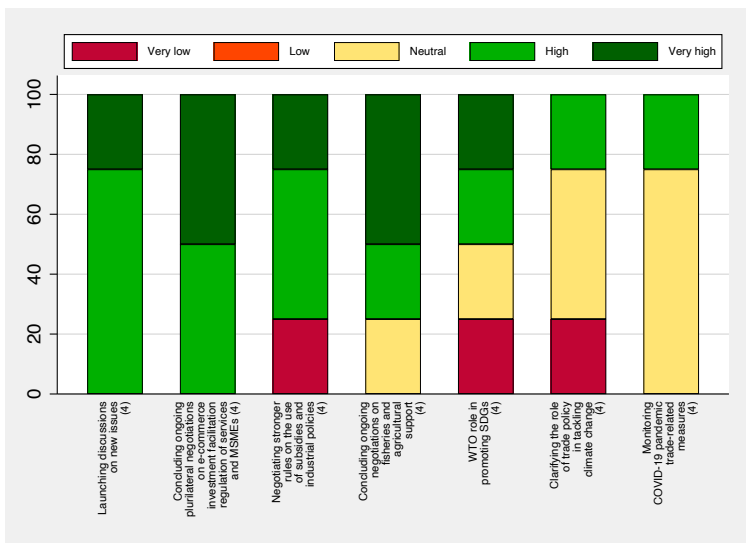

(g) CIS

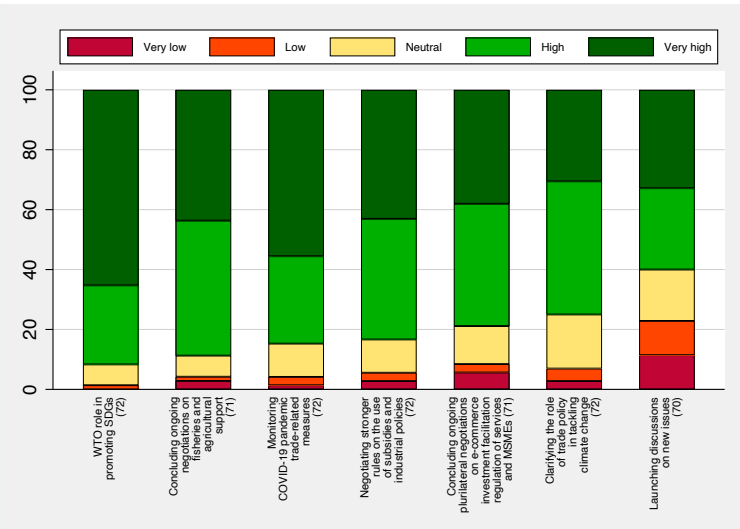

(b) Africa

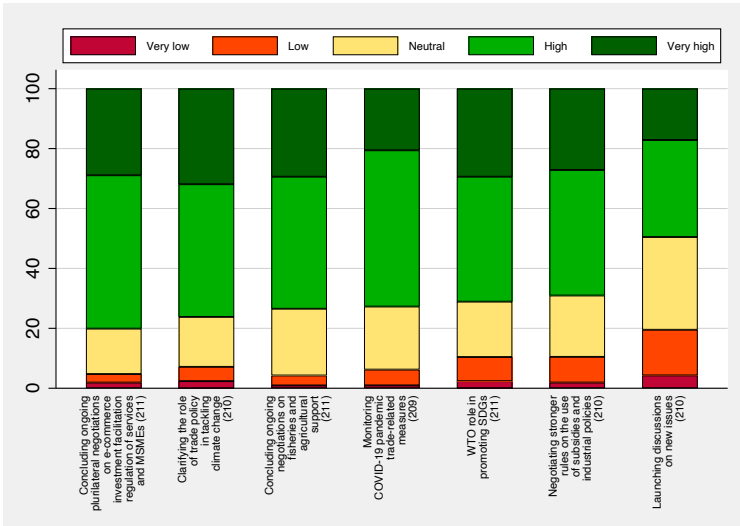

(d) Europe

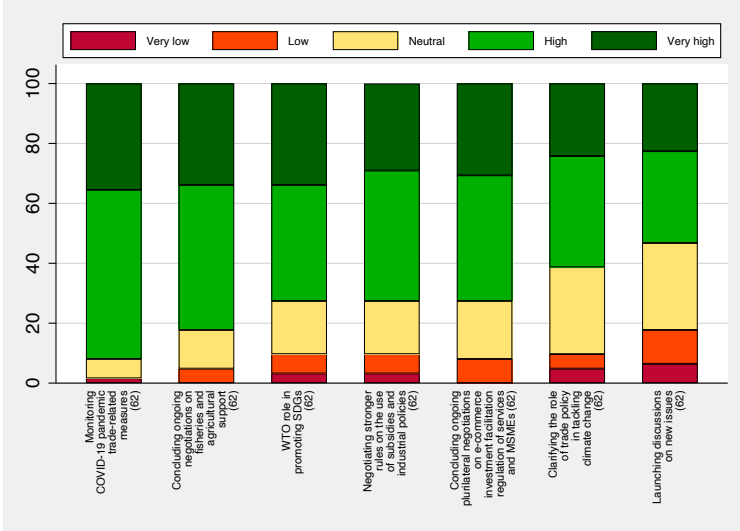

(f) South and Central America and the Caribbean

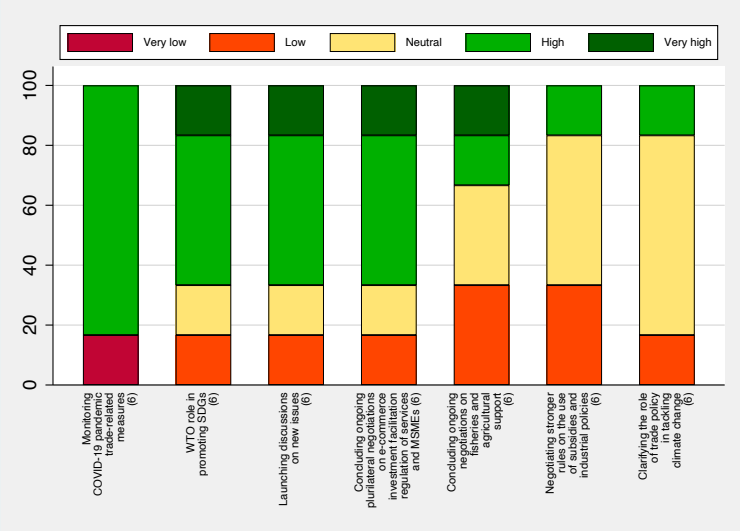

(h) Middle East 
In terms of institutional reform, what priority do you assign to each of the following issues the next DG should take up:

Figure A2.9: Responses by category of professional affiliation

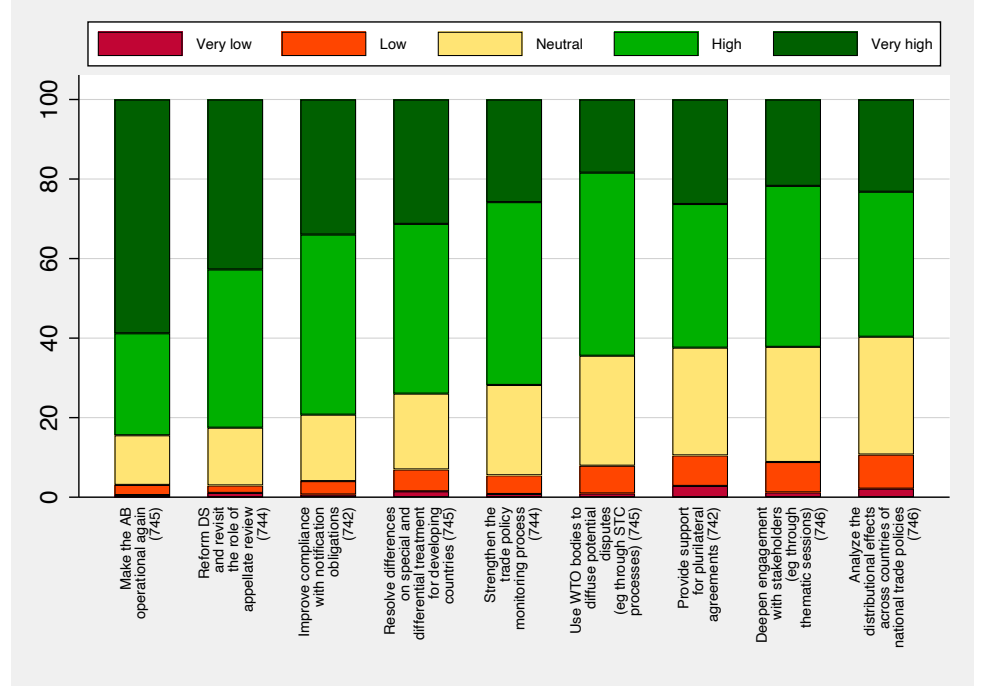

(a) Whole sample

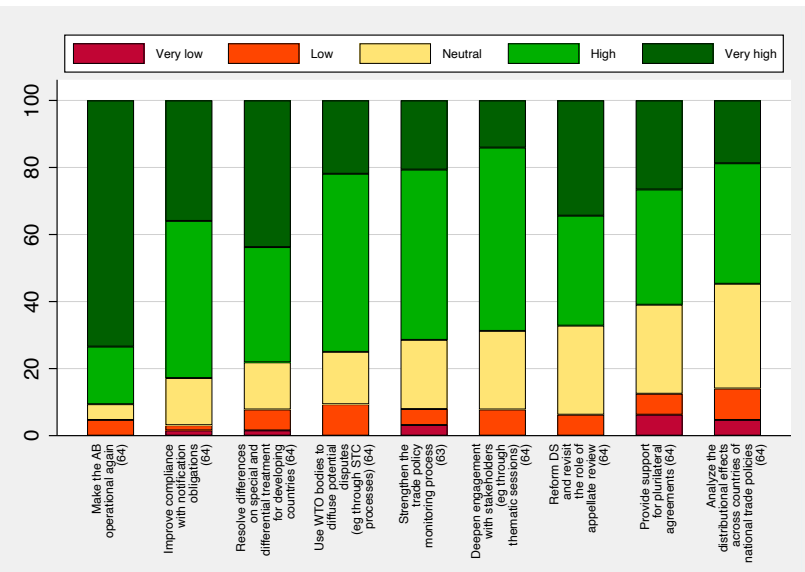

(b) Government (including EU) in Geneva

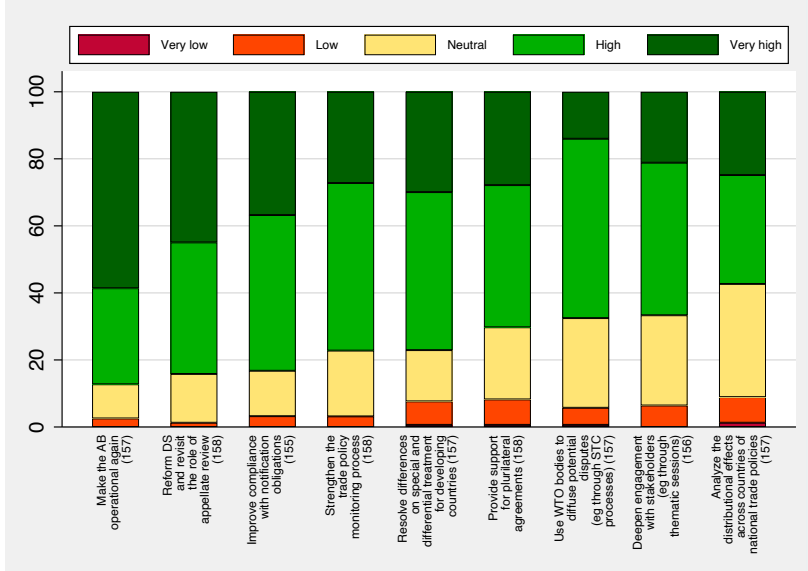

(d) Private sector

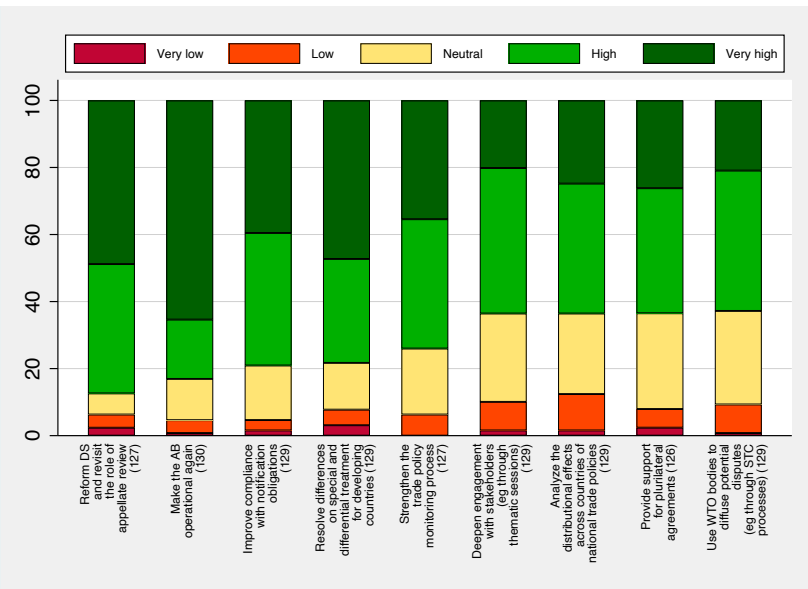

(c) Government (including EU) outside Geneva

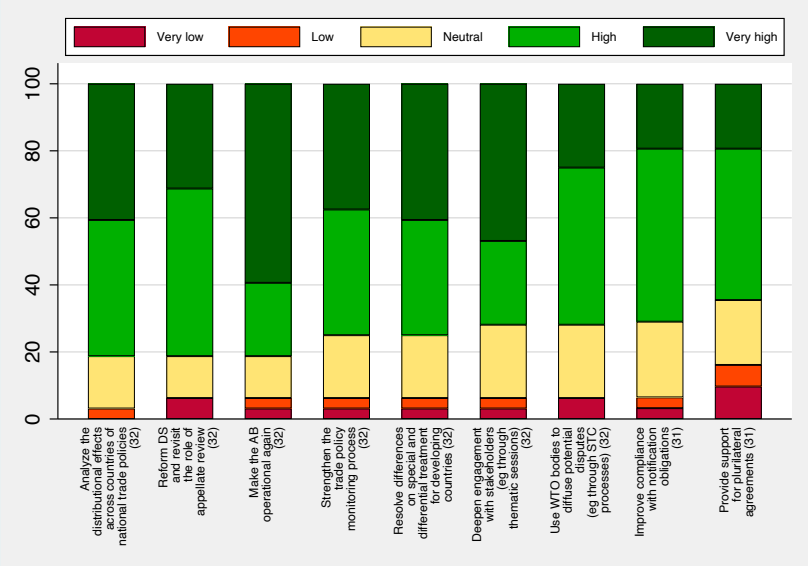

(e) NGOs and Labour organizations 
Figure A2.10: Responses by geographic region

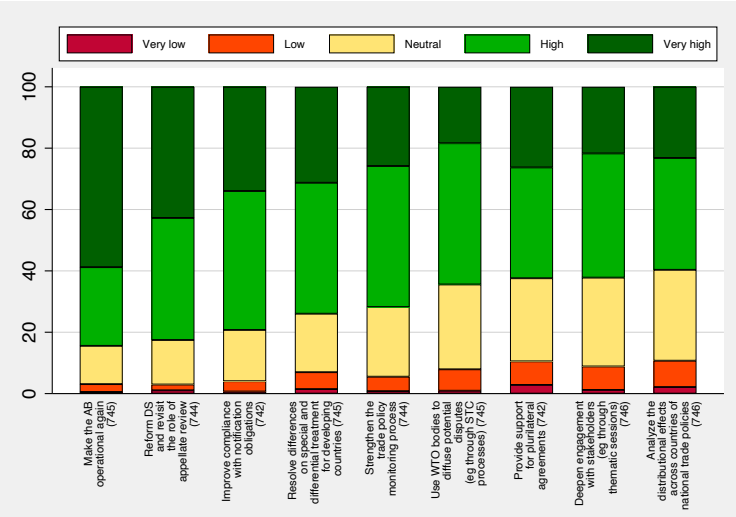

(a) Whole sample

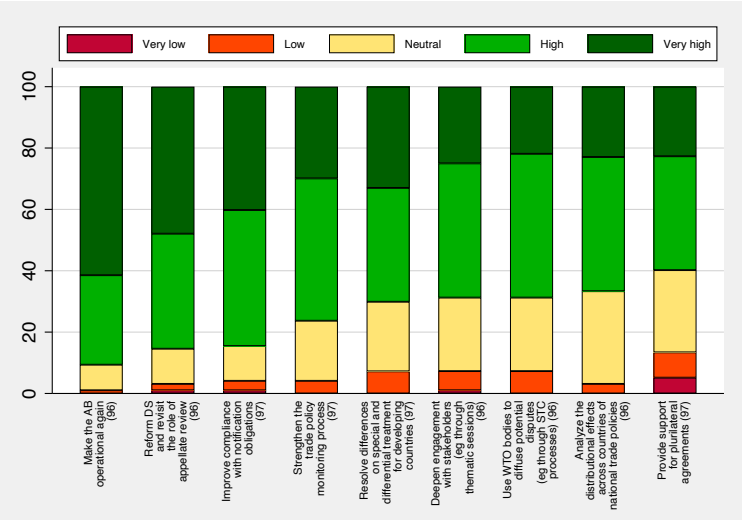

(c) Asia

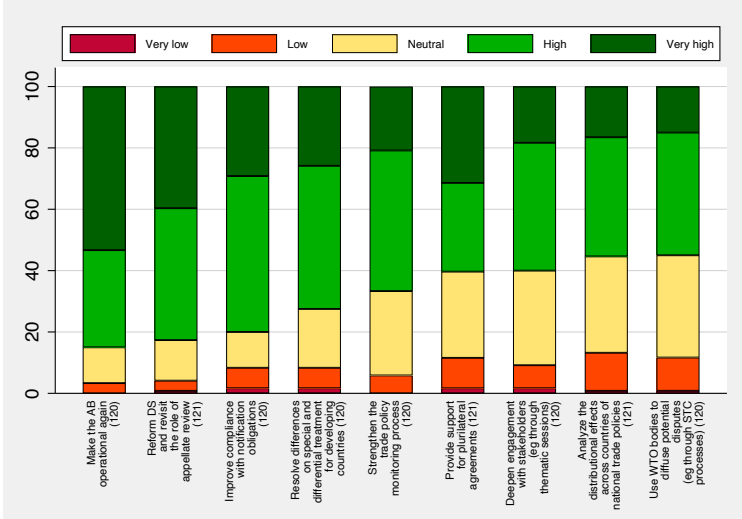

(e) North America

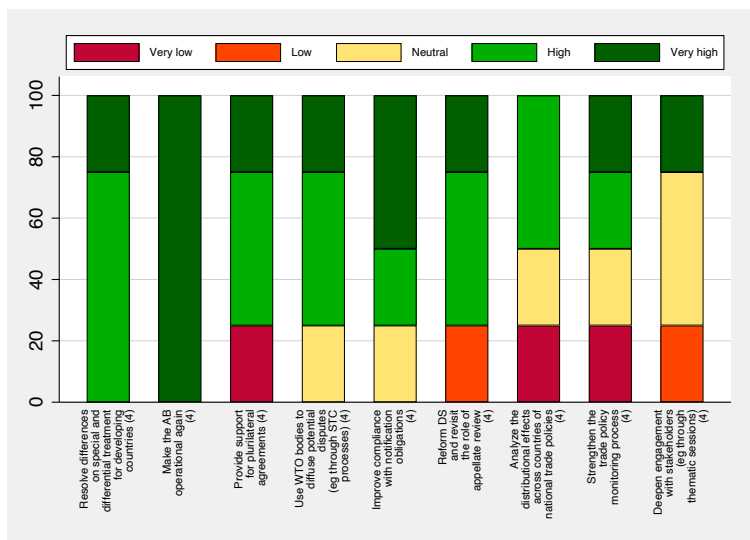

(g) CIS

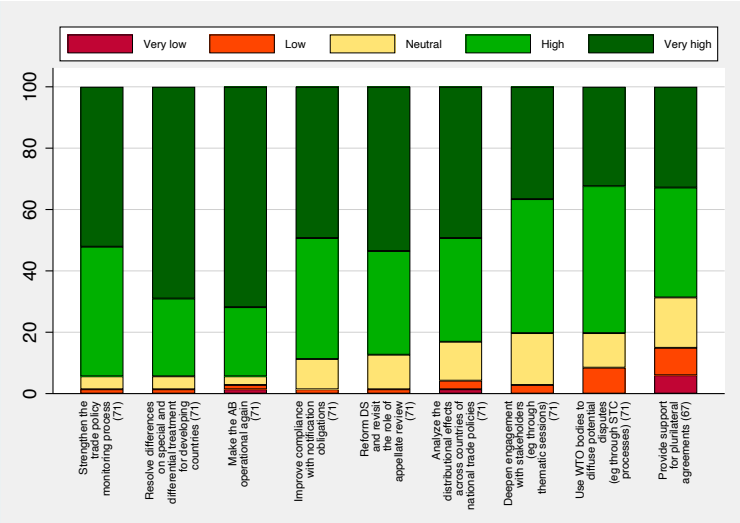

(b) Africa

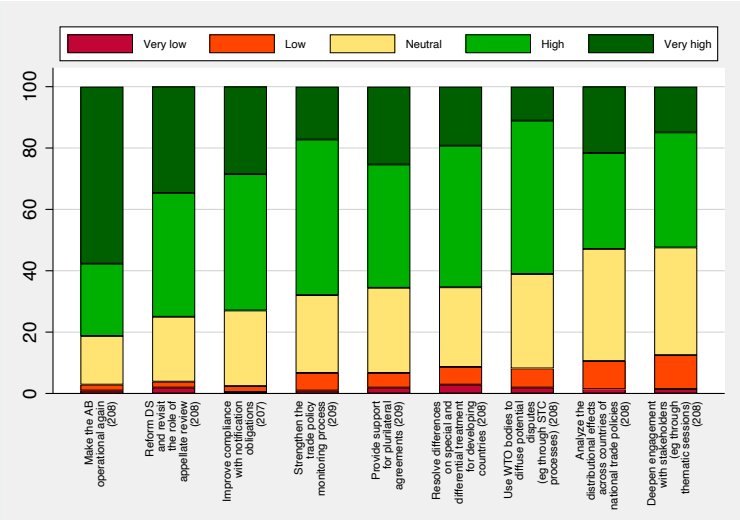

(d) Europe

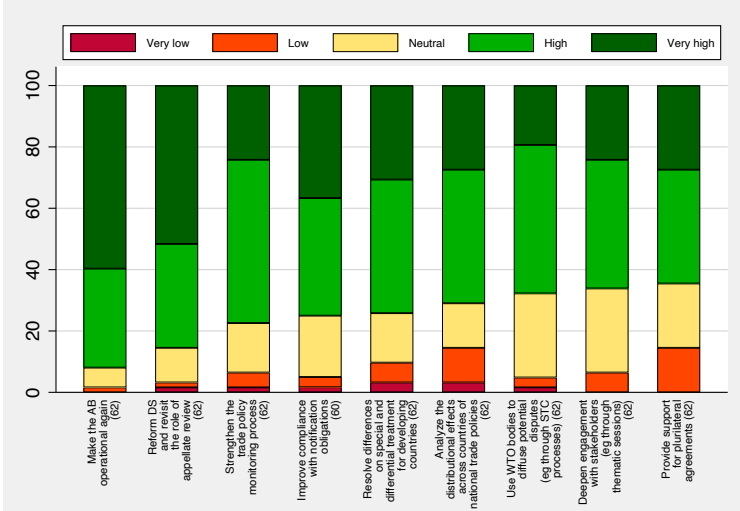

(f) South and Central America and the Caribbean

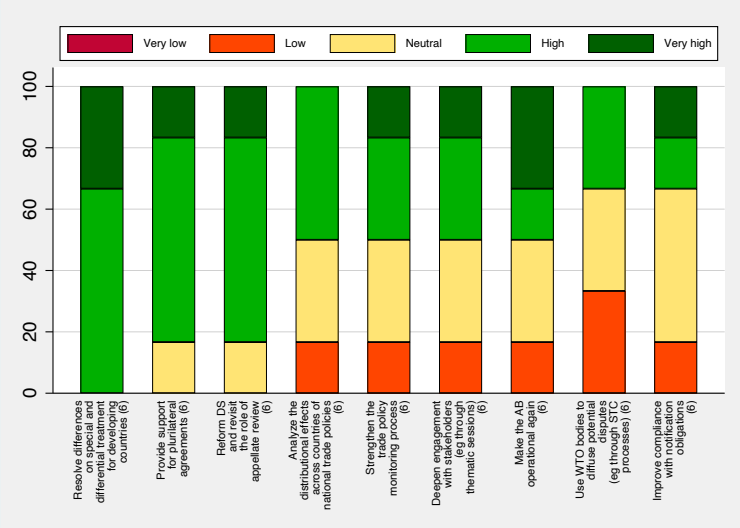

(h) Middle East 
In terms of daily operations, what priority do you assign to each of the following issues the next DG should take up:

Figure A2.11: Responses by category of professional affiliation

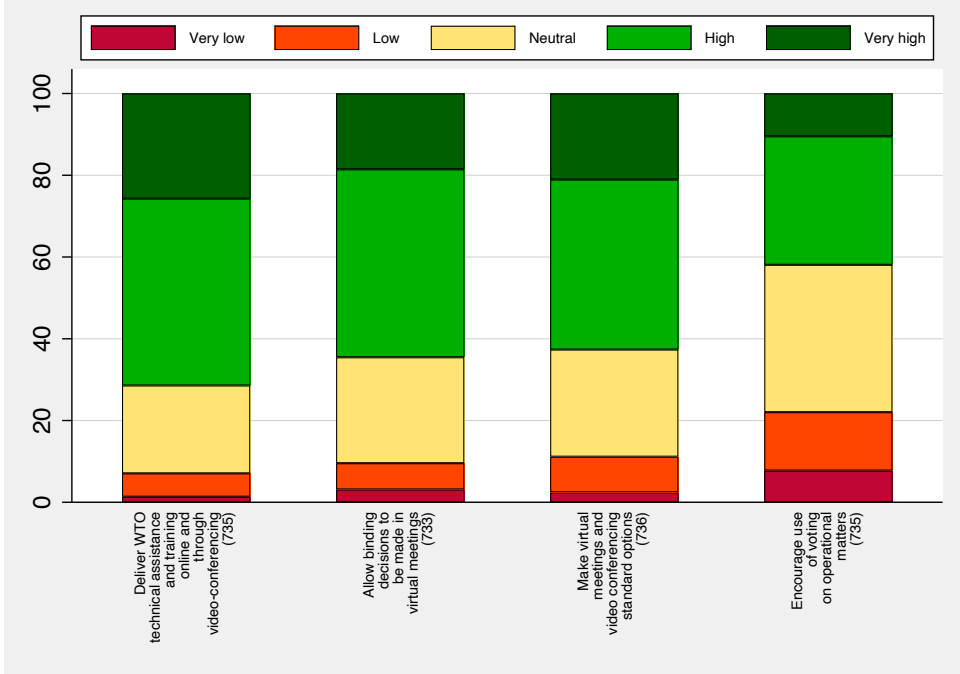

(a) Whole sample

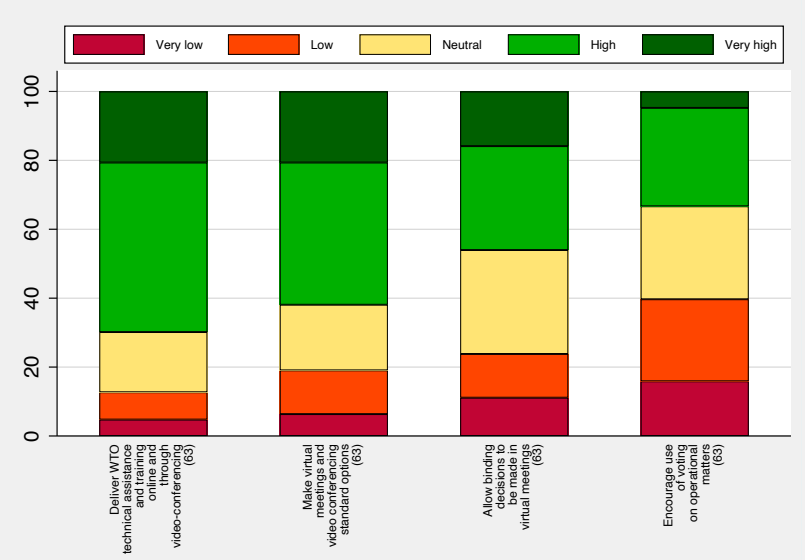

(b) Government (including EU) in Geneva

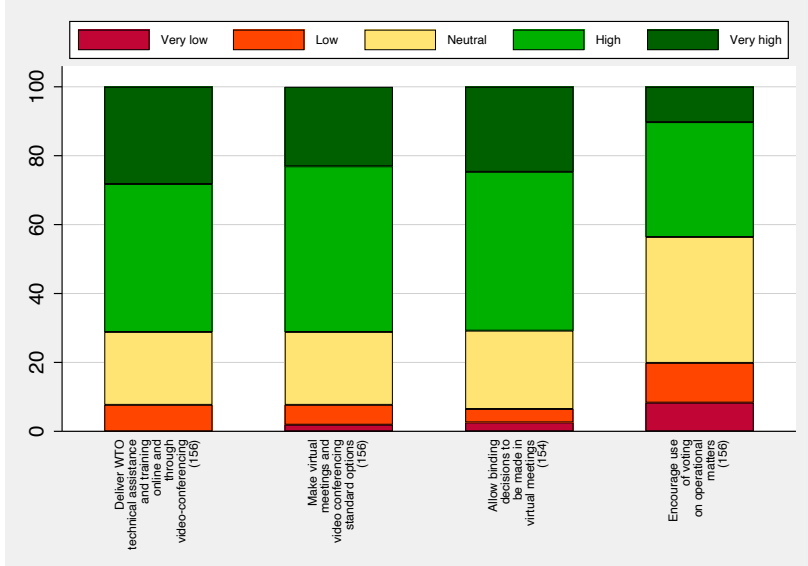

(d) Private sector

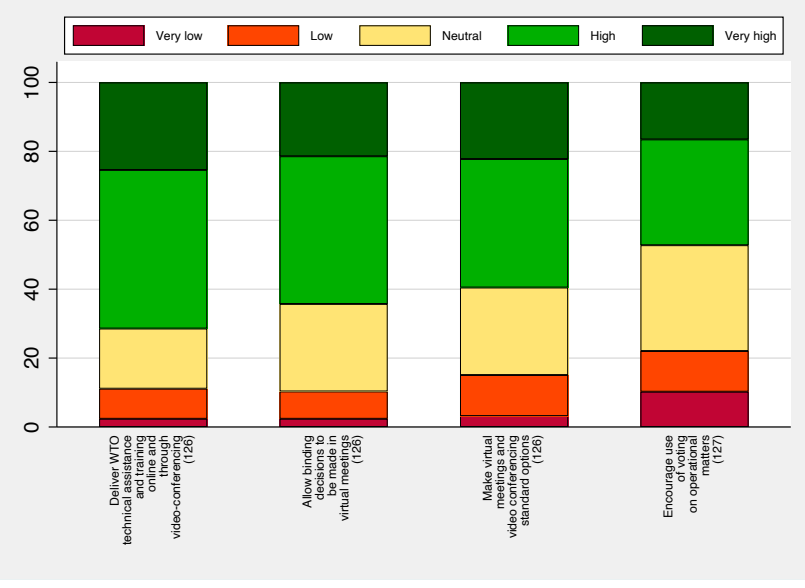

(c) Government (including EU) outside Geneva

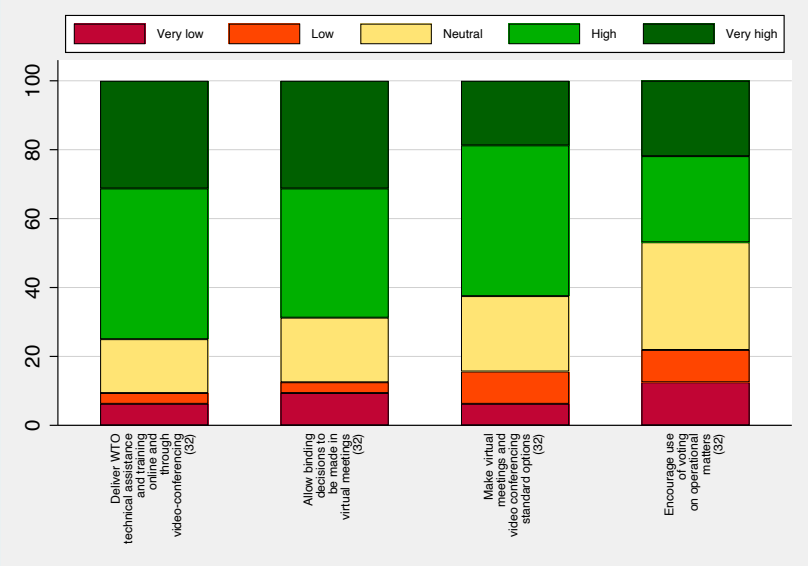

(e) NGOs and Labour organizations 
Figure A2.12: Responses by geographic region

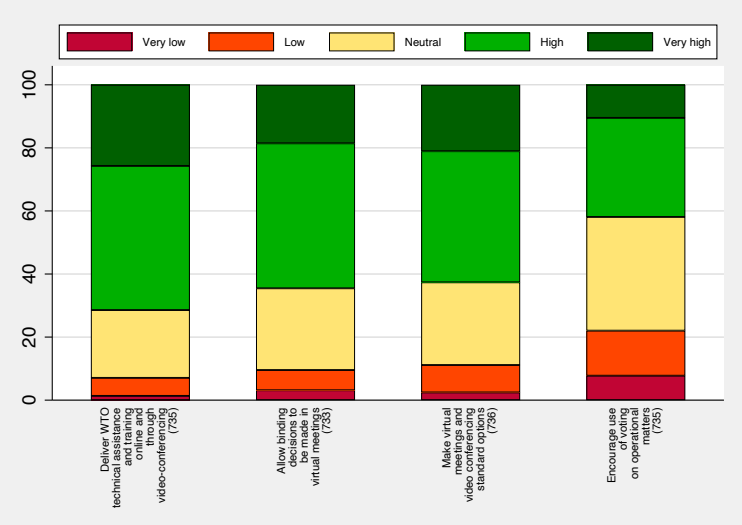

(a) Whole sample

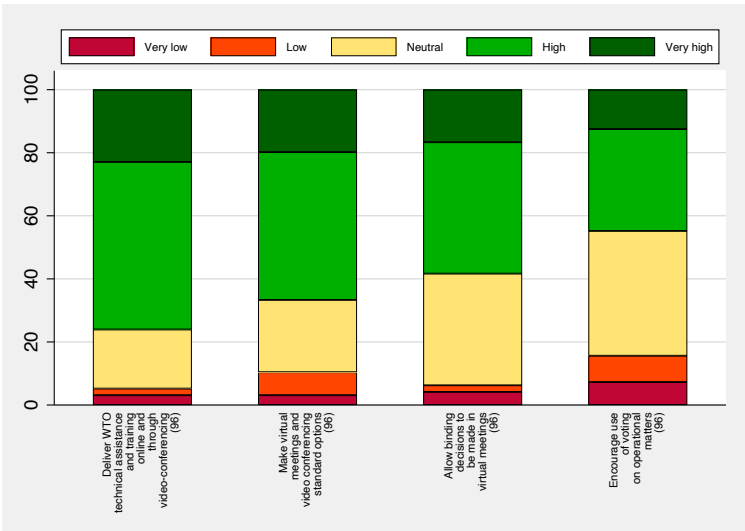

(c) Asia

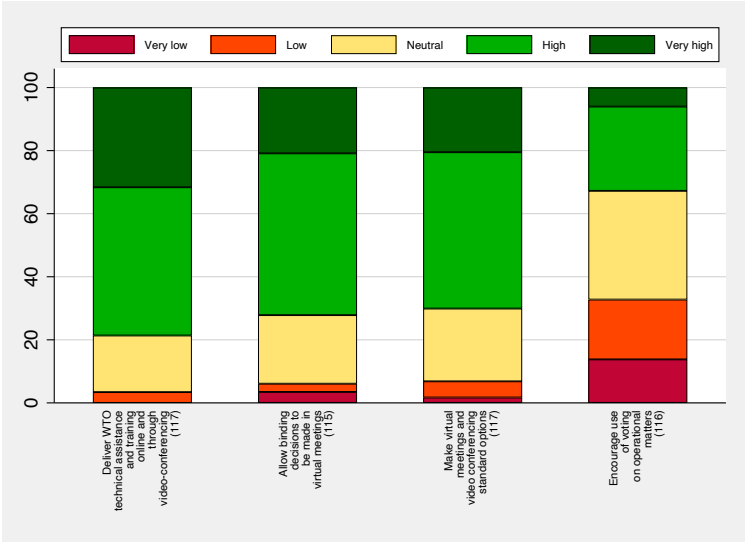

(e) North America

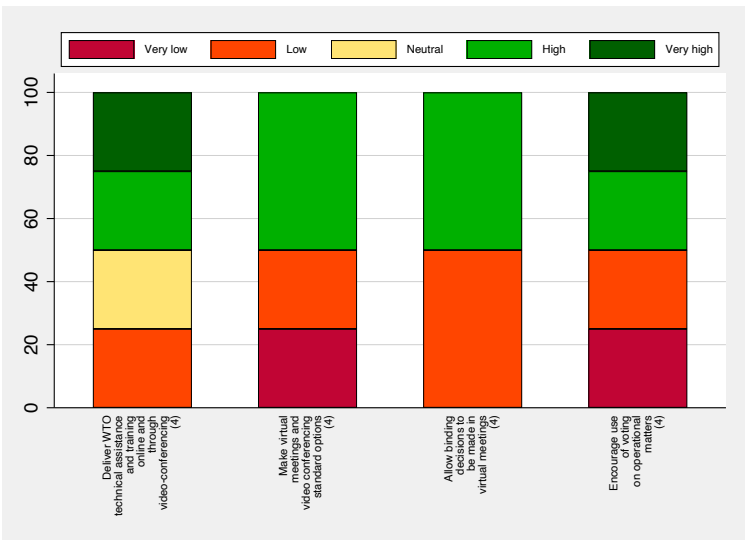

(g) CIS

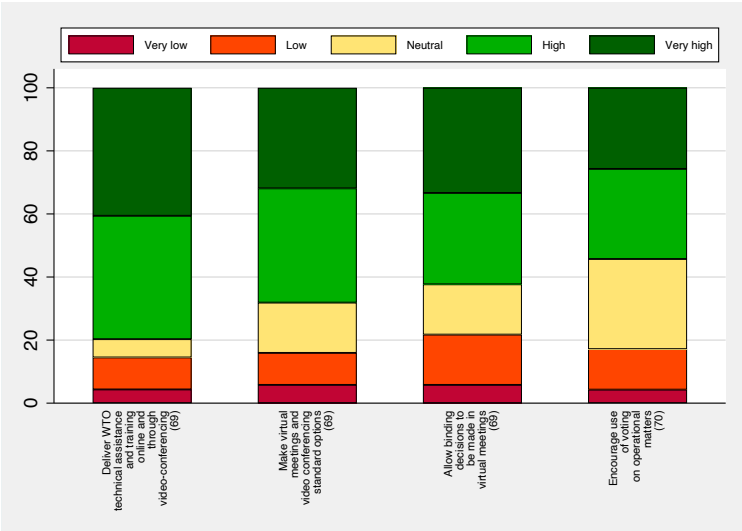

(b) Africa

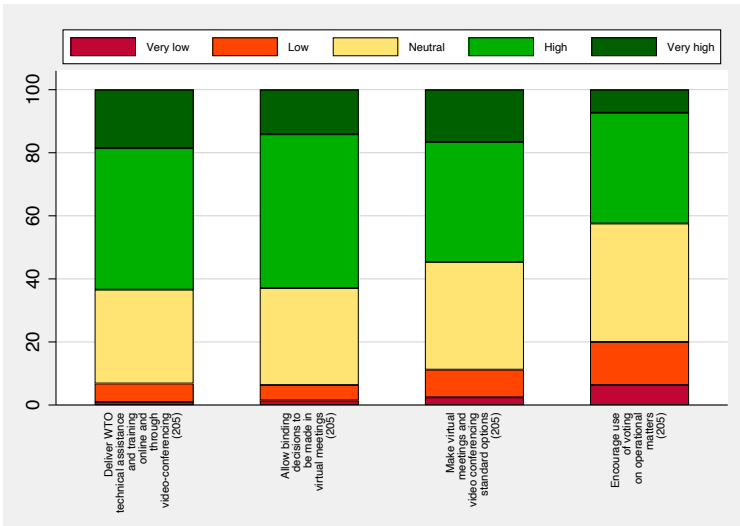

(d) Europe

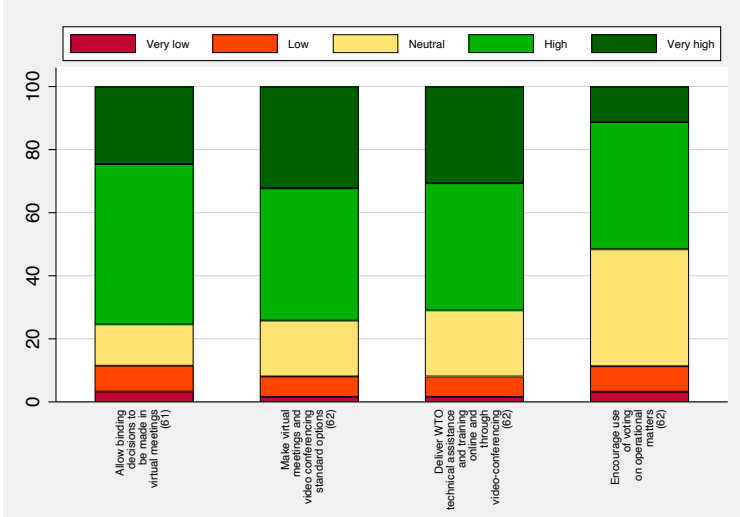

(f) South and Central America and the Caribbean

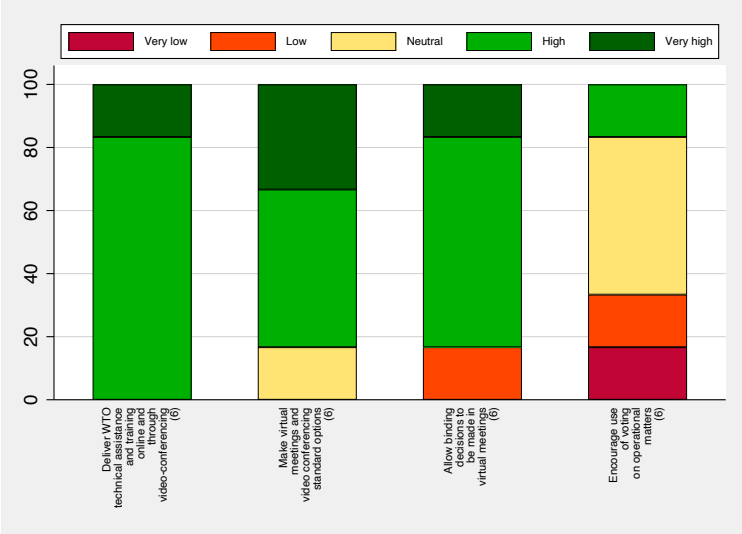

(h) Middle East 


\section{What priority do you assign to the following characteristics for the WTO DG?}

Figure A2.13: Political experience

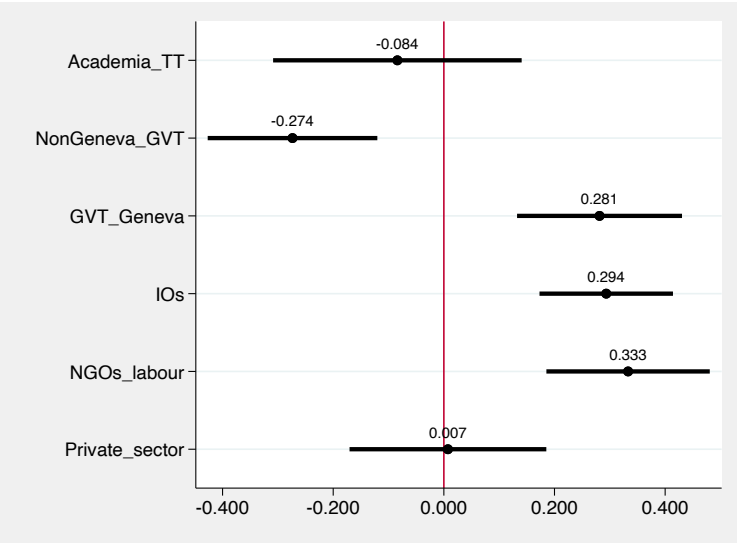

(a) Professional categories

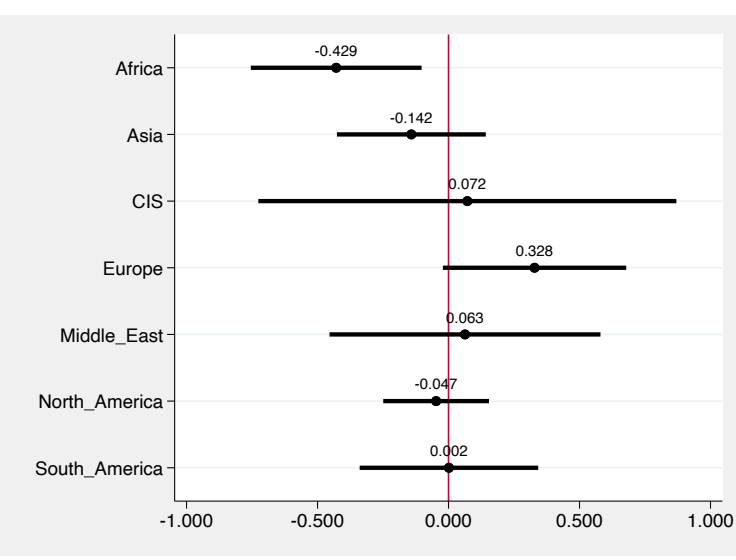

(b) Geographic regions

Figure A2.14: Experienced WTO negotiator

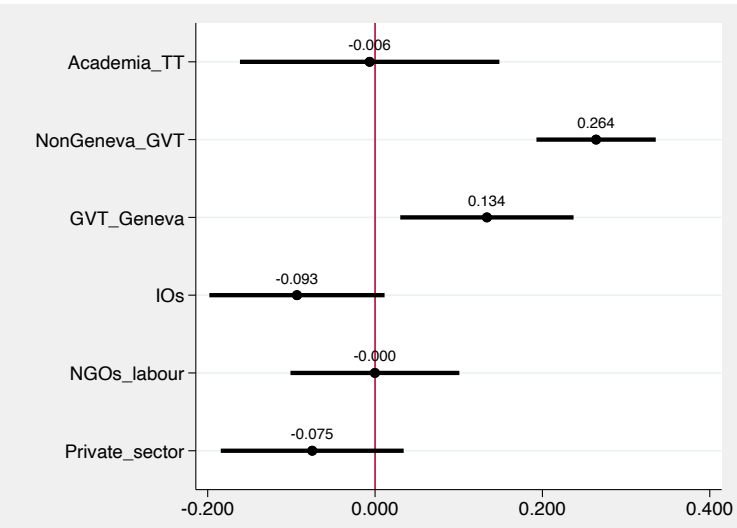

(a) Professional categories

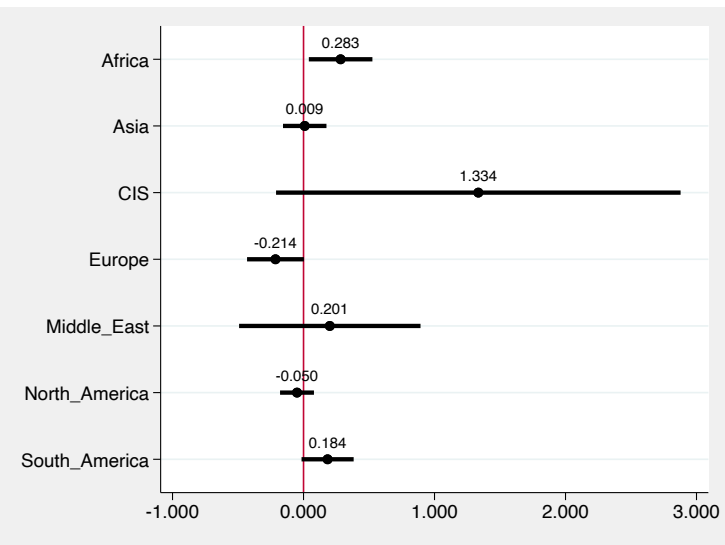

(b) Geographic regions

Figure A2.15: Gender

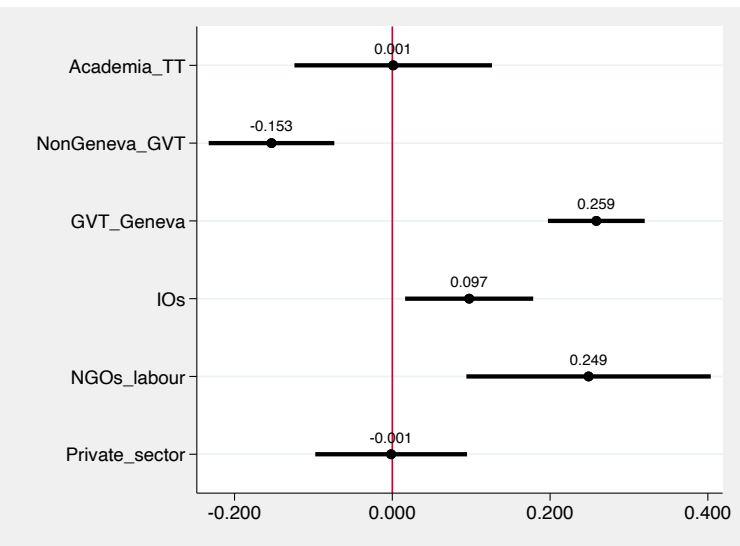

(a) Professional categories

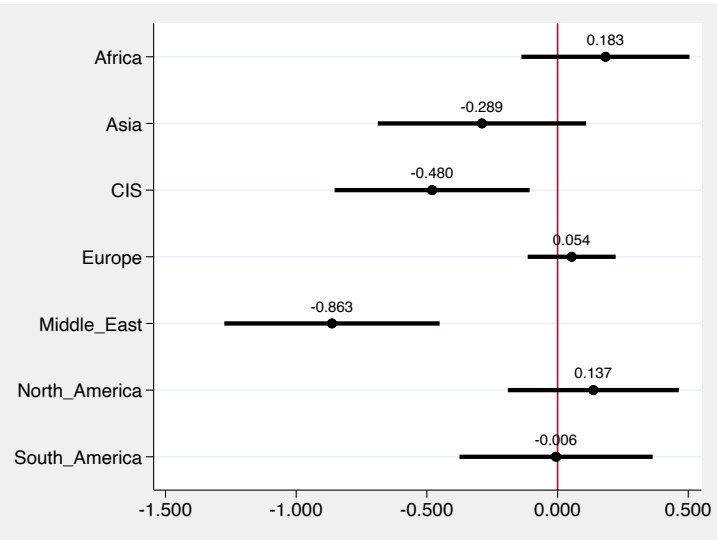

(b) Geographic regions 
Figure A2.16: Public profile

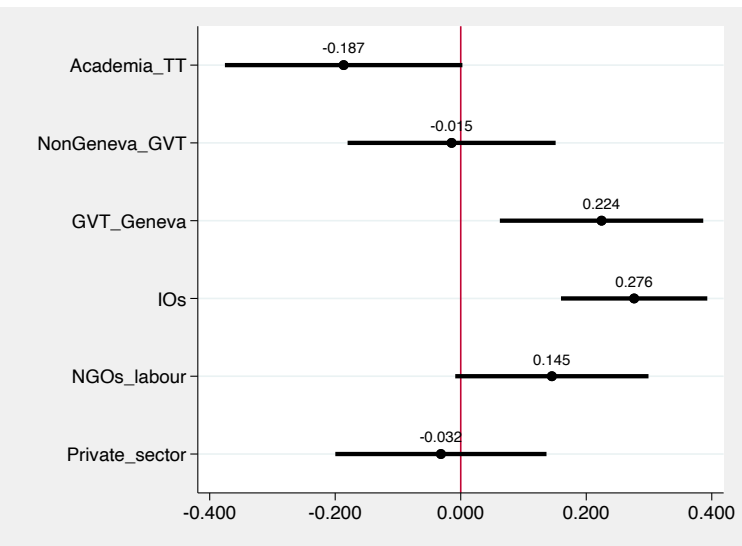

(a) Professional categories

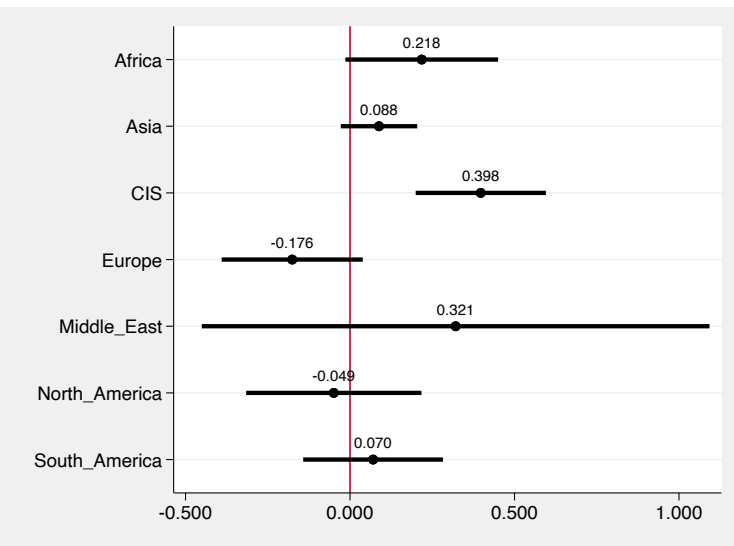

(b) Geographic regions

Figure A2.17: National of a developing country

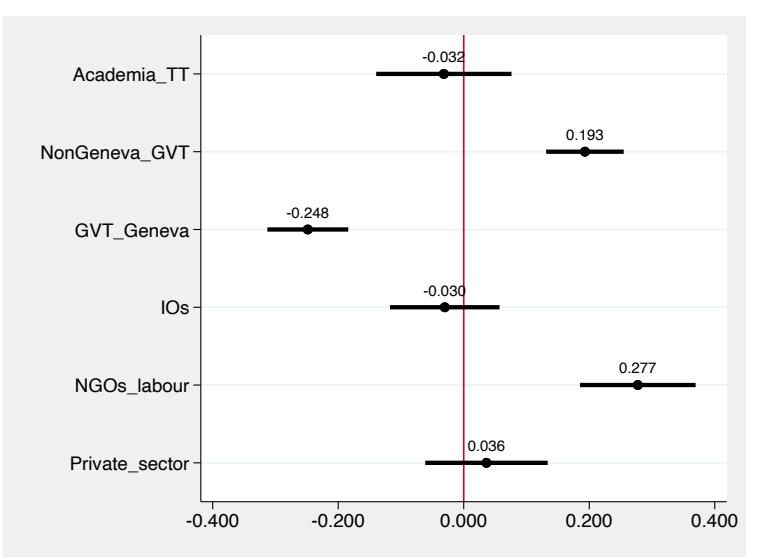

(a) Professional categories

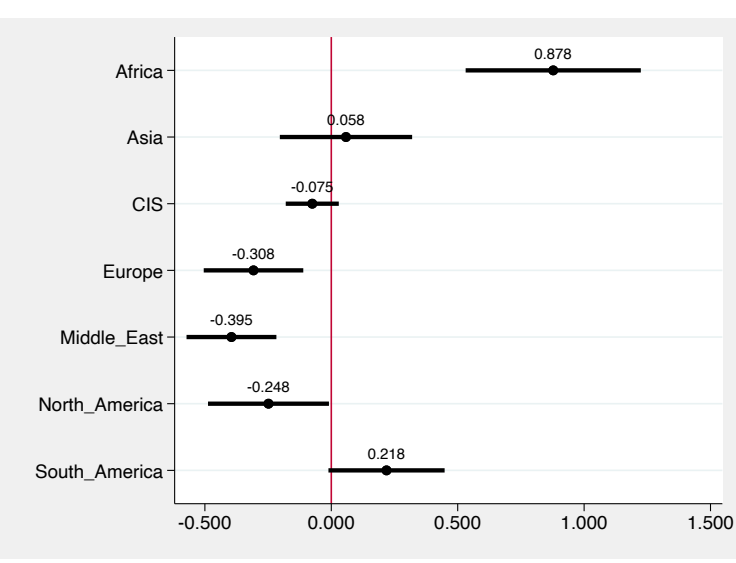

(b) Geographic regions

Figure A2.18: National of a developed country

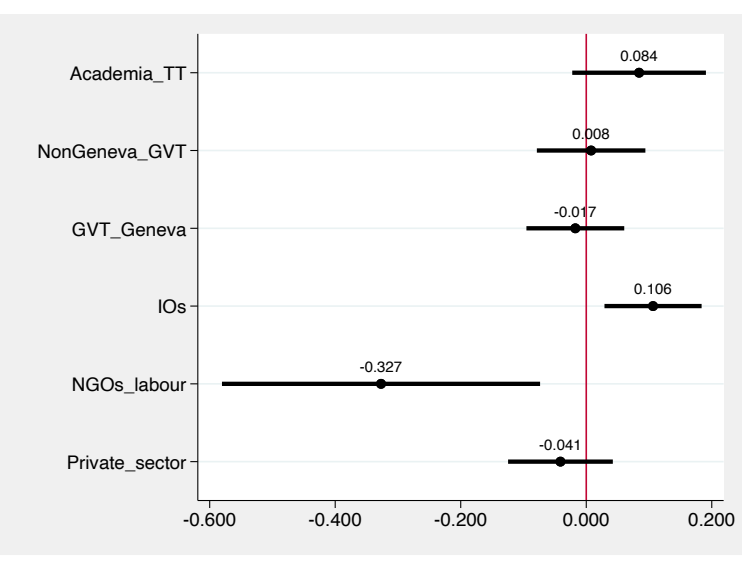

(a) Professional categories

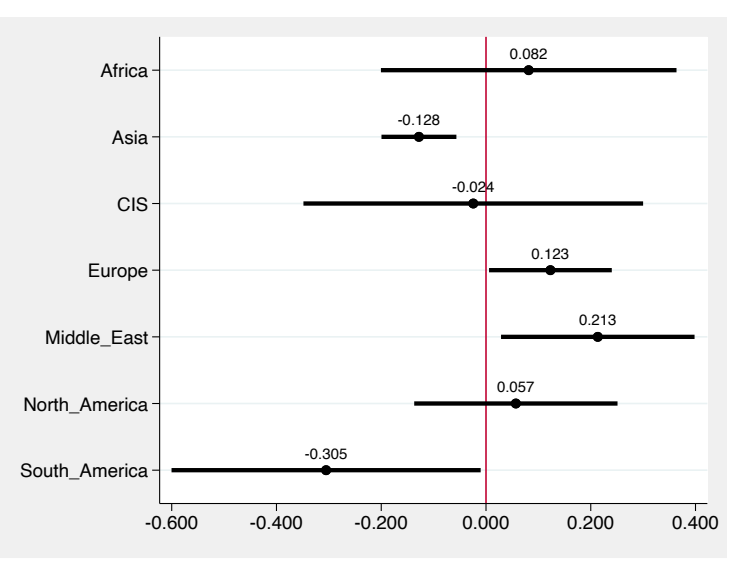

(b) Geographic regions 
Figure A2.19: Representing a region that has not yet had a DG

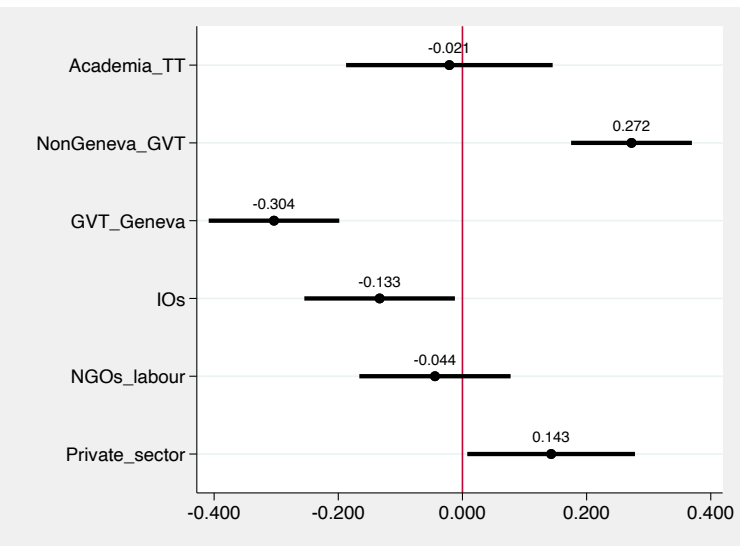

(a) Professional categories

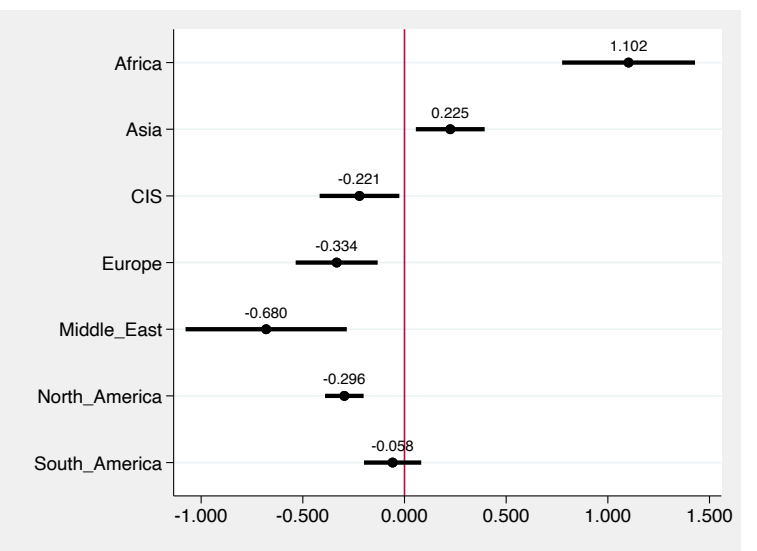

(b) Geographic regions

Figure A2.20: Economic training

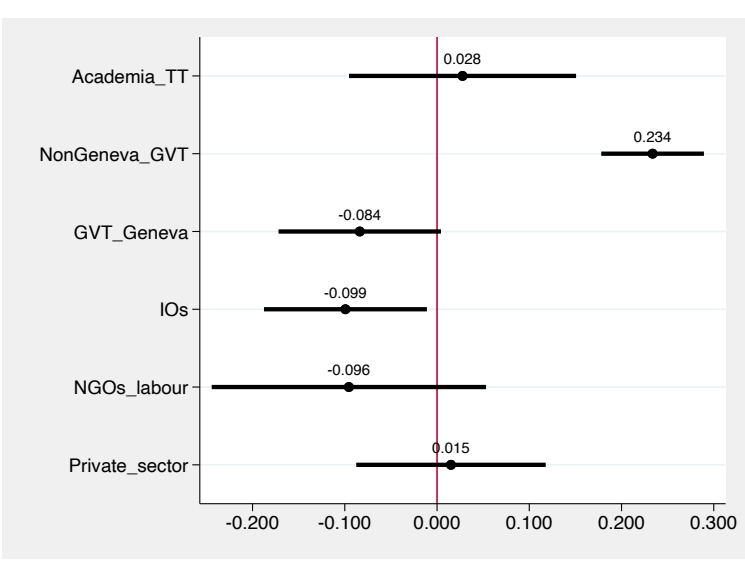

(a) Professional categories

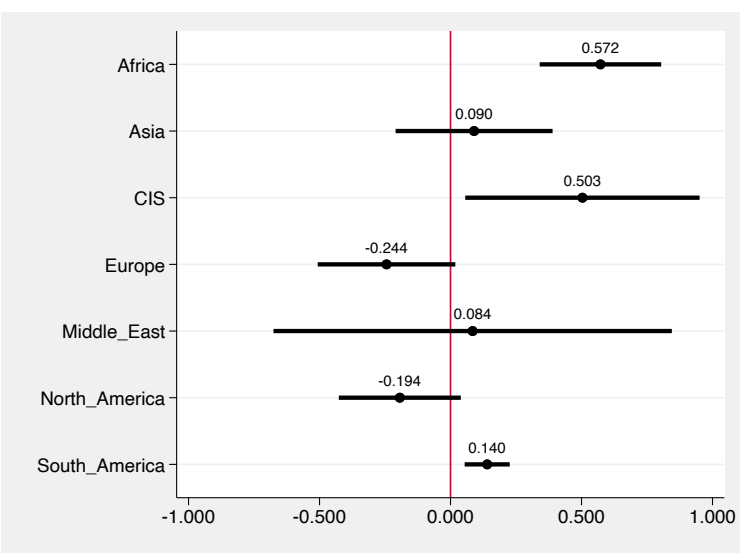

(b) Geographic regions

Figure A2.21: Legal background

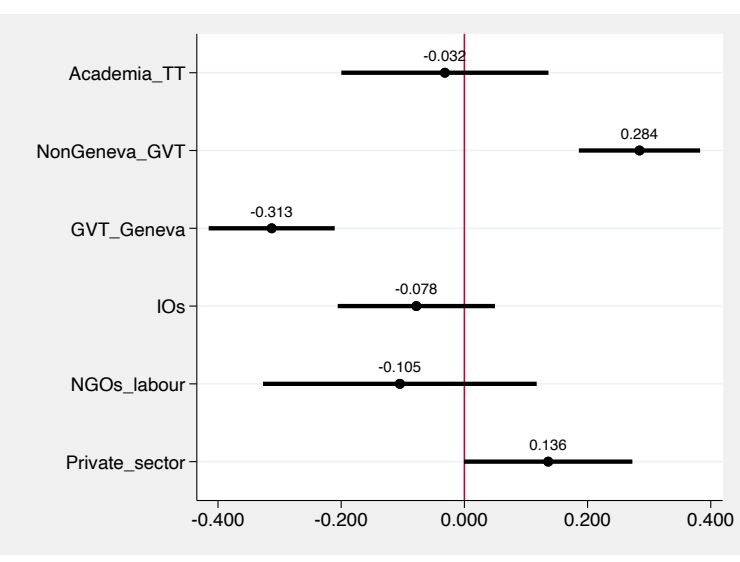

(a) Professional categories

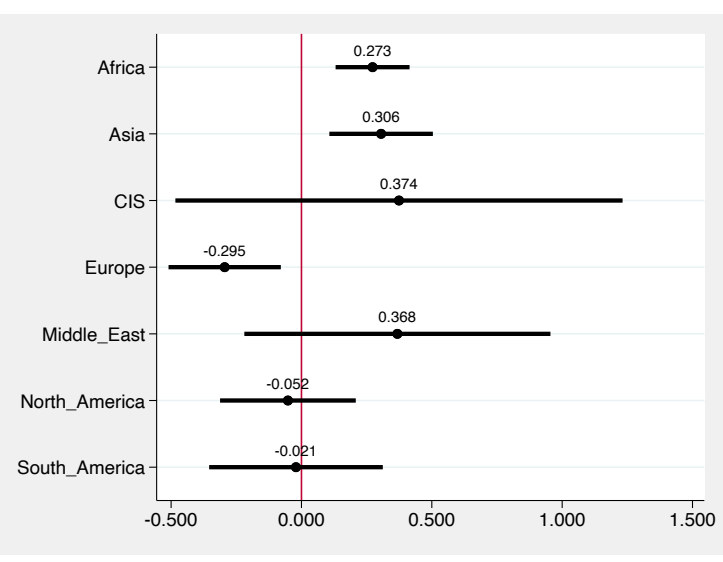

(b) Geographic regions 
Figure A2.22: Experience in managing organizations

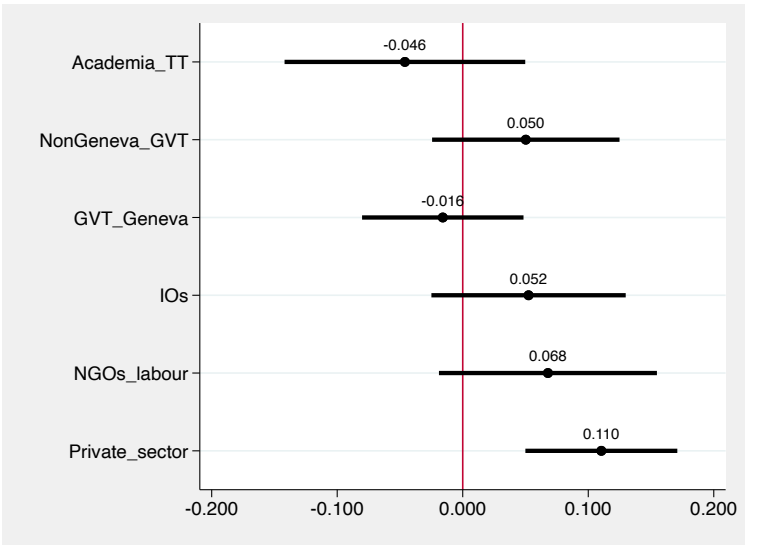

(a) Professional categories

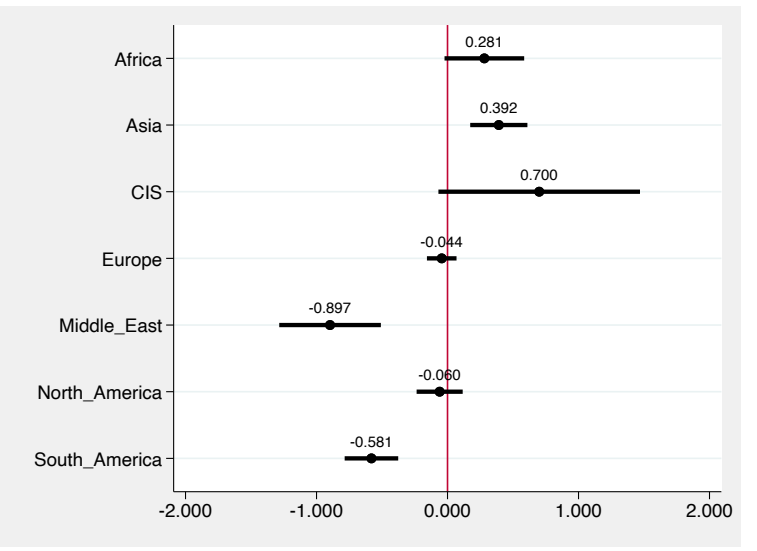

(b) Geographic regions 


\section{The selection of the DG should:}

Figure A2.23: Alternate between a developed and a developing country

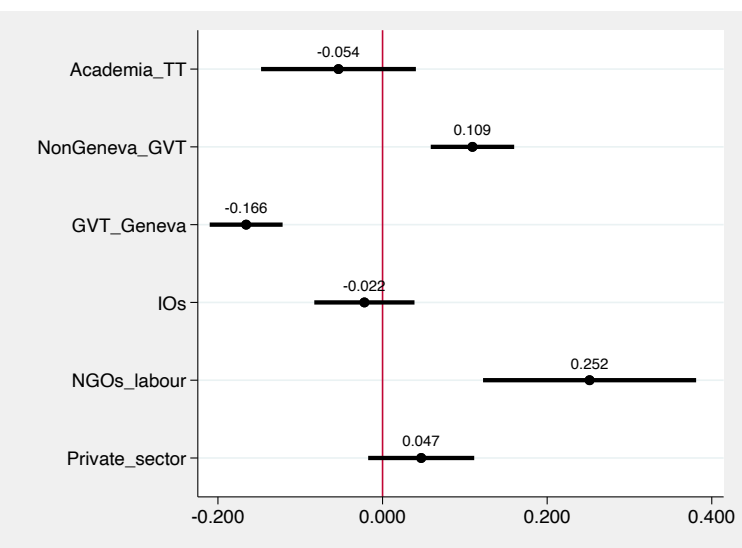

(a) Professional categories

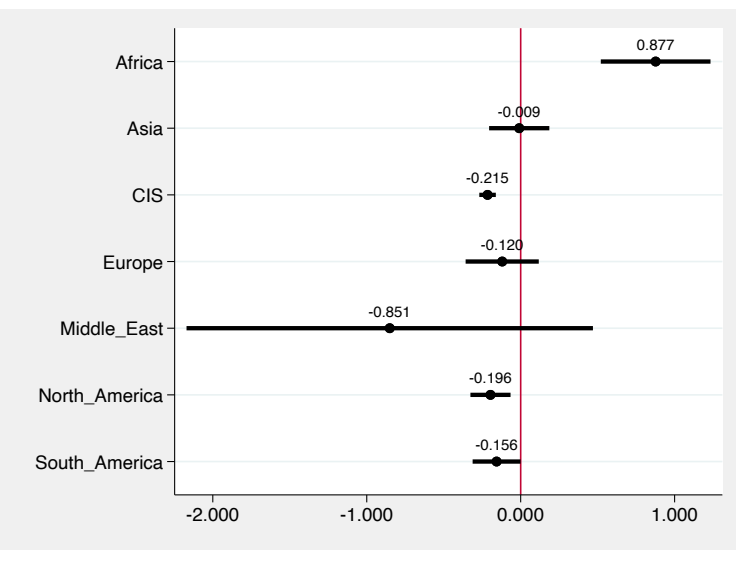

(b) Geographic regions

Figure A2.24: Ensure regional diversity over time

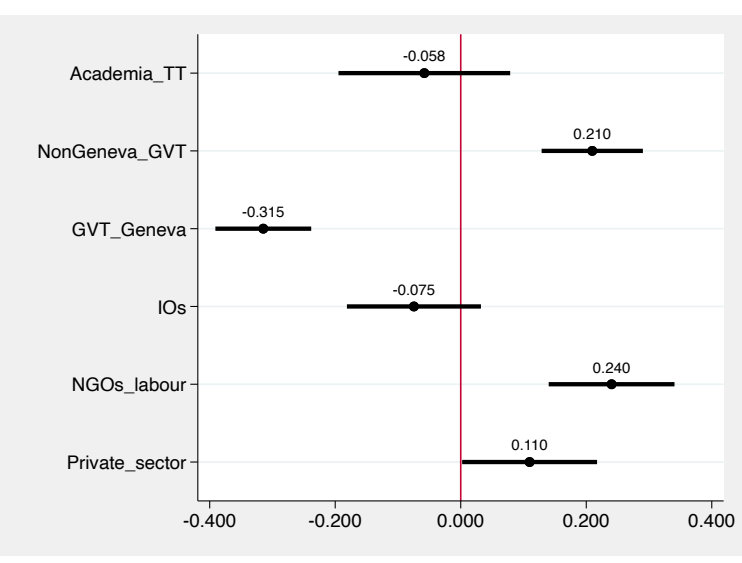

(a) Professional categories

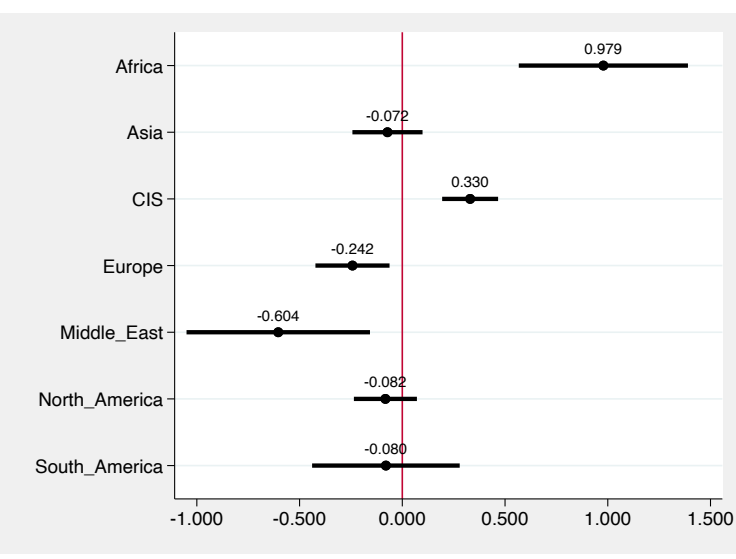

(b) Geographic regions

Figure A2.25: Be solely based on expertise and competence, independent of origin or gender

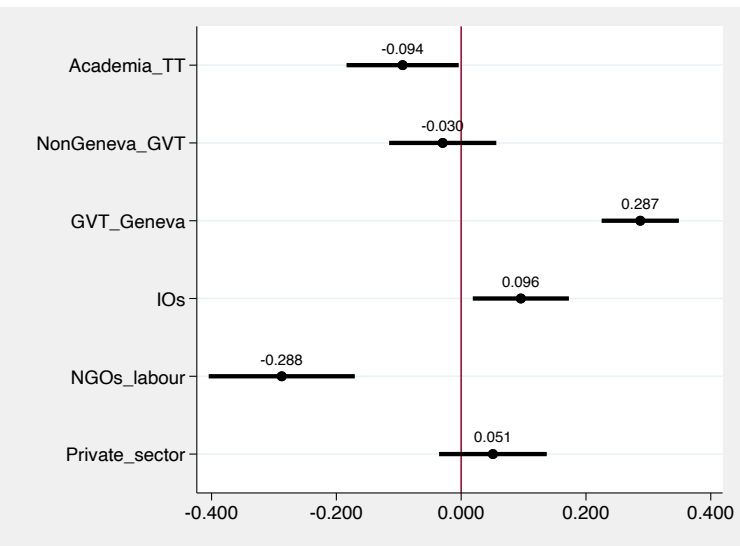

(a) Professional categories

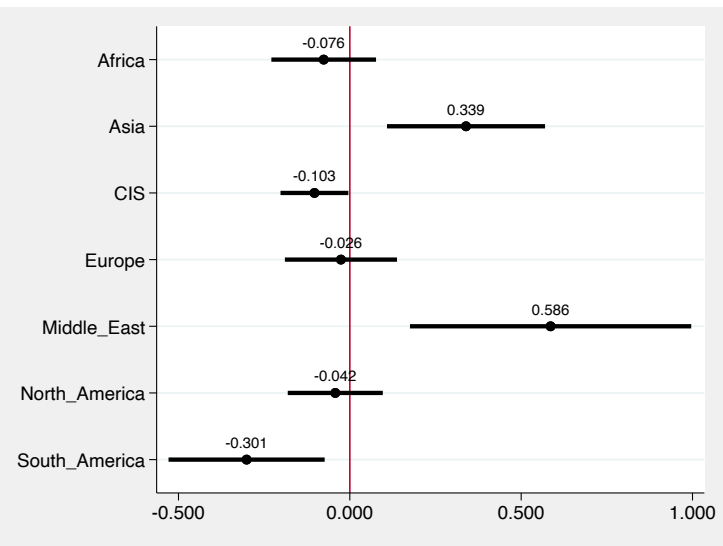

(b) Geographic regions 
Figure A2.26: Exclude officials who have worked for or are nationals of one of the three major trading powers (China, the EU, and the US)

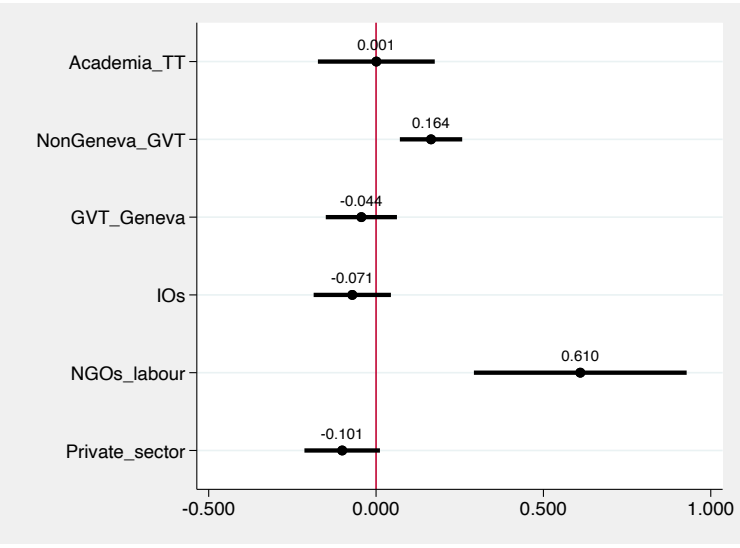

(a) Professional categories

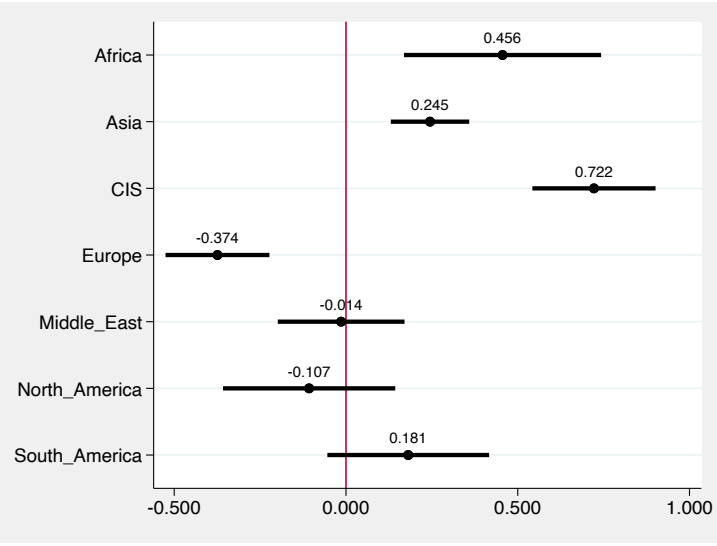

(b) Geographic regions

\section{What priority do you assign to the new DG having personal connections and recent professional experience with:}

Figure A2.27: The capitals of the largest trade powers (Beijing; Washington DC; Brussels; Berlin; Tokyo)

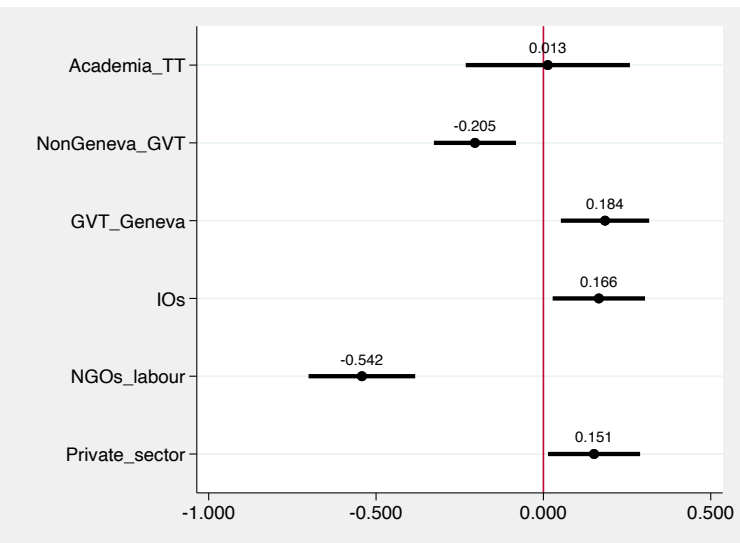

(a) Professional categories

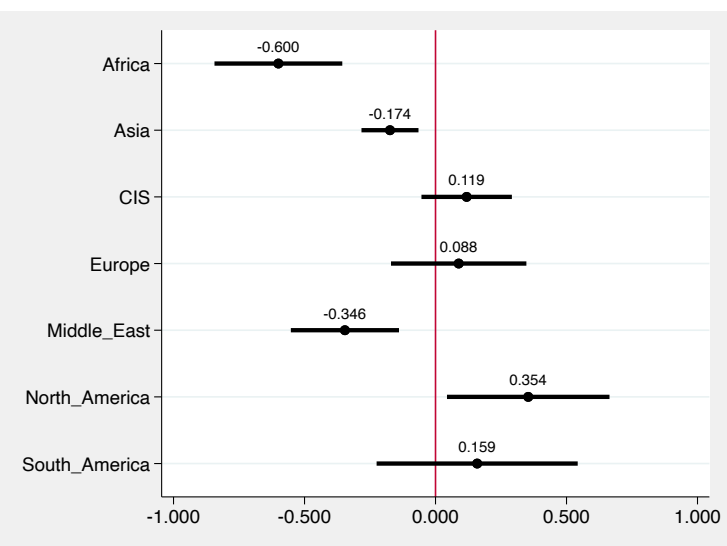

(b) Geographic regions

Figure A2.28: International business

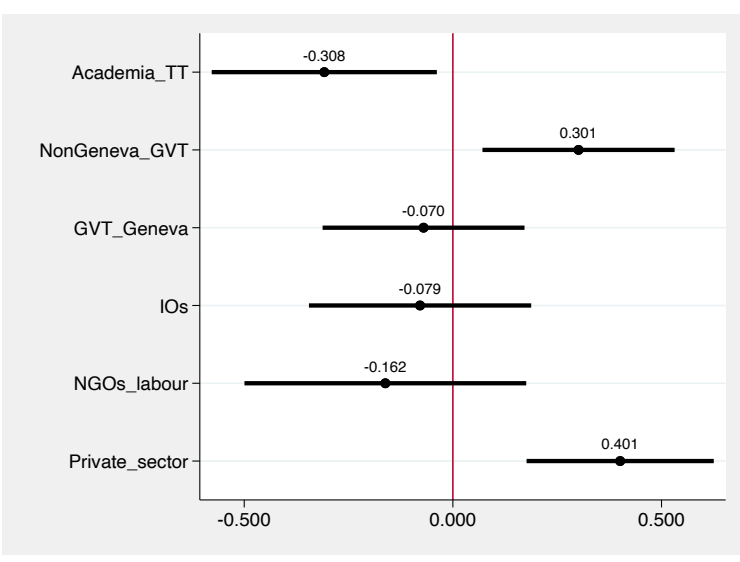

(a) Professional categories

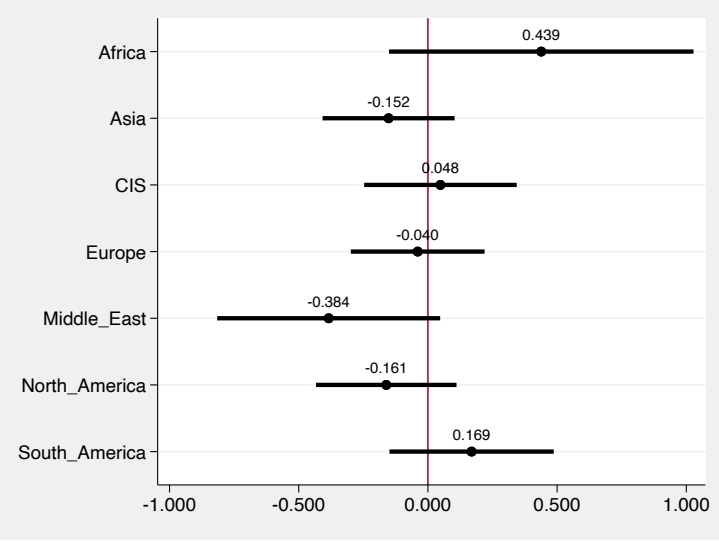

(b) Geographic regions 
Figure A2.29: Labour organizations

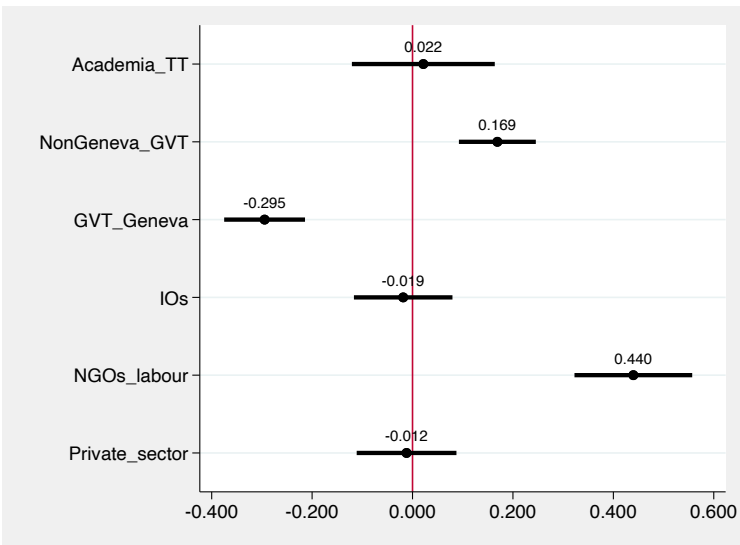

(a) Professional categories

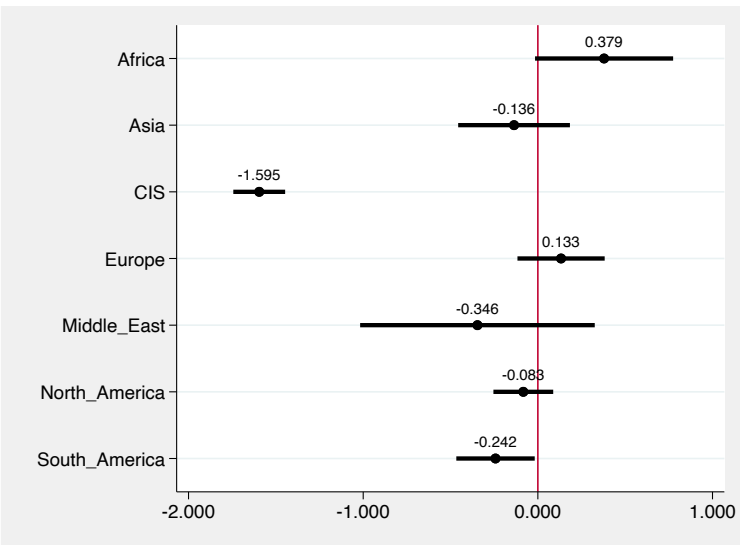

(b) Geographic regions

Figure A2.30: Nongovernmental organizations

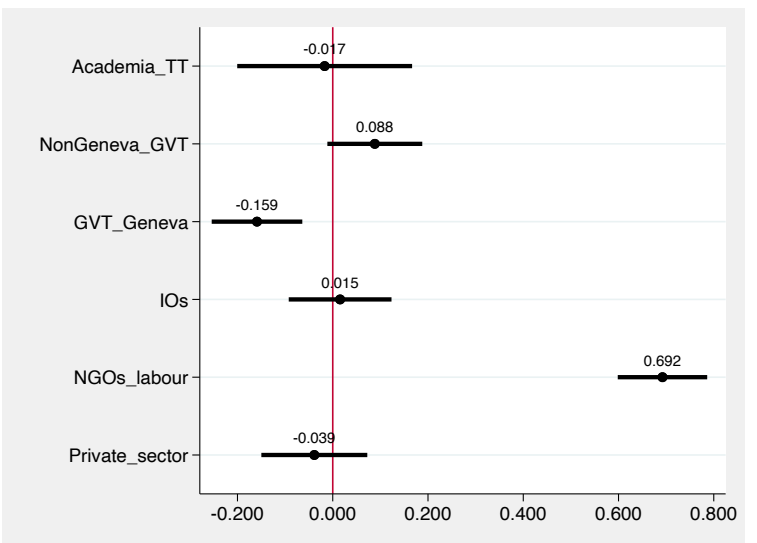

(a) Professional categories

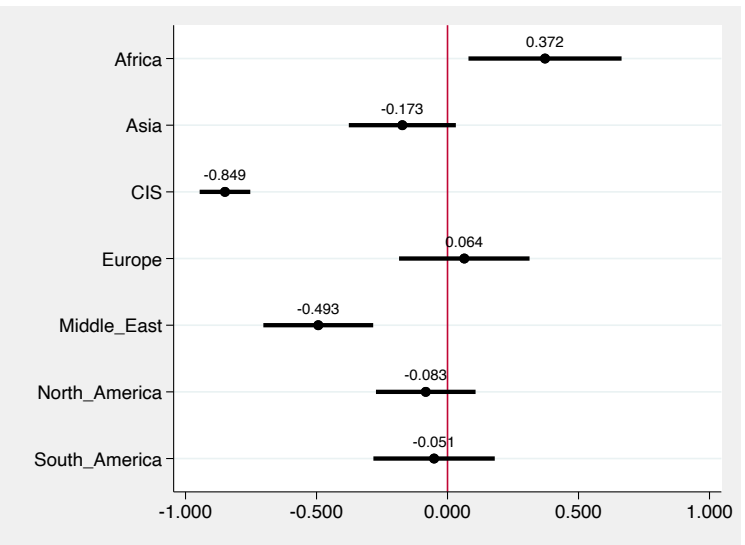

(b) Geographic regions

Figure A2.31: Academia

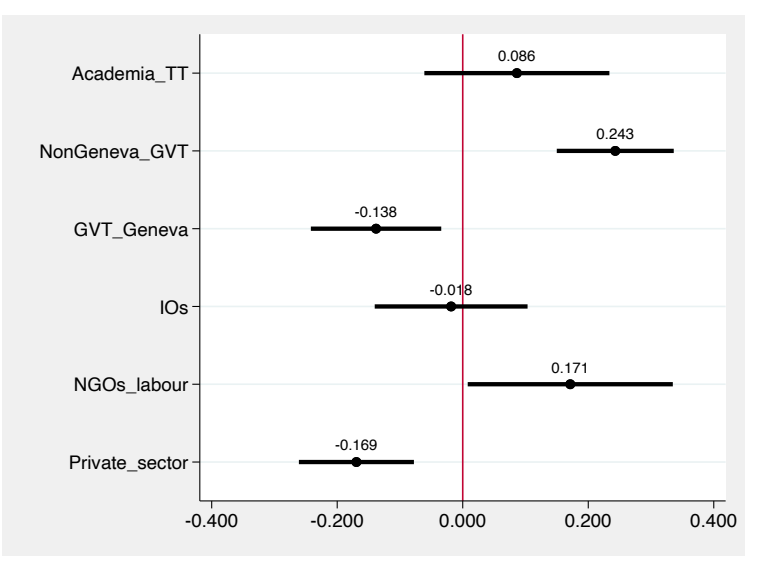

(a) Professional categories

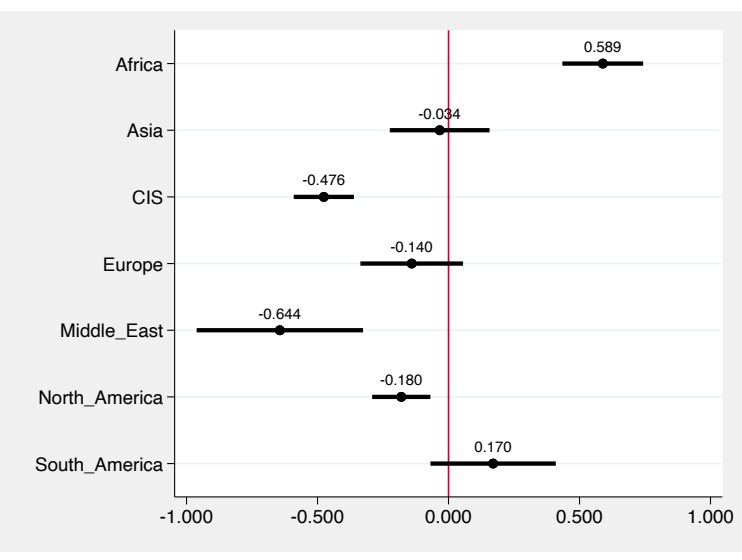

(b) Geographic regions 
Figure A2.32: Think tanks

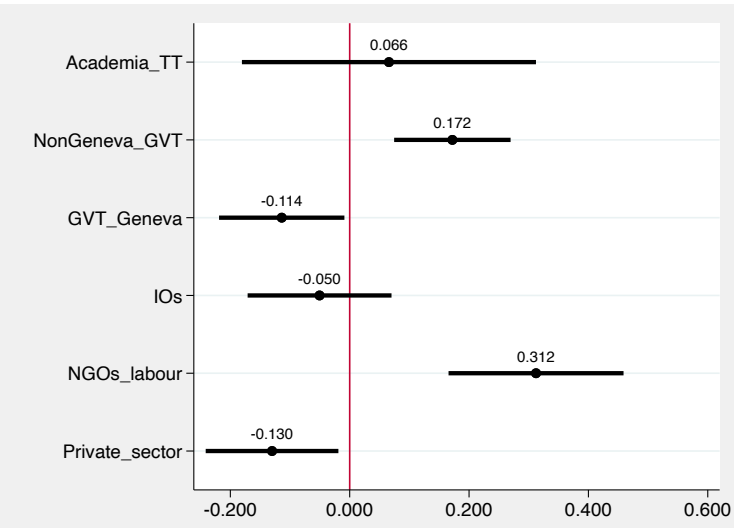

(a) Professional categories

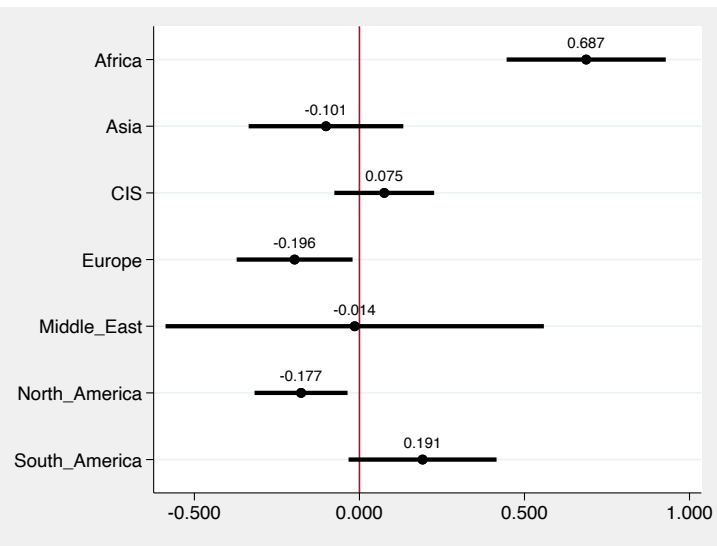

(b) Geographic regions

Figure A2.33: International organizations (e.g., UN, OECD, international financial institutions)

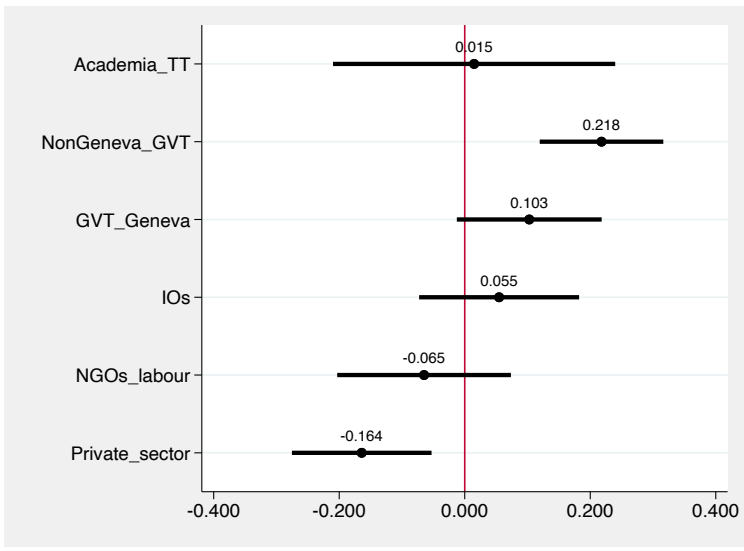

(a) Professional categories

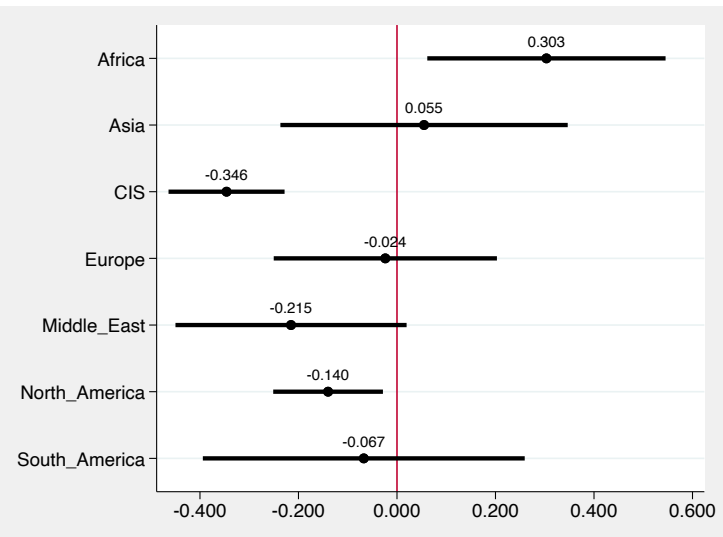

(b) Geographic regions

Figure A2.34: Regional organizations (e.g., APEC)

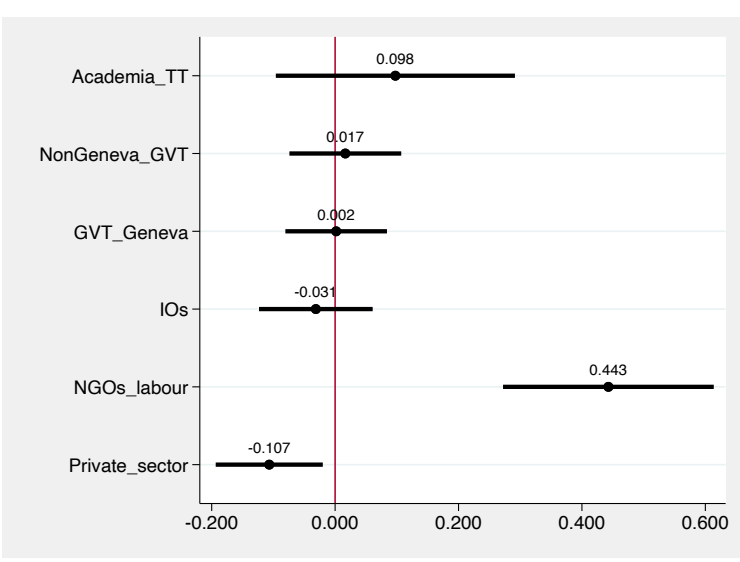

(a) Professional categories

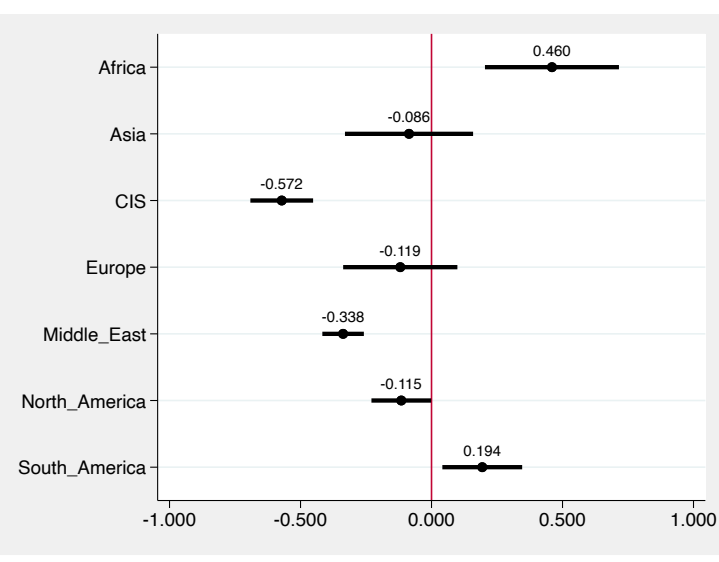

(b) Geographic regions 


\section{The new DG will have to turn first to MC12. What priority do you assign to:}

Figure A2.35: Monitoring COVID-19 pandemic trade-related measures

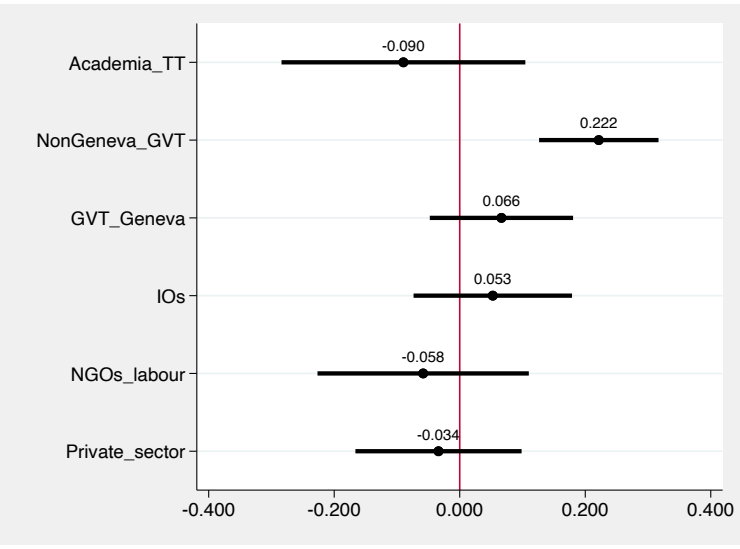

(a) Professional categories

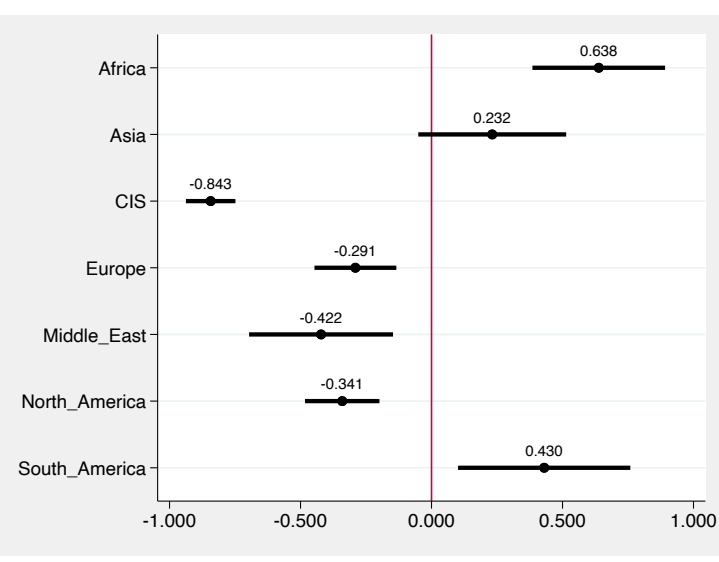

(b) Geographic regions

Figure A2.36: Concluding ongoing negotiations on fisheries and agricultural support

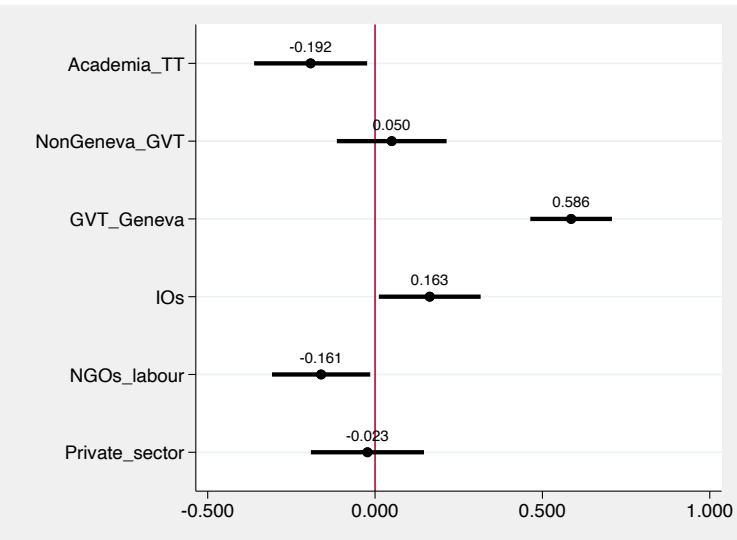

(a) Professional categories

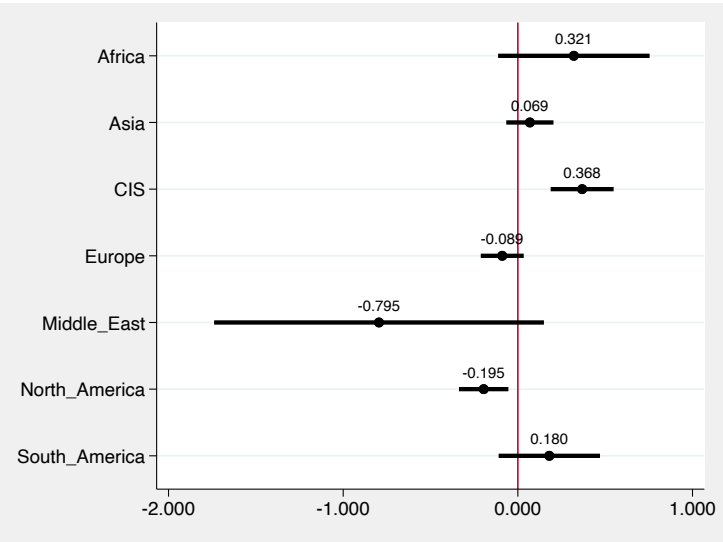

(b) Geographic regions

Figure A2.37: Concluding ongoing plurilateral negotiations on e-commerce, investment facilitation, regulation of services and MSMEs

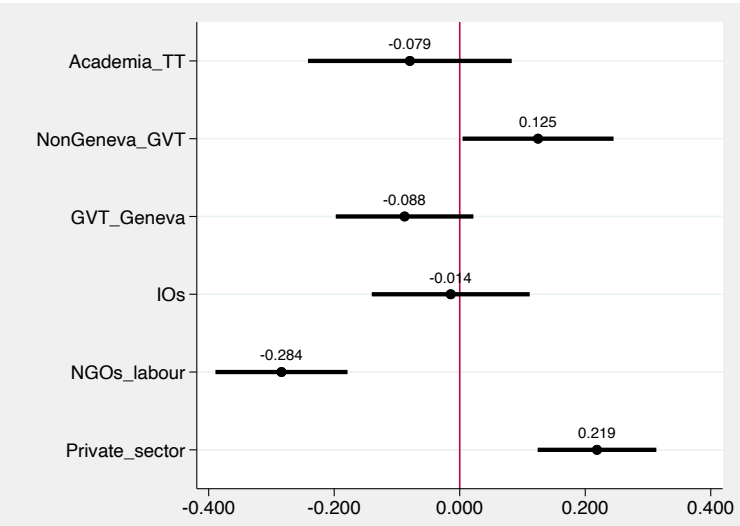

(a) Professional categories

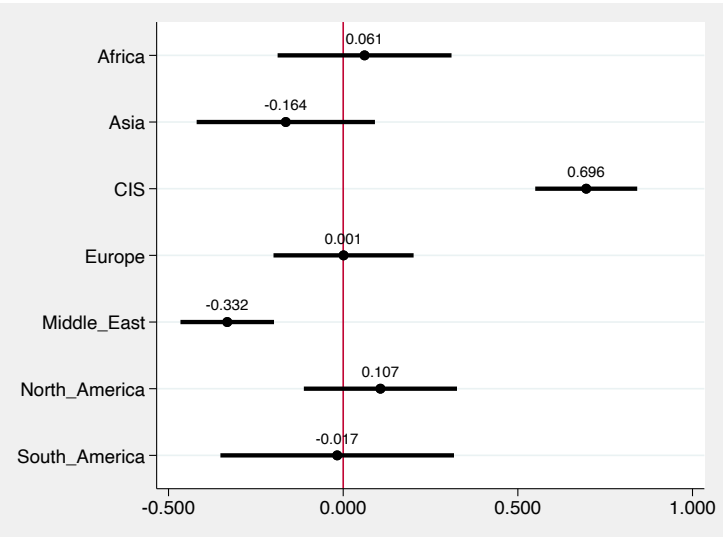

(b) Geographic regions 
Figure A2.38: Launching discussions on new issues

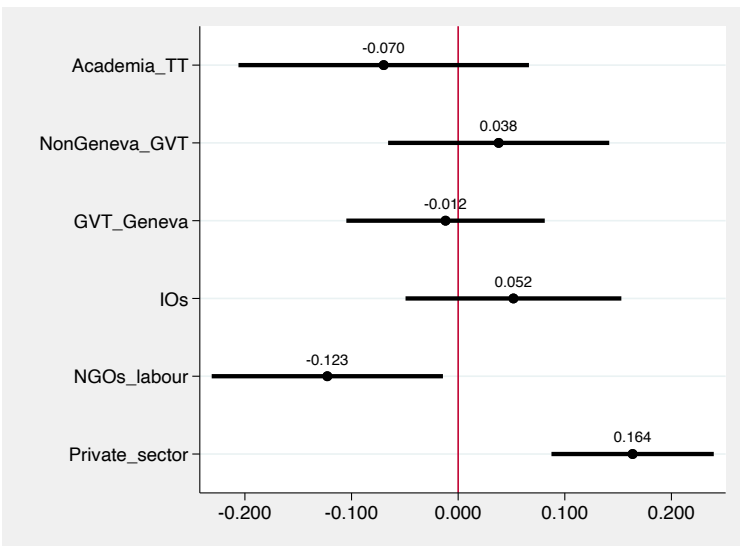

(a) Professional categories

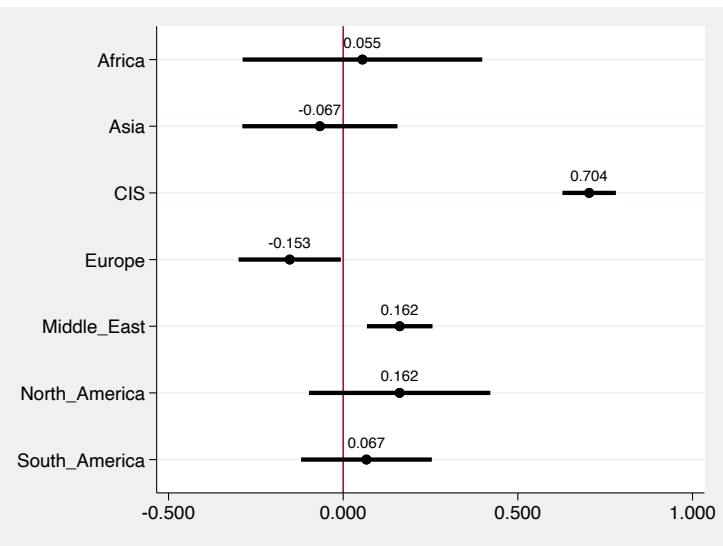

(b) Geographic regions

Figure A2.39: Clarifying the role of trade policy in tackling climate change

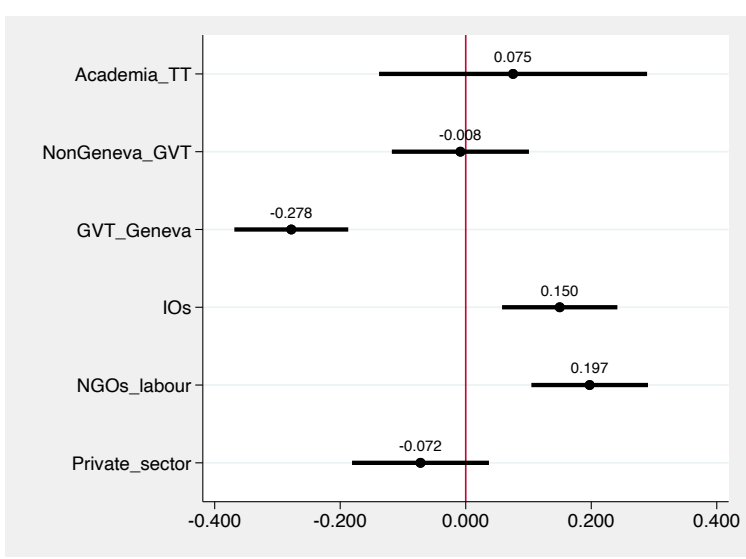

(a) Professional categories

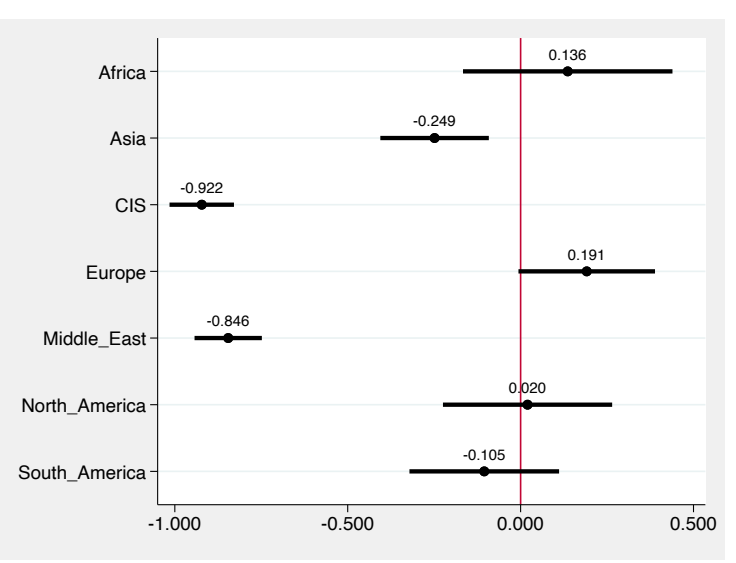

(b) Geographic regions

Figure A2.40: Negotiating stronger rules on the use of subsidies and industrial policies

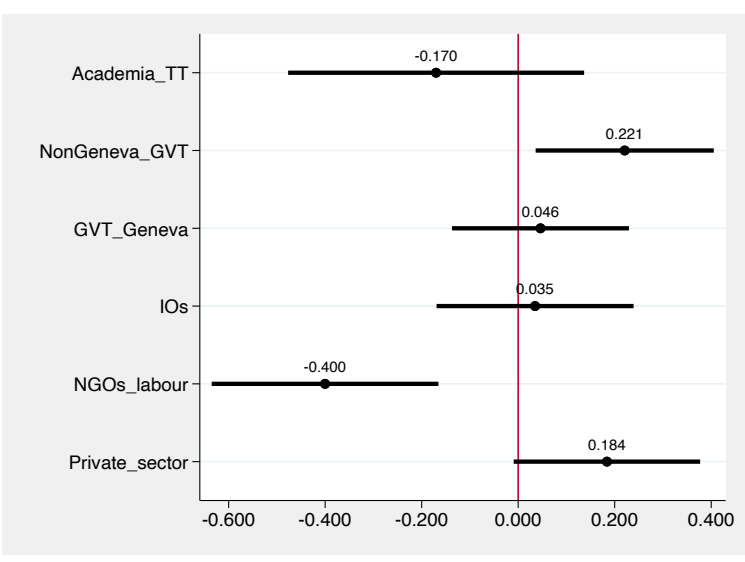

(a) Professional categories

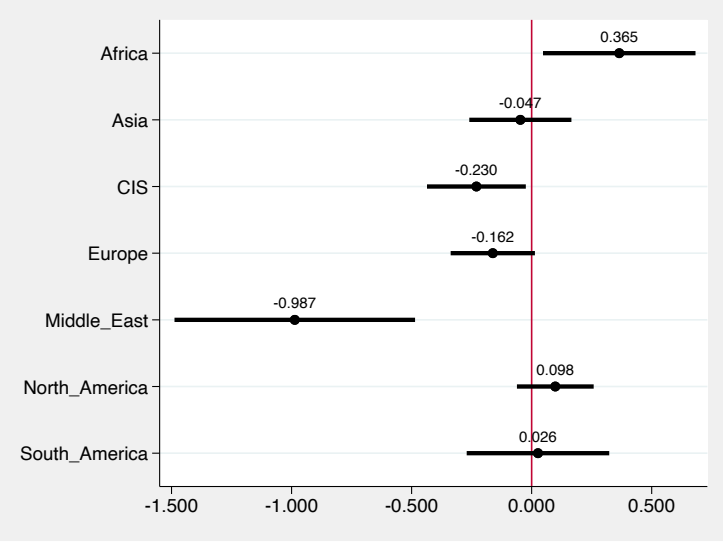

(b) Geographic regions 
Figure A2.41: WTO role in promoting the sustainable development goals

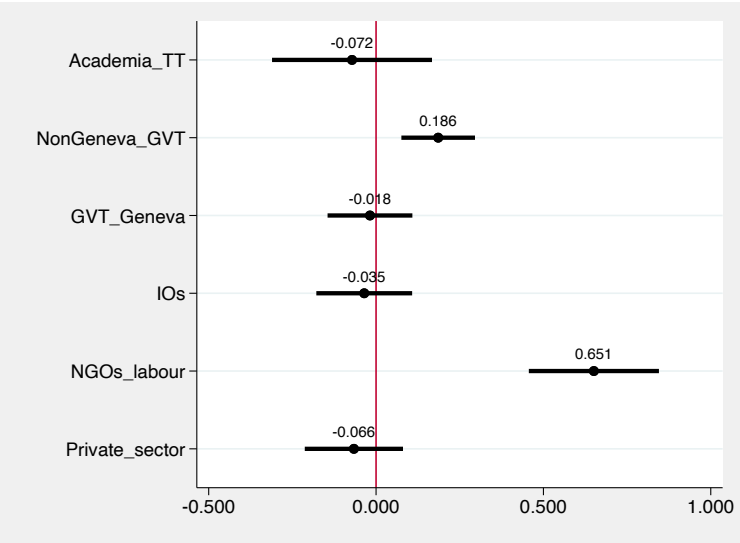

(a) Professional categories

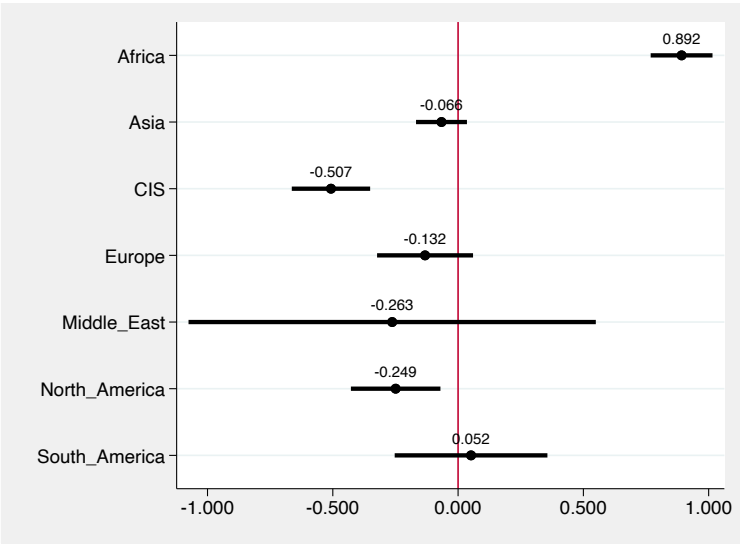

(b) Geographic regions 
In terms of institutional reform, what priority do you assign to each of the following issues the next DG should take up:

Figure A2.42: Make the Appellate Body operational again

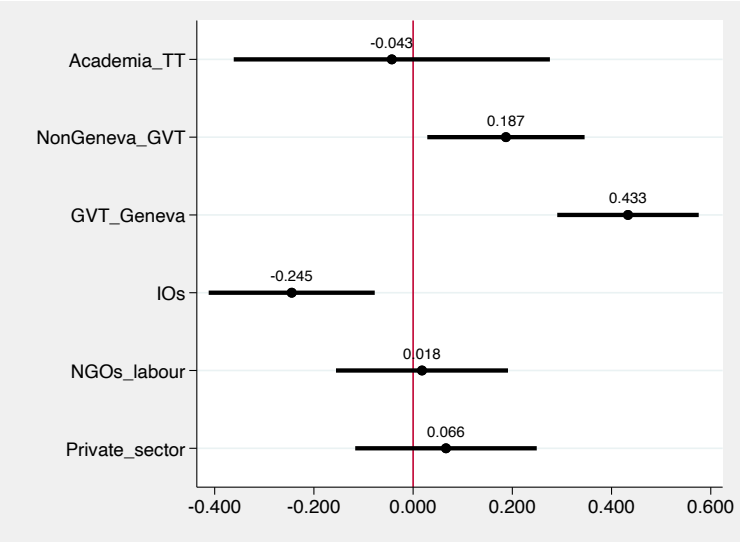

(a) Professional categories

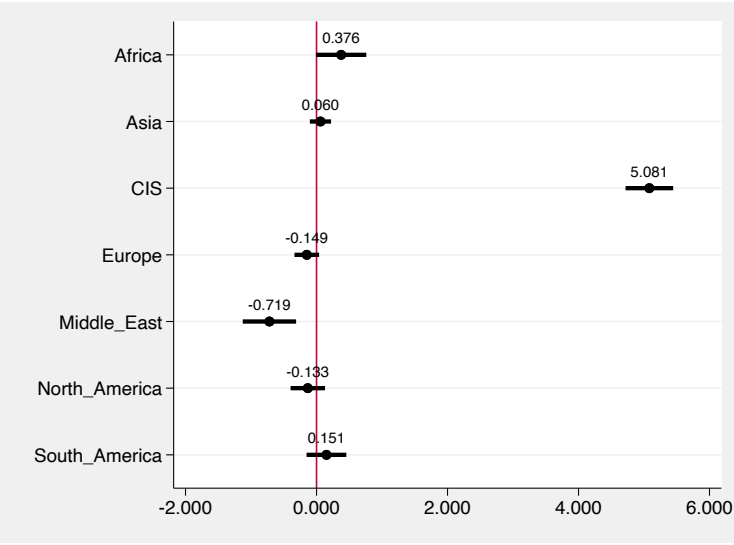

(b) Geographic regions

Figure A2.43: Reform dispute settlement and revisit the role of appellate review

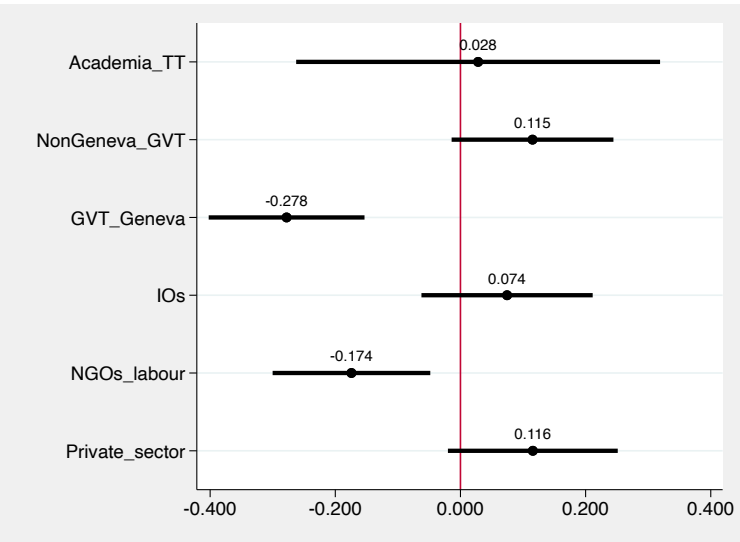

(a) Professional categories

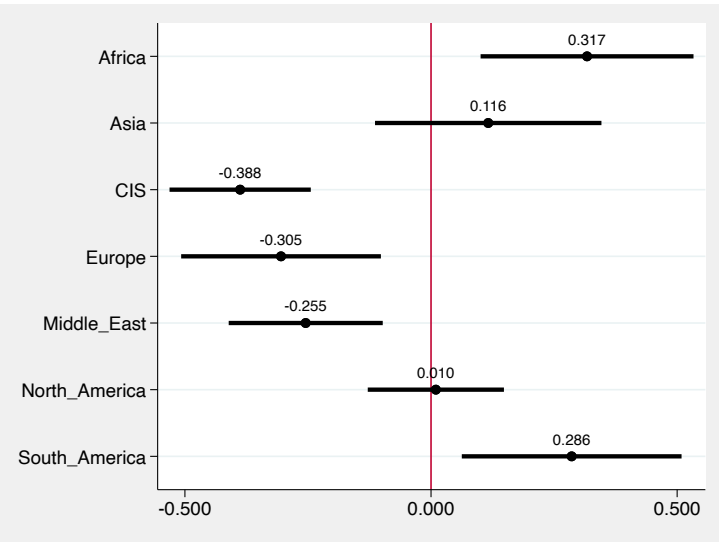

(b) Geographic regions

Figure A2.44: Improve compliance with notification obligations

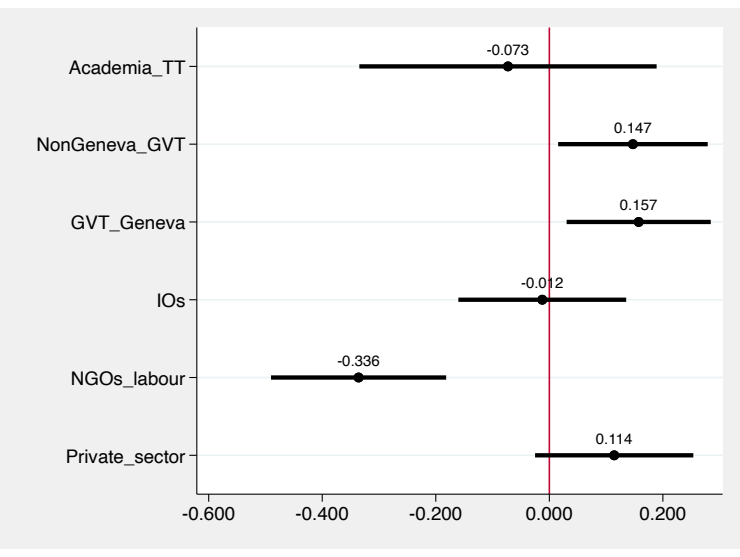

(a) Professional categories

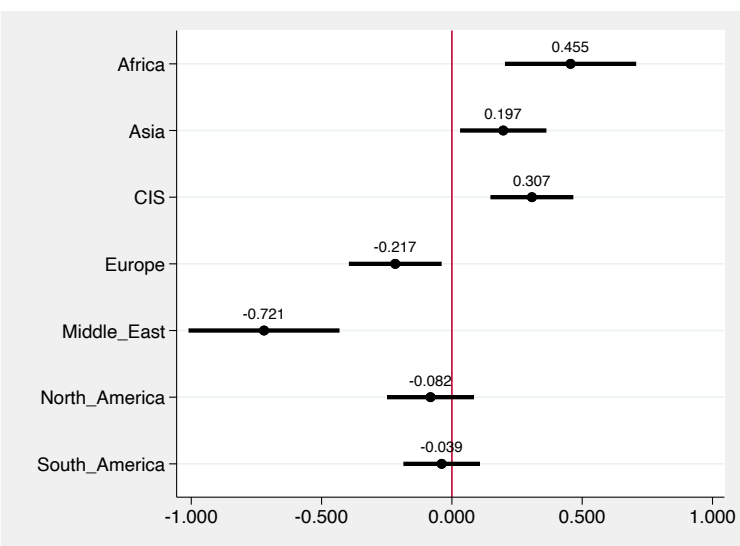

(b) Geographic regions 
Figure A2.45: Resolve differences on special and differential treatment for developing countries

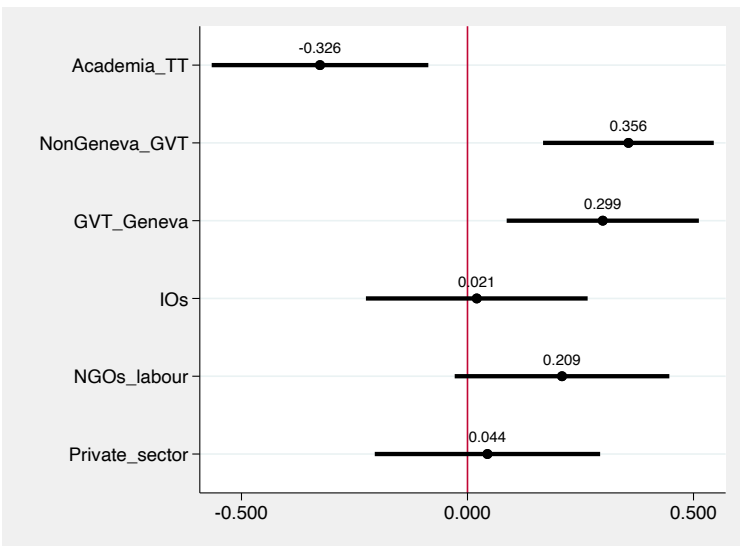

(a) Professional categories

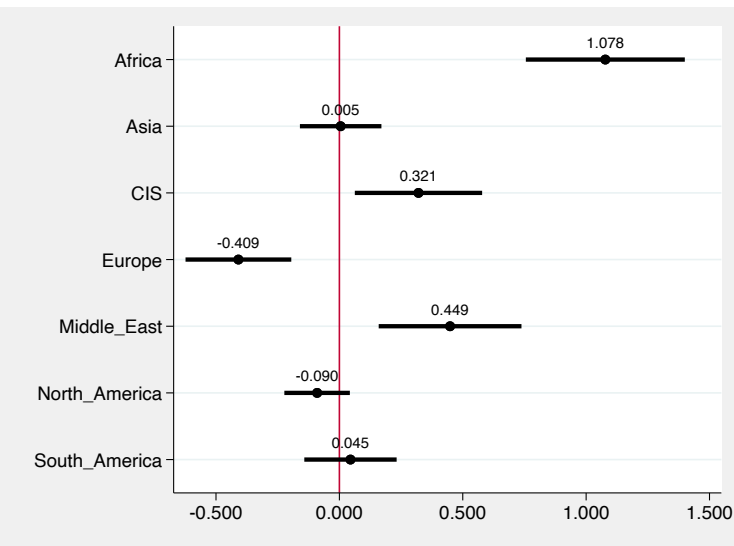

(b) Geographic regions

Figure A2.46: Use WTO bodies to diffuse potential disputes (e.g., through "specific trade concern" processes)

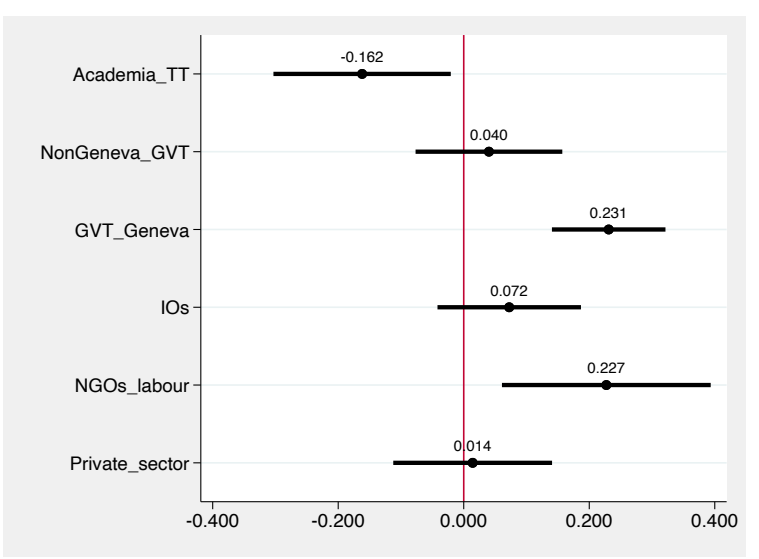

(a) Professional categories

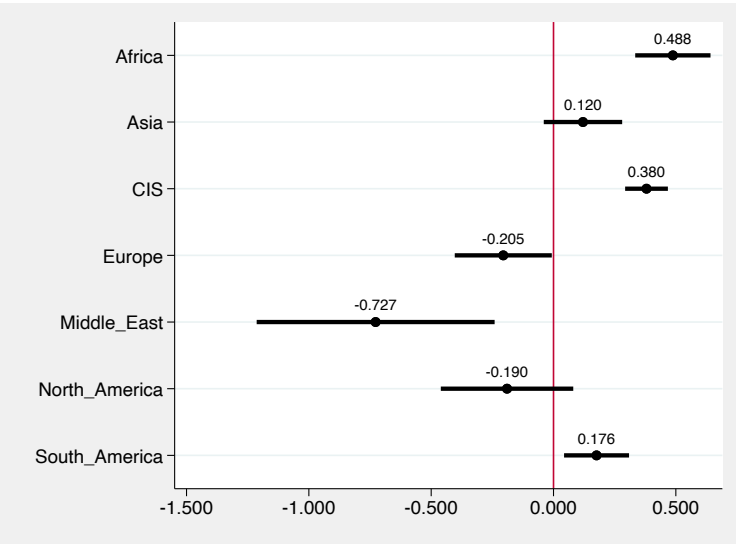

(b) Geographic regions

Figure A2.47: Deepen engagement with stakeholders (e.g. through thematic sessions)

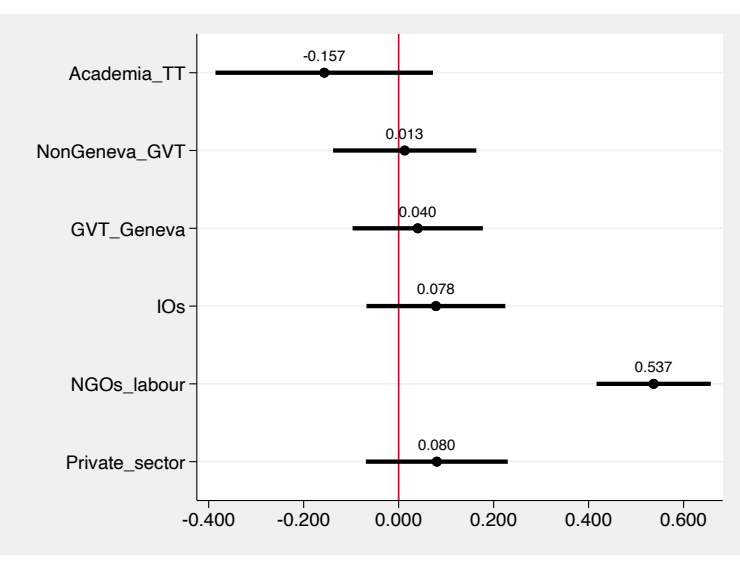

(a) Professional categories

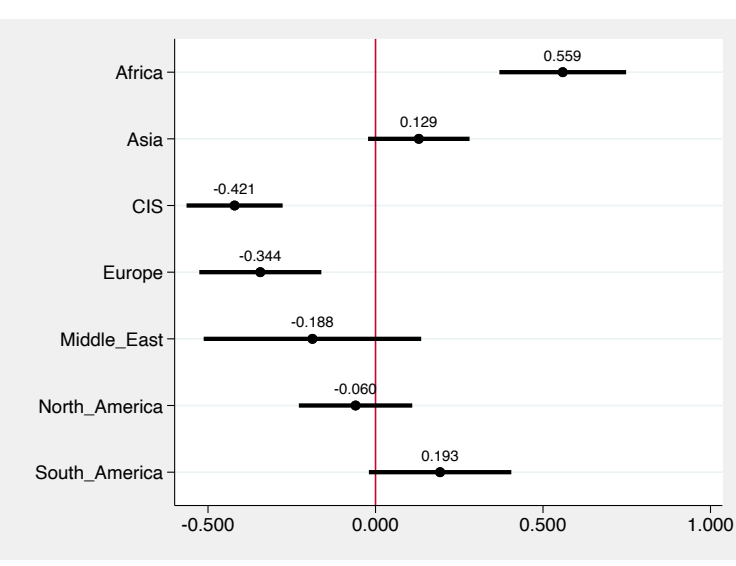

(b) Geographic regions 
Figure A2.48: Strengthen the trade policy monitoring process

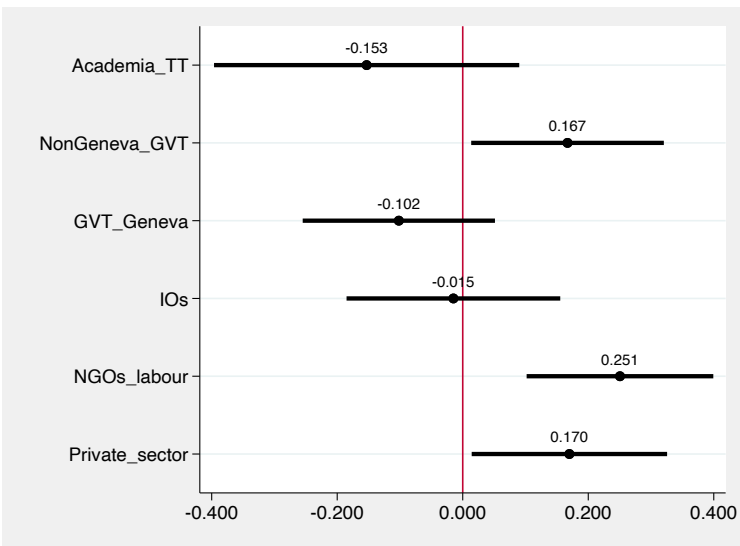

(a) Professional categories

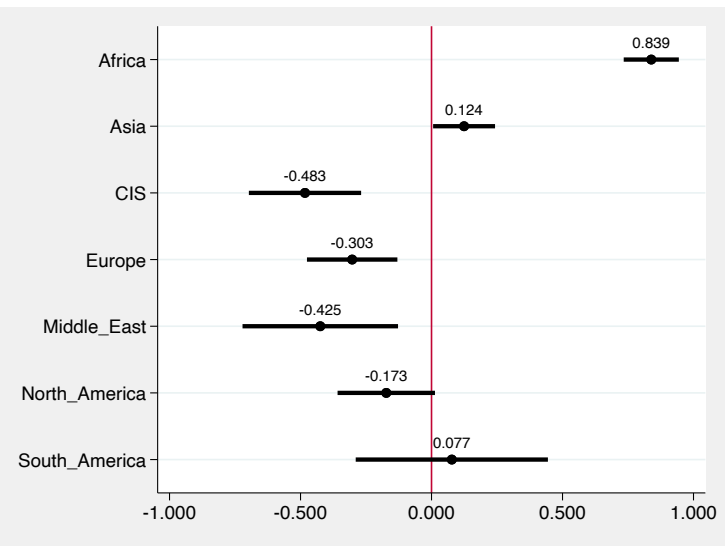

(b) Geographic regions

Figure A2.49: Analyze the distributional effects across countries of national trade policies

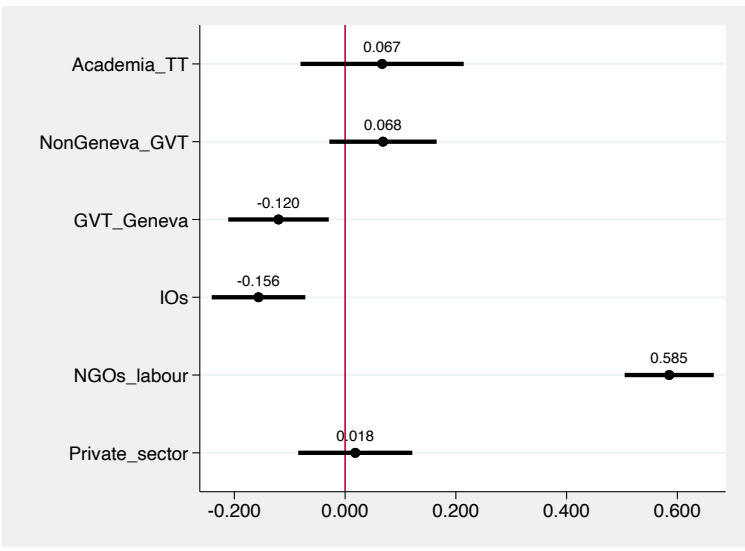

(a) Professional categories

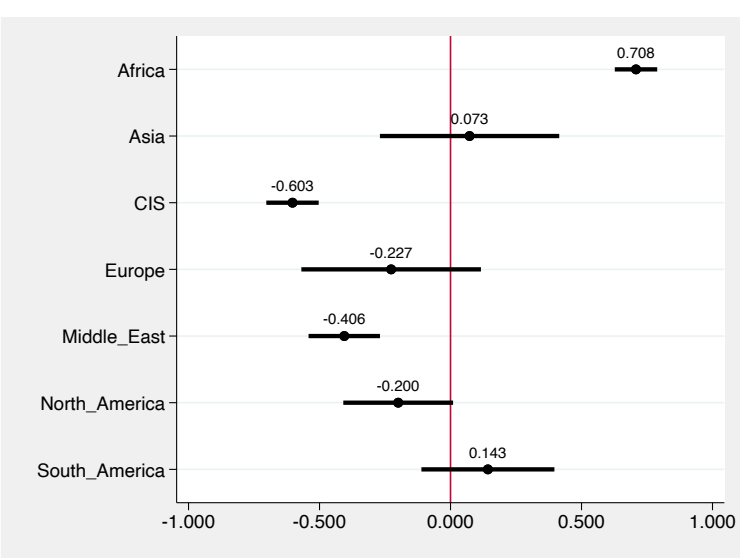

(b) Geographic regions

Figure A2.50: Provide support for plurilateral agreements

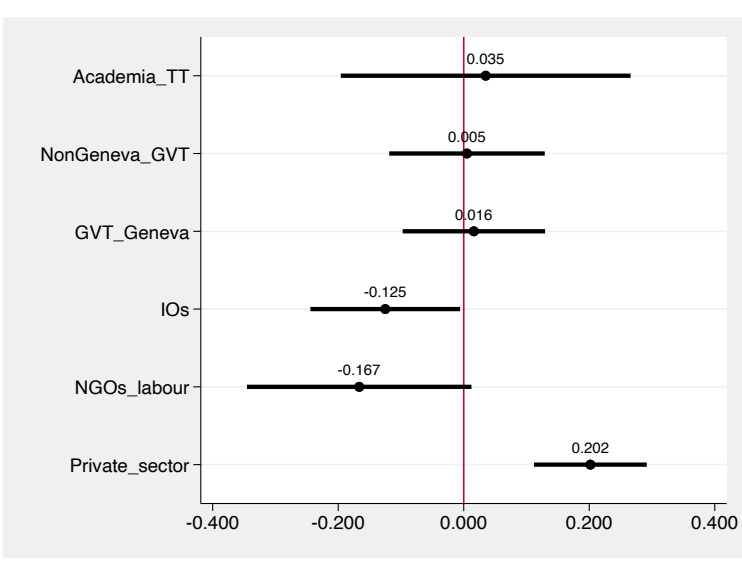

(a) Professional categories

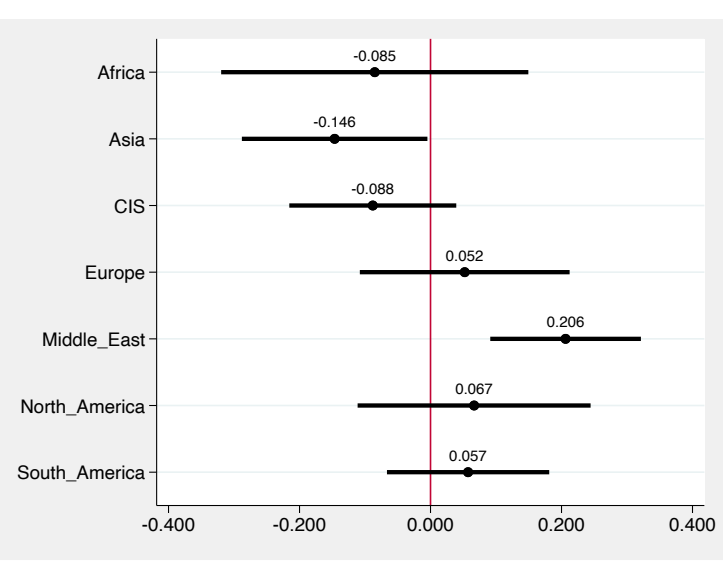

(b) Geographic regions 
In terms of institutional reform, what priority do you assign to each of the following issues the next DG should take up:

Figure A2.51: Encourage use of voting on operational matters

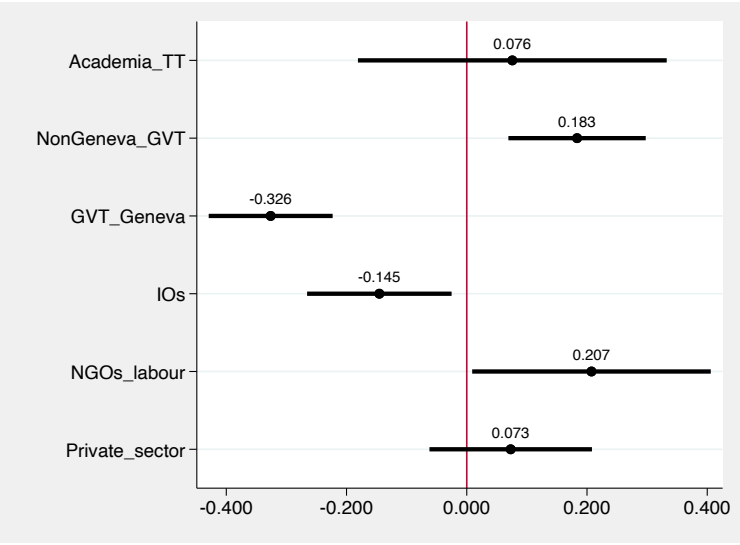

(a) Professional categories

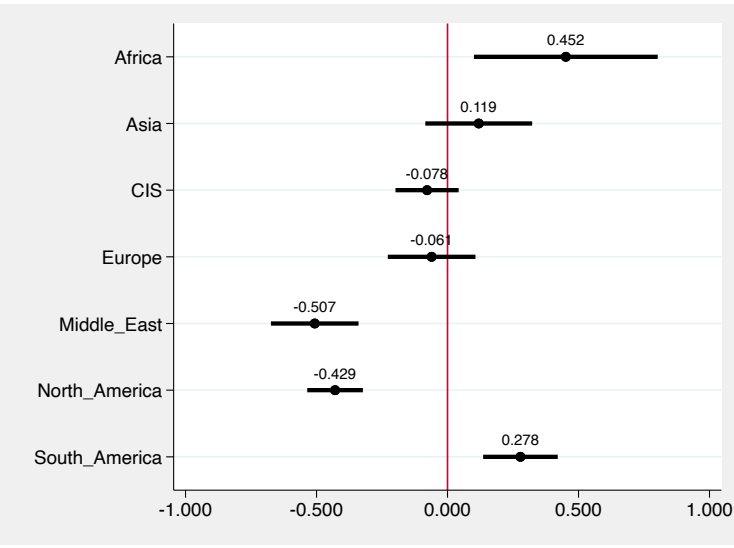

(b) Geographic regions

Figure A2.52: Allow binding decisions to be made in virtual meetings

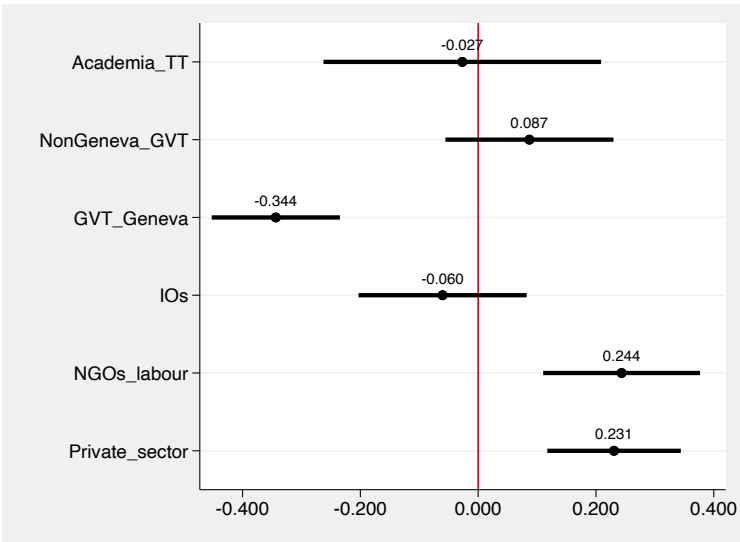

(a) Professional categories

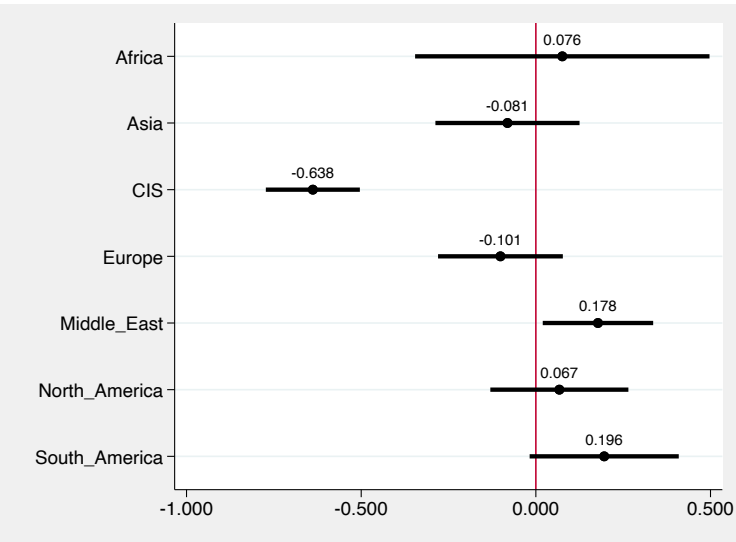

(b) Geographic regions

Figure A2.53: Make virtual meetings and video conferencing standard options

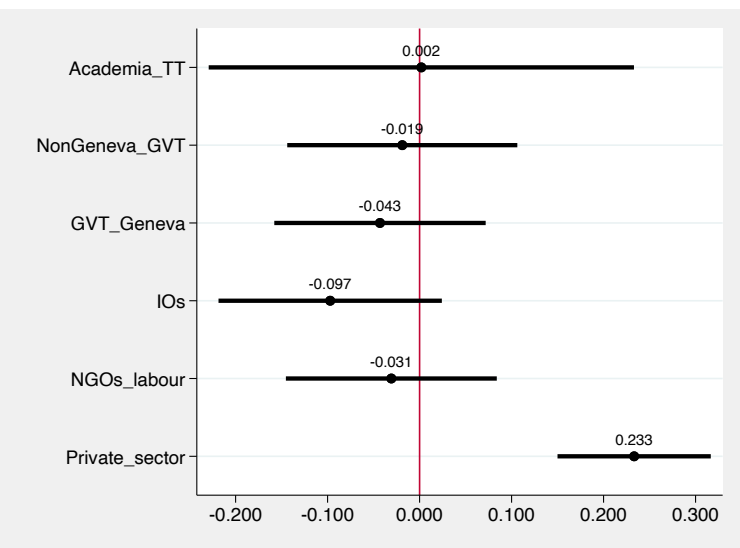

(a) Professional categories

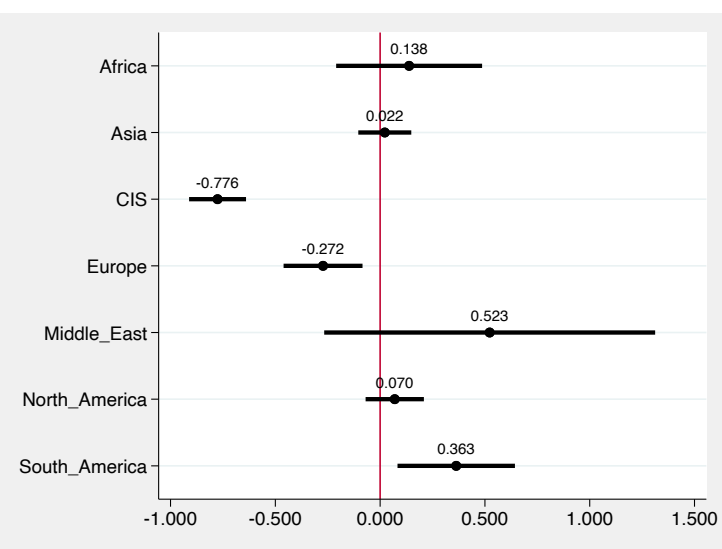

(b) Geographic regions 
Figure A2.54: Deliver WTO technical assistance and training online and through video-conferencing

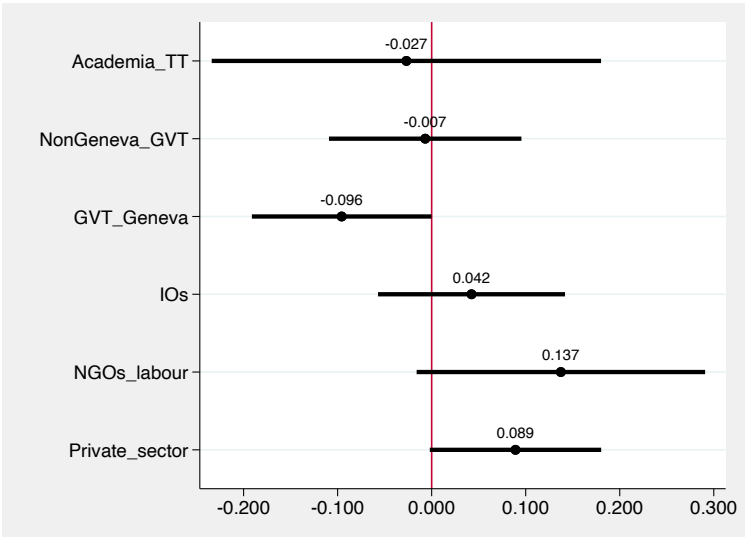

(a) Professional categories

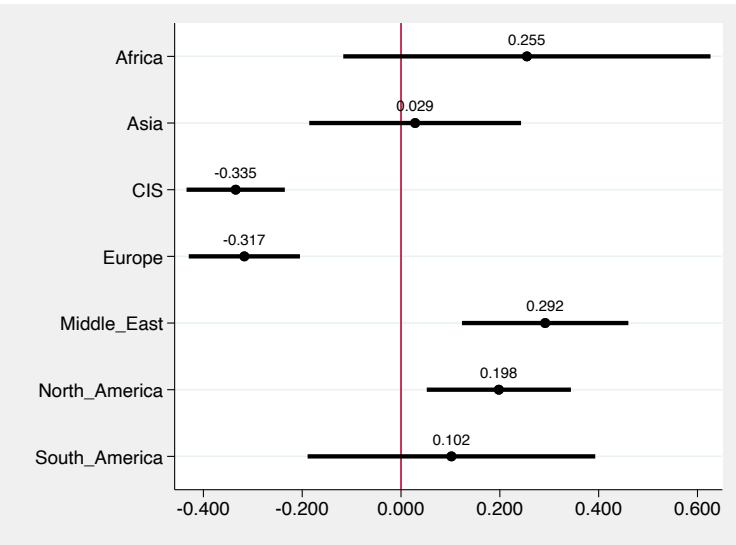

(b) Geographic regions 


\section{Author contacts:}

\section{Matteo Fiorini}

Robert Schuman Centre for Advanced Studies, European University Institute Villa Schifanoia, Via Boccaccio 121

I-50133 Florence

Email: matteo.fiorini@eui.eu

\section{Bernard Hoekman}

Robert Schuman Centre for Advanced Studies, European University Institute Villa Schifanoia, Via Boccaccio 121

I-50133 Florence and CEPR

Email: Bernard.Hoekman@eui.eu

\section{Petros C. Mavroidis}

Columbia Law School

Edwin B. Parker Professor of Law at Columbia Law School

Jerome Greene Hall, Room 734

435 West 116th Street

New York, NY 10027

Email: pmavro@law.columbia.edu

\section{Douglas Nelson}

Tulane University, Murphy Institute

Email:dnelson@tulane.edu

\section{Robert Wolfe}

School of Public Studies, Queen's University

138, Union Street, Suite 301

Kingston, Ontario, Canada K7L 3N6

Email: robert.wolfe@queensu.ca 
With the support of the The European Commission supports the EUI through the European Union budget. This
Erasmus+ Programme publication reflects the views only of the author(s), and the Commission cannot be held of the European Union responsible for any use which may be made of the information contained therein. 